\title{
C,N-环状偶氮次甲基亚胺参与的反应研究进展
}

\author{
华庭碧 $a, b$ 阳青青*,a,b 肖文精*,c \\ ( ${ }^{a}$ 三峡大学 天然产物研究与利用湖北省重点实验室 湖北宜昌 443002) \\ ( ${ }^{b}$ 三峡大学材料与化工学院 无机非金属晶态与能源转换材料重点实验室 湖北宜昌 443002) \\ ( ${ }^{c}$ 华中师范大学化学学院 农药与化学生物学教育部重点实验室 武汉 430079)
}

\begin{abstract}
摘要 在环状偶氮次甲基亚胺类 1,3-偶极子中, $\mathrm{C}, \mathrm{N}$-环状偶氮次甲基亚胺是使用最广泛的反应试剂, 用于结构多样化的 四氢异喹啉衍生物的构建. 简单综述了 $\mathrm{C}, \mathrm{N}$-环状偶氮次甲基亚胺参与的反应研究进展, 重点介绍 $[3+2] 、[3+3] 、[3+$ 4]、[5+1]、[3+1]环加成以及其他反应, 并讨论了反应的特点、反应过程及合成应用，最后展望了它的发展前景. 关键词 1,3-偶极子; 偶氮次甲基亚胺; C,N-环状偶氮次甲基亚胺; 环加成反应; 异喹啉衍生物
\end{abstract}

\section{Recent Developments of Reactions with C,N-Cyclic Azomethine Imines}

\author{
Hua, Tingbi ${ }^{a, b} \quad$ Yang, Qingqing ${ }^{*, a, b} \quad$ Xiao, Wengjing ${ }^{*, c}$ \\ $\left({ }^{a}\right.$ Hubei Key Laboratory of Natural Products Research and Development, \\ China Three Gorges University, Yichang, Hubei 443002) \\ $\left({ }^{b}\right.$ Key Laboratory of Inorganic Nonmetallic Crystalline and Energy Conversion Materials, \\ College of Materials and Chemical Engineering, China Three Gorges University, Yichang, hubei 443002) \\ ( ${ }^{c}$ Key Laboratory of Pesticide \& Chemical Biology, Ministry of Education, College of Chemistry, \\ Central China Normal University, Wuhan 430079)
}

\begin{abstract}
Among various 1,3-dipoles of cyclic azomethine imines, C,N-cyclic azomethine imines are the most widely used reagents in the construction of diverse tetrahydroisoquinoline derivatives. The developments of reactions with $\mathrm{C}, \mathrm{N}$-cyclic azomethine imines including $[3+2],[3+3],[3+4],[5+1],[3+1]$ cycloaddition reactions and miscellaneous reactions are summarized. The properties of reactions, reaction processes and synthetic applications are discussed. Finally, the prospects of the reaction with this reagent are also proposed.

Keywords 1,3-dipole; azomethine imine; $\mathrm{C}, \mathrm{N}$-cyclic azomethine imine; cycloaddition reaction; isoquinoline derivative
\end{abstract}

四氢异喹啉衍生物广泛存在于天然产物和药物分 子中, 具有抗肿瘤、抗菌、抗病毒、抗炎、抗凝和支气 管扩张等作用 ${ }^{[1]}$. 因此, 该骨架受到了合成化学家和药 学工作者的密切关注. 其中, 已发现的许多有重要生物 活性的四氢异喹啉化合物都是基于 $\mathrm{C}(1)$-取代的四氢异 喹啉骨架 ${ }^{[2]}$. 如图 1 所示, $(S)$-Norcoclaurine 是从天然植 物乌头花中分离提取得到, 被证实是一种有效的 $\beta-1$ 和 $\beta-2$ 肾上腺素促效剂, 常用于中药 ${ }^{[3]}$. (S)-Coclaurine 是从
形形色色的植物源如 Neclumbo nucifera 中分离出来, 是 烟碱乙酰胆碱受体拮抗剂 ${ }^{[4]}$. Jamtine 是从攀缘灌木 Cocculus hirsutus 分离得到的一种药用生物碱, 具有重要 的降血糖活性 ${ }^{[5]}$. (+)-Oleracein E 是从 Portulaca oleracea $L$.中分离得到, 具有抗氧化作用 ${ }^{[6]}$. (一)-Xylopinine 是一 种从Xylopia Discreta 分离出来的原小檗碱, 这类生物碱 有抗白血病、抗肿瘤、抗炎等作用 ${ }^{[7]}$. 鉴于 $C(1)$-取代的 四氢异喹啉化合物具有广泛的生物活性及其潜在的生

\footnotetext{
* Corresponding authors. E-mail: qingqing_yang@ctgu.edu.cn; wxiao@mail.ccnu.edu.cn Received June 30, 2020; revised September 4, 2020; published online September 15, 2020. Dedicated to the 40th anniversary of Chinese Journal of Organic Chemistry Project supported by the National Natural Science Foundation of China (No. 21702121), the Open Fund from Hubei Key Laboratory of Natural Products Research and Development (China Three Gorges University) (No. NPRD-2018010), the Research Fund for Excellent Dissertation of China Three Gorges University and the Programme of Introducing Talents of Discipline to Universities (111 Project, No. D20015).

国家自然科学基金(No. 21702121)、三峡大学天然产物研究与利用湖北重点实验室开放基金(No. NPRD-2018010)、三峡大学学位论文培优基金和高等 学校学科创新引智计划(111 计划, No. D20015)资助项目.
} 


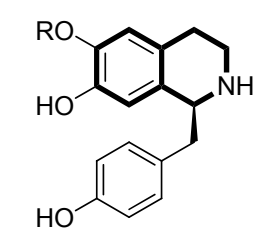

$\mathrm{R}=\mathrm{H},(S)$-Norcoclaurine $\mathrm{R}=\mathrm{Me},(S)$-Coclaurine
(+)-Oleracein E

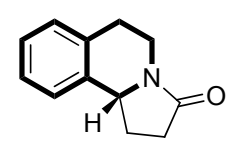

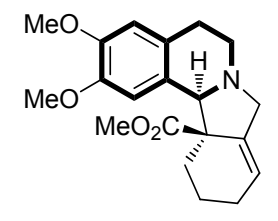

jamtine

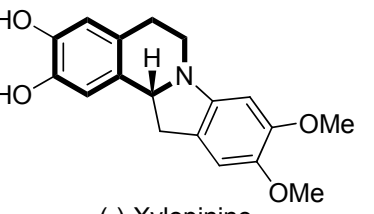

(-)-Xylopinine
图 1 代表性的含 $\mathrm{C}(1)$ 取代四氢异喹啉的天然产物或药物分 子

Figure 1 Representative examples of bioactive natural products and pharmaceutical molecules containing $\mathrm{C}(1)$-substituted tetrahydroisoquinolines

理用途，探索新的有效反应策略来构建这类有价值的骨 架具有重要的理论意义和应用前景 ${ }^{[8]}$. 最近, C,N-环状 偶氮次甲基亚胺的环加成反应已经成为构建含 $\mathrm{C}(1)$-取 代异喹啉骨架的化合物的普遍方法之一. C,N-环状偶氮 次甲基亚胺是一种高活性的 1,3-偶极子, 因独特的结构 受到了化学家们的青睐 ${ }^{[9]}$. 因此本文将对近年来 $\mathrm{C}, \mathrm{N}$-环 状偶氮次甲基亚胺参与的反应研究进展进行简单综述, 原位产生这类偶极子的反应不在本文讨论范围. 如 Scheme 1 所示, 根据不同的反应类型, 主要分为 C,N-环 状偶氮次甲基亚胺参与的 $[3+2]$ 环加成反应、 $[3+3]$ 环 加成反应、 $[3+4]$ 环加成反应、 $[3+1]$ 环加成反应、
$[5+1]$ 环加成反应以及 $\mathrm{C}, \mathrm{N}-$ 环状偶氮次甲基亚胺参与的 其他反应.

\section{$1 \mathrm{C}, \mathrm{N}-\mathrm{x}$ 环状偶氮次甲基亚胺参与的[3+2]环加 成反应}

\section{1 路易斯酸催化}

1,3-偶极子和烯烃、炔烃及其他亲偶极子试剂的 $[3+2]$ 环加成反应是构建五元杂环化合物的有力合成策 略. 1973 年, Tamura 等 ${ }^{[10]}$ 首次合成了 $\mathrm{C}, \mathrm{N}-$ 环状偶氮次甲 基亚胺 1,3-偶极子. 但最近十年来, 该偶极子才引起了 人们的关注. 2010 年, Maruoka 课题组 ${ }^{[11]}$ 首次发现了钛酸 二钠(Ti-BINOL)复合物催化的高对映选择性的 C,N-环状 偶氮次甲基亚胺 $\mathbf{1}$ 与 $\alpha, \beta$-不饱和醛 $\mathbf{2}$ 的不对称 1,3-偶极 环加成反应(Eq. 1), 得到了药学上具有吸引力的手性吡 唑并[5,1- $a$ ]异喹啉 $3^{[12]}$. 作者还对产物进行了合成转换 研究，发现产物在 $\mathrm{SmI}_{2}$ 作用下发生 $\mathrm{N}-\mathrm{N}$ 键断裂，得到 有三个连续立体中心的四氢异喹啉化合物 5 (Eq. 2).

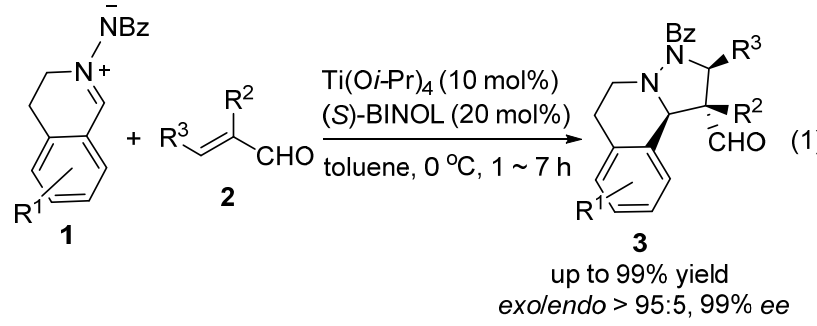

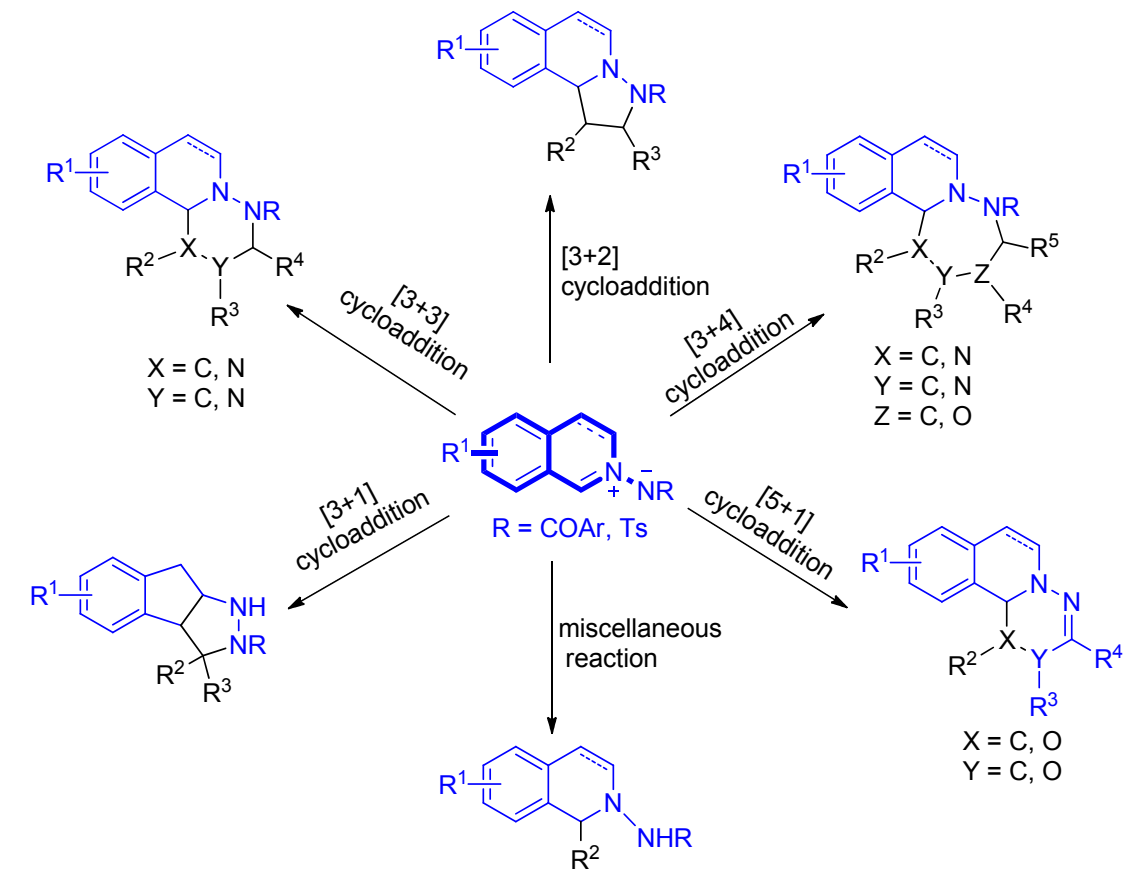

图式 $1 \mathrm{C}, \mathrm{N}$-环状偶氮次甲基亚胺参与的六类不同类型的反应

Scheme 1 Six different types of reactions involving C,N-cyclic azomethine imines 




(2)

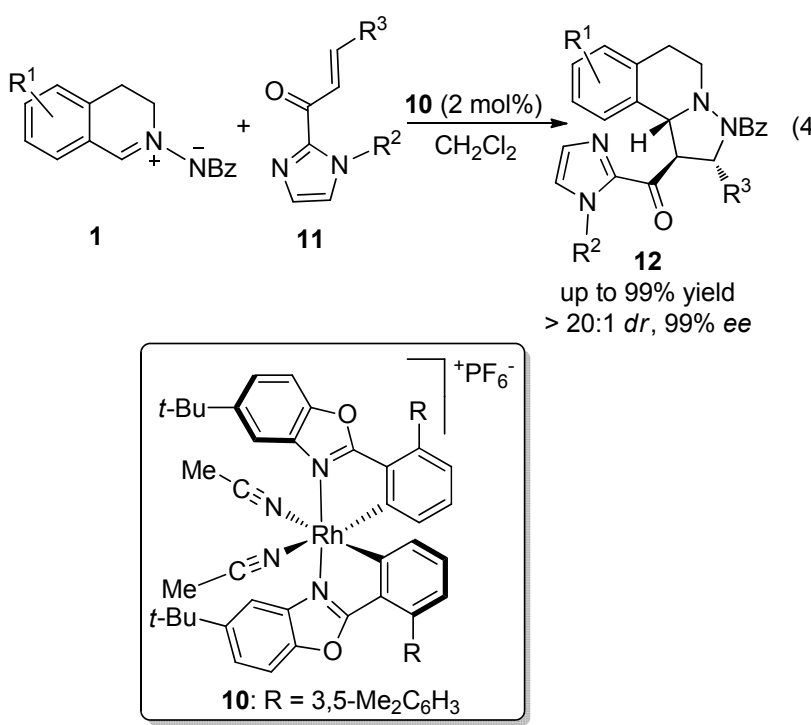

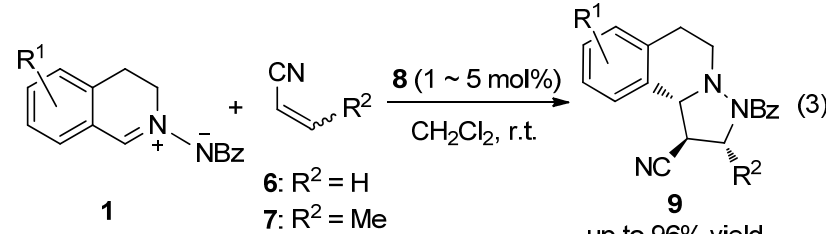

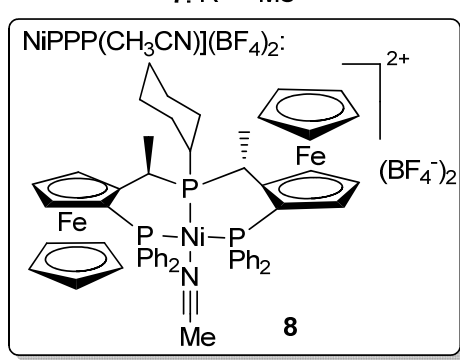

2019 年, 康强课题组 ${ }^{[14]}$ 实现了手性铑配合物 10 催 化的 $\alpha, \beta$-不饱和 2-酰基咪唑 11 与 $\mathrm{C}, \mathrm{N}$-环状偶氮次甲基 亚胺的不对称 $[3+2]$ 环加成反应, 高效、高产率、高立 体选择性地合成了富对映体的 C(1)-取代四氢异喹啉衍 生物 12 (Eq. 4). 产物中的酰基咪唑片段可以通过还原 和进一步脱去转变为光学活性的醛 13 (Scheme 2), 而产 物的对映选择性并没有损失. 醛还可以很容易地转换成 其它的取代基, 比如胺基 14. 基于前期的研究, 作者提 出了该立体控制可能的模型(图 2): 铑催化剂通过 N,O双齿配体活化 $\alpha, \beta$-不饱和 2-酰基咪唑, 催化剂的不对称 诱导归因于铑中心的高立体位阻效应. 配位后底物的 $S i$ 面被催化剂中一个叔丁基有效地遮挡住, C,N-环状偶氮 次甲基亚胺可以高选择性地进攻配位底物的 $R e$ 面. 同 时, exo-选择性可以减小位阻作用, 产生 $(1 S, 2 S, 3 R)$ 构型 的五元环状化合物.

2018 年, Efremova 和 Molchanov 等 ${ }^{[15]}$ 报道了 $N$-乙 烯基吡咯 17 与 $\mathrm{C}, \mathrm{N}$-环状偶氮次甲基亚胺 16 的[3+2]环 加成反应(Eq. 5). 发现当不使用催化剂时, 产物以反式 异构体 18 为主; 当使用路易斯酸 $\mathrm{Ni}\left(\mathrm{ClO}_{4}\right)_{2} \cdot 6 \mathrm{H}_{2} \mathrm{O}$ 催化

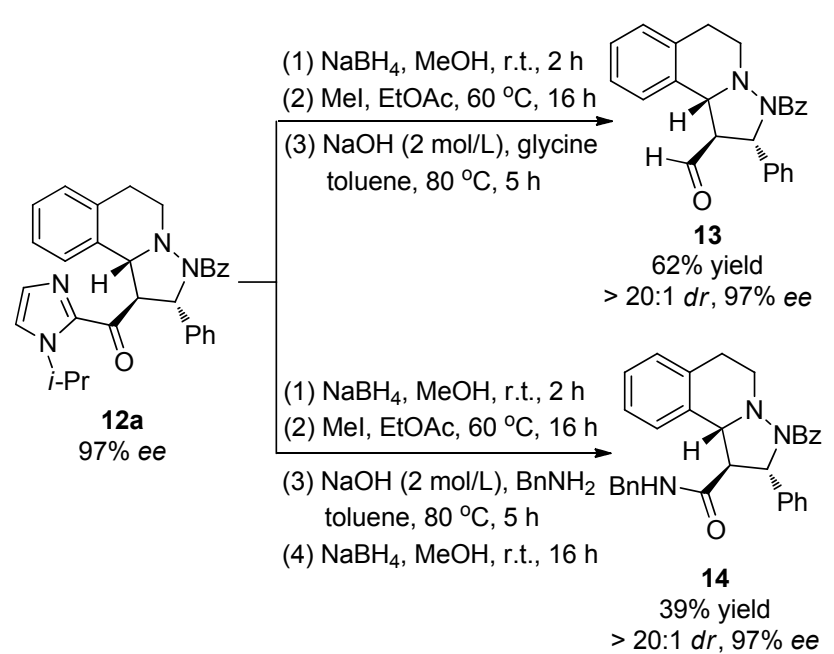

图式 $2 \mathrm{C}(1)$-取代四氢异喹啉衍生物 12a 的合成转换

Scheme 2 Synthetic transformations of C(1)-substituted tetrahydroisoquinoline derivatives 12a

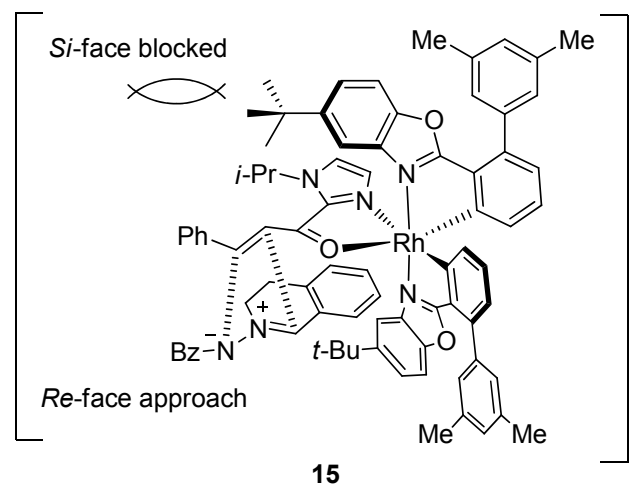

图 2 铑催化诱导不对称合成四氢异喹啉衍生物可能的过渡 态

Figure 2 Possible transition state of asymmetric synthesis of tetrahydroisoquinoline derivatives induced by rhodium 
剂时, 顺式异构体 18 ' 占主导. 作者指出路易斯酸还可 以和 $\mathrm{C}, \mathrm{N}-$ 环状偶氮次甲基亚胺中的具有亲核性的氮原 子或空间位阻更小的共轭氧原子配位. 在 1,3-偶极环加 成的过渡态中和氧原子配位产生更小的空间位阻，同 时, 路易斯酸能改变 $[3+2]$ 环加成的机理, 使反应从协 同过程向分步过程转变.

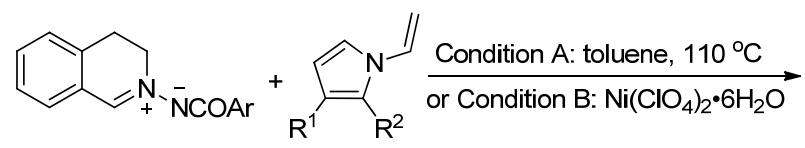<smiles>[R]c1ccn(C2CC3c4ccccc4CCN3C2[R10])c1[R]</smiles>

18
17

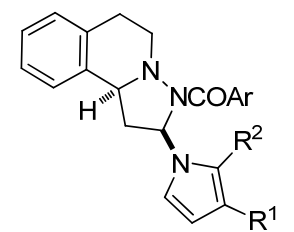

$18^{\prime}$
Condition A: $53 \%$ yield, 18:18' = 93:7

Condition B: $17 \%$ yield, $32 \%$ yield, 18:18' $=25: 75$

2013 年, 李玉学等 ${ }^{[16]}$ 报道了 $\mathrm{Cu}(\mathrm{OAc})_{2}$ 促进的 $\mathrm{C}, \mathrm{N}-$ 环状偶氮次甲基亚胺 19a 与末端炔 20 的[3+2]环加成反 应以制备吡唑并 [5,1- $a$ ]异喹啉类衍生物 23a (Scheme 3), 在该反应中, $\mathrm{Cu}(\mathrm{OAc})_{2}$ 还充当了氧化剂的角色.



图式 $3 \mathrm{C}, \mathrm{N}$-环状偶氮次甲基亚胺与末端炔的反应

Scheme 3 Reaction of C,N-cyclic azomethine imines with terminal alkynes

2013 年, Alcaide 和 Almendros 等 ${ }^{[17]}$ 报道了酸/金共 催化 $\mathrm{C}, \mathrm{N}$-环状偶氮次甲基亚胺 19a 和炔丙基过氧化物 24 发生 $[3+2]$ 环加成串联的反应, 整个串联过程包括金 催化的过氧化物重排/迈克尔加成反应, 最终的酸催化 环化反应, 得到吡唑并异喹啉类化合物 26 (Scheme 4).

\section{2 有机催化}

2014 年, 郭红超课题组 ${ }^{[18]}$ 报道了膦催化的 C,N-环



图式 4 膦催化的缺电子烯烃与 $\mathrm{C}, \mathrm{N}$-环状偶氮次甲基亚胺的 $[3+2]$ 环加成反应的可能机理

Scheme 4 Putative mechanism of phosphine-catalyzed [3+2] cycloaddition of $\mathrm{C}, \mathrm{N}$-cyclic azomethine imines with electrondeficient alkenes

状偶氮次甲基亚胺 1 或 19 与两端苯磺酰基取代烯烃 27 的 $[3+2]$ 环加成反应(Eq. 6). 在室温条件下, 高收率地 得到了一系列含两个苯磺酰基的吡唑啉类化合物 28 . 作者还使用了两端酯基取代的顺式烯烃作为亲偶极子 试剂，与 $\mathrm{C}, \mathrm{N}$-环状偶氮次甲基亚胺 $1 \mathrm{a}$ 反应以 70\%的产 率得到了相应的环加成产物(Eq. 7). 作者对磺酰基取代 的反应产物进行了简单的合成转化. 在 $\mathrm{Mg}$ /甲醇条件下, 两个苯磺酰基很容易移除(Eq. 8). 作者提出了该膦催化 $[3+2]$ 环加成反应机理(Scheme 5): 膦催化剂对缺电子 烯烃的共轭加成得到中间体 32, 该中间体进攻 C,N-环 状偶氮次甲基亚胺形成中间体 33, 接下来分子内亲
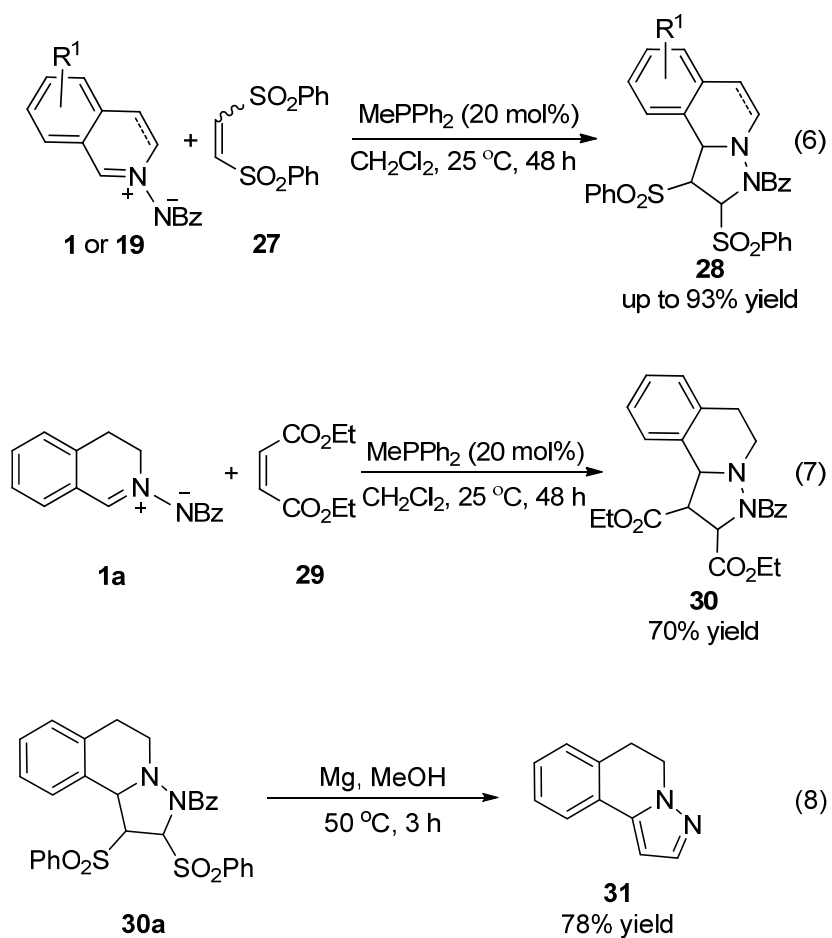


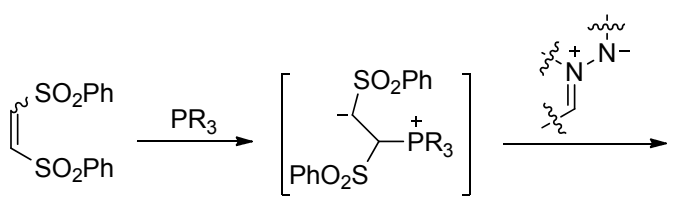

27

32

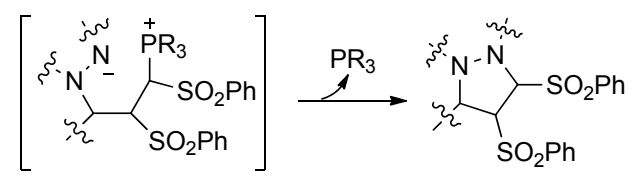

33

28

图式 5 膦催化的缺电子烯烃与 $\mathrm{C}, \mathrm{N}-$ 环状偶氮次甲基亚胺的 $[3+2]$ 环加成反应的可能机理

Scheme 5 Putative mechanism of phosphine-catalyzed [3+2] cycloaddition of $\mathrm{C}, \mathrm{N}$-cyclic azomethine imines with electrondeficient alkenes

核进攻完成 $[3+2]$ 环化, 再生催化剂, 形成了最终 $[3+$ 2]环加成产物。

2015 年, 杜志云和汪舰等 ${ }^{[19]}$ 利用类似的策略, 使用 三乙烯二胺(DABCO)作为催化剂, 实现了温和条件下 $\mathrm{C}, \mathrm{N}$-环状偶氮次甲基亚胺 16 与 $N$-芳基马来酰亚胺 34 的 1,3-偶极环加成(Eq. 9). 该反应能在比较温和的条件 下，高效、高立体选择性地构建立体稠合的四环化合物 35 .

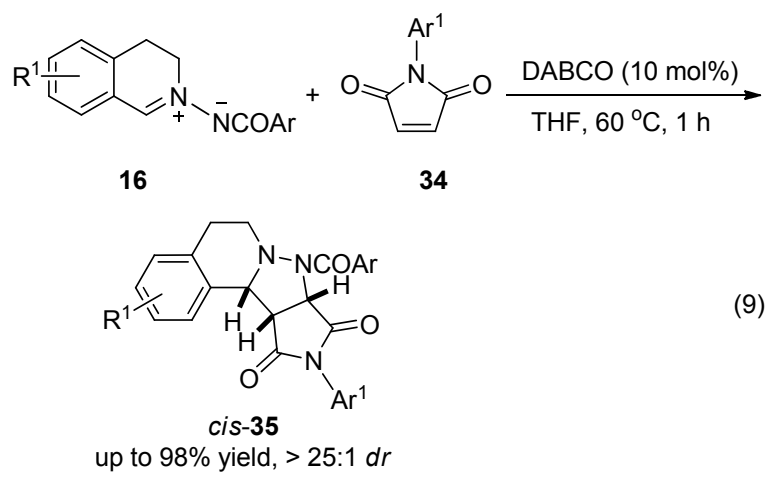

亲核膦催化的分子间环加成反应是合成各种碳杂 环化合物的有效方法之一. 在这些环加成反应中, 活化 的累积二烯是一个多样化的反应底物, 并对亲电试剂表 现出特有的反应活性. 它可以作为一碳、二碳、三碳或 四碳的合成子, 这样的活性通常受另一亲电组分的影 响. 2012 年, 郭红超课题组 ${ }^{[20]}$ 报道了膦催化的 $\mathrm{C}, \mathrm{N}$-环状 偶氮次甲基亚胺 1 与 $\alpha$-取代累积二烯酸酯 36 在室温条 件下的 $[3+2]$ 环化反应, 得到了一系列吡唑 $[5,1-a]$ 异喹 啉衍生物 37 (Eq. 10). 累积二烯酸酯参与反应的活性位 点与亲核性的膦催化剂以及累积二烯酸酯 $\alpha$ 位的取代基 有关. 当使用 $\beta^{\prime}$-烷基取代的累积二烯酸酯, 无论使用哪 种膦催化剂, 反应都以 $[3+2]$ 环化的途径进行. 当累积 二烯酸酯的 $\alpha$-取代基为 $\mathrm{ArCH}_{2}$ (即 $\beta^{\prime}$-取代基为 $\mathrm{Ar}$ )时, 反
应的途径受亲核性的膦催化剂影响. 催化剂为 $\mathrm{PMe}_{3}$ 的 反应给出了相应的 $[3+2]$ 环化产物. 作者提出了该 $[3+$ 2]环加成反应的机理并解释了上述结果产生的可能原 因(Scheme 6). $\mathrm{PR}_{3}$ 对累积二烯酸酯的 $\beta$ 位-C 加成形成中 间体 38, 该中间体的 $\gamma-\mathrm{C}$ 进攻 C,N-环状偶氮次甲基亚胺 $1 \mathrm{a}$ 得到中间体 39, 中间体 39 分子内的共轭加成完成了 该 $[3+2]$ 环化, 形成中间体 40, 接着经历了 $\beta$-消除再生 催化剂得到 $[3+2]$ 产物 37. 当 $\mathrm{PMe}_{3}$ 为催化剂时，中间体 39 的酰胺 $\mathrm{N}$ 对 $\beta$-膦正离子烯酸酯的共轭加成是主要的 反应途径, 这是由于 $\beta$-C 原子空间位阻减弱.

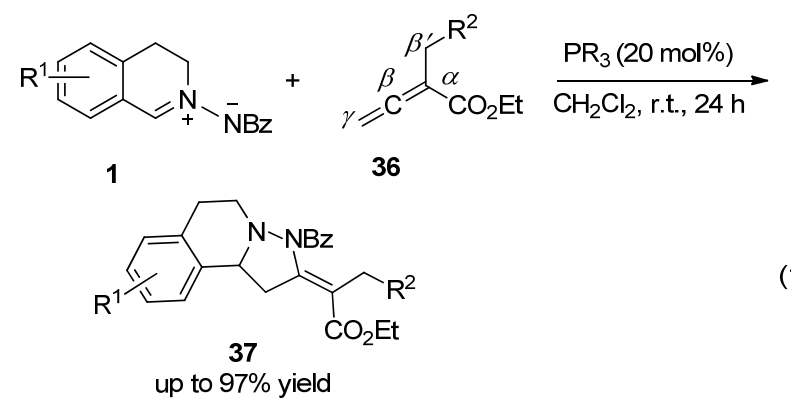

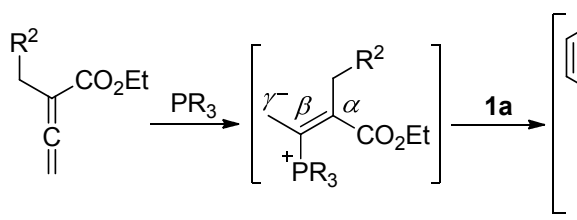

36

38

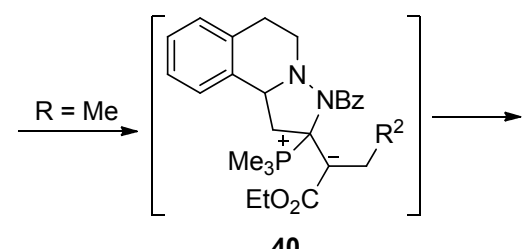

40<smiles>[R7]CC(CC)=C(CC)CC1c2ccccc2CCN1[N+](=O)[O-]</smiles>

39<smiles>[R]C/C(C)=C1\CC2c3ccccc3CCN2C1[R16]</smiles>

37
图式 6 膦催化的烯丙酸酯与 $\mathrm{C}, \mathrm{N}$-环状偶氮次甲基亚胺的 $[3+2]$ 环加成反应的反应机理

Scheme 6 Proposed mechanism of the phosphine-catalyzed $[3+2]$ cycloaddtion of $\mathrm{C}, \mathrm{N}$-cyclic azomethine imines with allenoates

在上述 $[3+2]$ 环加成反应中 $\alpha$-取代累积二烯酸酯作 为亲偶极子的 $2 \mathrm{C}$ 合成子, 参与反应的是 $\alpha, \beta-\mathrm{C}=\mathrm{C}$ 键或 者 $\beta, \gamma-\mathrm{C}=\mathrm{C}$ 键, 而对于 $\delta$-位取代的累积二烯酸酯在膦催 化剂作用下的环加成反应报道较少. 2014 年, 施敏课题 组 ${ }^{[21]}$ 成功实现了 $(S)$-Me-f-Ketalphos (41)催化的 C,N-环 状偶氮次甲基亚胺与 $\delta$-取代的累积二烯酸酯 $\mathbf{4 2}$ 的 [3+ 2]环加成反应，合成了官能化的四氢异喹啉骨架 $\mathbf{4 3}$ (Eq. 11). 该反应的条件温和, 收率和对映选择性都较好, 非 对映选择性也非常高. 这是 $\delta$-取代的累积二烯酸酯首次 在不对称合成中以 $\delta, \gamma-\mathrm{C}-\mathrm{C}$ 键作为 $2 \mathrm{C}$ 合成子参与反应. 
作者提出了这个膦催化的新型 $[3+2]$ 环加成反应的可能 机理(Scheme 7): 首先, 累积二烯酸酯与膦催化剂形成 了中间体 44, 该中间体经过一个质子转移可以转化为 中间体 45; 中间体可以作为 1,4-偶极子与 C,N-环状偶氮 次甲基亚胺发生 $\delta$-加成得到中间体 46; 接着, $\mathrm{N}$ 负离子 对烯烃的亲核加成可以产生膦叶立德 47 , 然后可能经 过一个分子内 $[1,2]$ 的质子转移将 42 转化为另一个两性 离子中间体 48, 消除膦催化剂, 最终得到[3+2]环加成 产物 43 .


图式 7 (S)-Me-f-Ketalphos 催化的 C,N-环状偶氮次甲基亚胺 与 $\delta$ 取代的累积二烯酸酯反应的可能机理

Scheme 7 Proposed mechanism of the (S)-Me- $f$-ketalphos catalyzed cycloaddtion of $\mathrm{C}, \mathrm{N}$-cyclic azomethine imines with $\delta$-substituted allenoates

2014 年汪舰团队 ${ }^{[22]}$ 报道了胺 49a 催化的醛 50 和 $\mathrm{C}, \mathrm{N}$-环状偶氮次甲基亚胺 16 的对映选择性 1,3-偶极环
加成反应(Eq. 12). 在该反应中, 醛与手性脯氨醇硅醚形 成的烯胺中间体 52 作为亲偶极子，与 $\mathrm{C}, \mathrm{N}$-环状偶氮次 甲基亚胺 $16 \mathrm{a}$ 反应得到中间体 53 , 水进攻得到化合物 51a (Scheme 8). $\mathrm{NaBH}_{4}$ 原位还原半胺醛可得 1-取代-四 氢异喹啉, 再脱除苯甲酰胺基团, $\mathrm{SmI}_{2}$ 促进 $\mathrm{N}-\mathrm{N}$ 键断 裂, 最终得到四氢异喹啉产物 $\mathbf{5 5}$, 三步总收率为 $85 \%$. 该产物的对映选择性由 $\mathbf{5 6}$ 的保护基 $e e$ 值来确定，产物 55 还可以进一步与醛反应，得到手性四氢 1,3-噁嗪 57 . 此外, 1a 和 50a 的环加成产物再经过 2,3-二氯-5,6-二氰 基对苯醌(DDQ)氧化可得四氢异喹啉并吡唑化合物 $\mathbf{5 8}$ (Scheme 9).

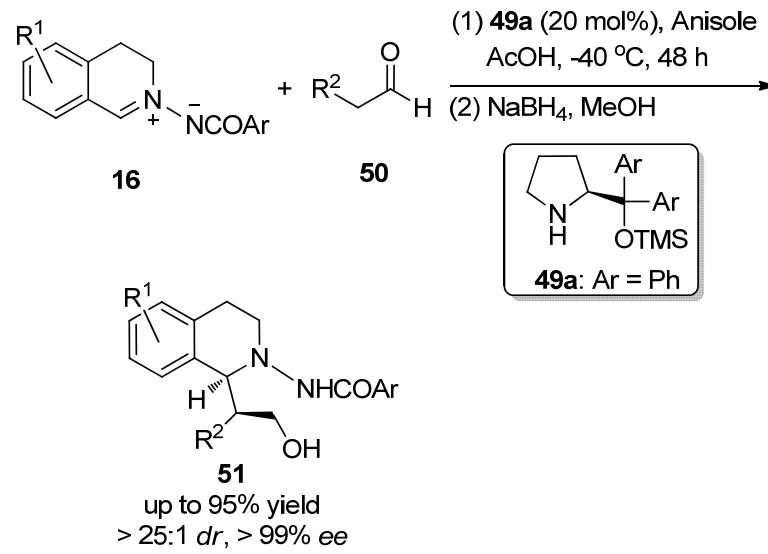

紧接着，该团队 ${ }^{[23]}$ 还实现了烯醛 59 与 $\mathrm{C}, \mathrm{N}$-环状偶 氮次甲基亚胺 16 的对映选择性 1,3-偶极环加成，以手性 脯氨醇硅醚 49b 作为有机催化剂, 与烯醛反应形成了二 烯胺中间体，该中间体与 $\mathrm{C}, \mathrm{N}$-环状偶氮次甲基亚胺反 应形成环加成产物，接着被 $\mathrm{NaBH}_{4}$ 原位还原得到相应 的醇化合物 62, 反应的产率和立体选择性都比较良好. 然而，当 $\mathrm{R}$ 为烷基时, $\alpha, \beta$-不饱和亚胺离子作为反应的亲 偶极子中间体，由此得到了区域异构体 65 (Scheme 10). 除此之外, 作者还对三烯胺活化的可能性进行了研究, 在标准条件下，以 $80 \%$ 收率得到目标产物 67, 但是其非 对映选择性中等(Eq. 13).

2014 年, Alemán 和 Fraile 等 ${ }^{[24]}$ 相继报道了关于 $\beta$ 烷基- $\alpha, \beta$-不饱和醛的亚胺一烯胺反应活性问题. 在这个 反应中, 作者通过改变添加剂和有机催化剂可完全控制 烯醛与 $\mathrm{C}, \mathrm{N}$-环状偶氮次甲基亚胺反应的化学选择性(Eq. 14). 作者还通过实验和密度泛函(DFT)计算对这些控制 因素给出了合理的解释.

2015 年, Mück-Lichtenfeid 和 Studer 等 ${ }^{[25]}$ 实现了异 硫嫝 71 催化的 C,N-环状偶氮次甲基亚胺 1 与混酐的 1,3偶极环加成反应(Eq. 15). 混酐是一种活化的酯衍生物, 在该反应中由相应的芳基乙酸和苯甲酰氯在 $i-\mathrm{Pr}_{2} \mathrm{NEt}$ 的 作用下原位产生, 进而在催化剂作用下与 $\mathrm{C}, \mathrm{N}$-环状偶 


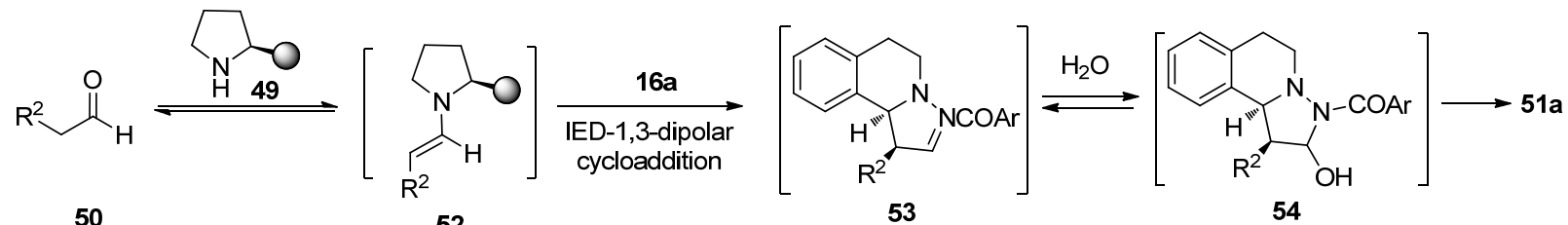

52

53

54

图式 8 胺催化 $[3+2]$ 环加成不对称反应的可能机理

Scheme 8 Possible mechanism of asymmetric reaction of [3+2] cycloaddition catalyzed by bisamide

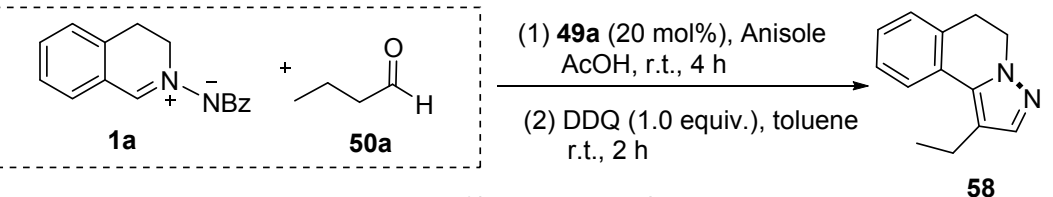

(1) $49 \mathrm{a}(20 \mathrm{~mol} \%)$, Anisole, $\mathrm{AcOH} \quad 57 \%$ yield

(2) $\mathrm{NaBH}_{4}, \mathrm{MeOH}$

(3) $\mathrm{Sml}_{2}$ (4.0 equiv.), $\mathrm{MeOH}$

r.t., $30 \mathrm{~min}$<smiles>CCC(CO)C1c2ccccc2CCN1C(=O)OCc1ccccc1</smiles>

$82 \%$ yield $d r>25: 1 d r, 99 \%$ ee<smiles>CCC(CO)C1NCCc2ccccc21</smiles>

55

$85 \%$ yield
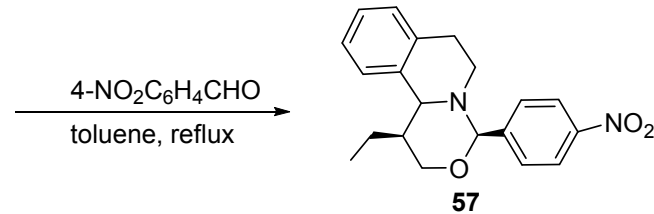

$82 \%$ yield

$>25: 1 d r, 99 \%$ ee

图式 $9 \mathrm{C}(1)$-取代的四氢异喹啉衍生物的合成转换

Scheme 9 Synthetic transformations of C(1)-substituted tetrahydroisoquinoline derivatives

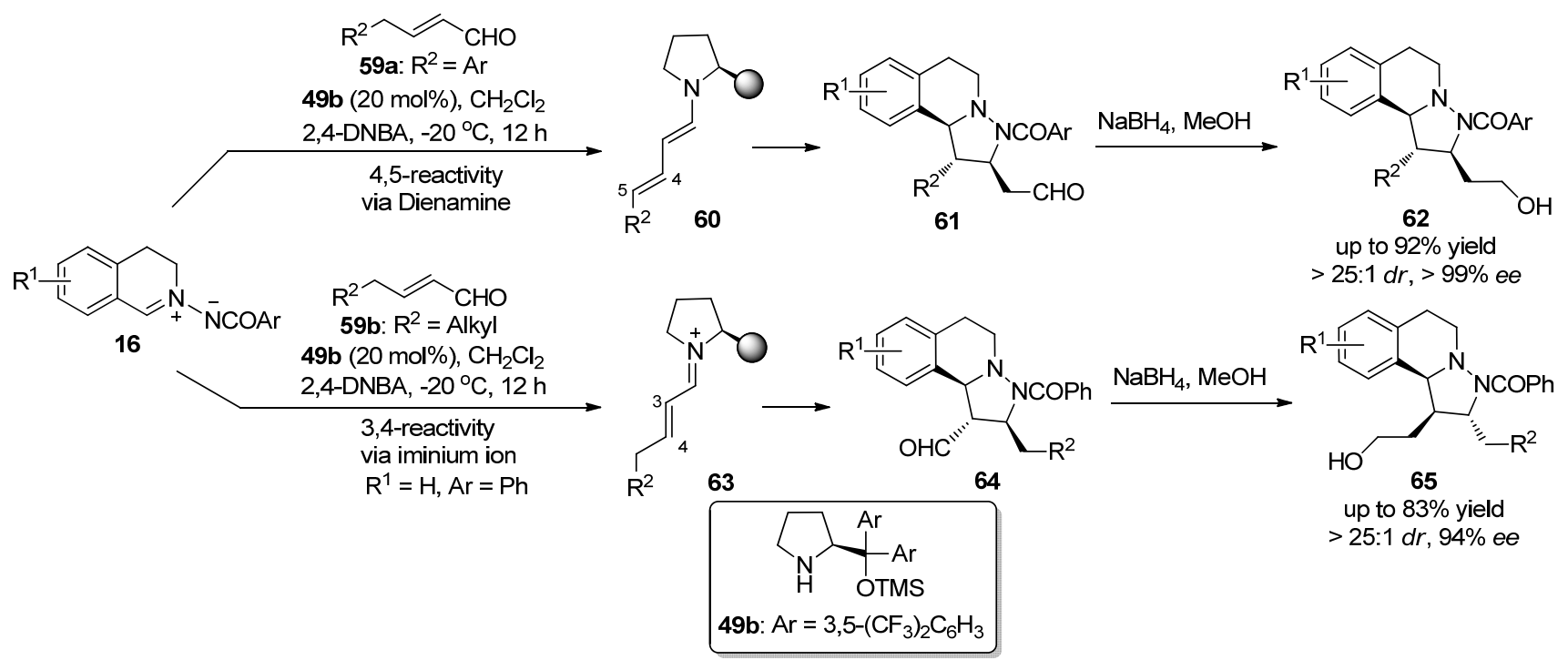

图式 10 烯醛与 $\mathrm{C}, \mathrm{N}$-环状偶氮次甲基亚胺的反应

Scheme 10 Reaction of enal with C,N-cyclic azomethine imines

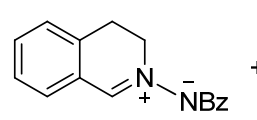

1a
(1) $49 \mathrm{~b}$ (20 mol\%), $\mathrm{CH}_{2} \mathrm{Cl}_{2}$ 2,4-DNBA, $-20^{\circ} \mathrm{C}, 12 \mathrm{~h}$

(2) $\mathrm{NaBH}_{4}, \mathrm{MeOH}$

$66 a$

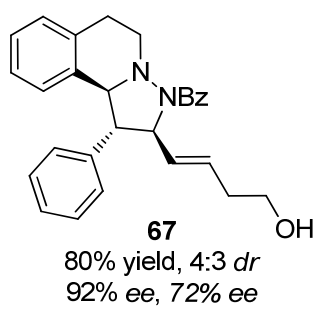




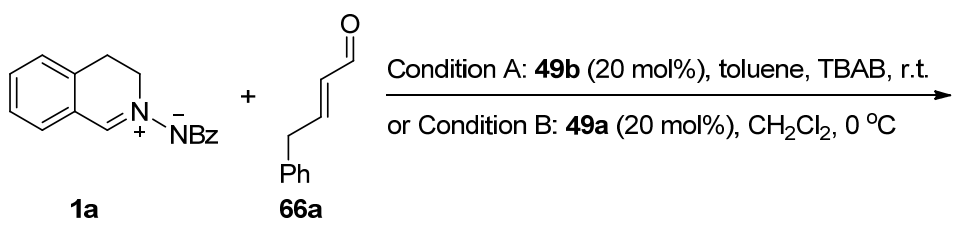

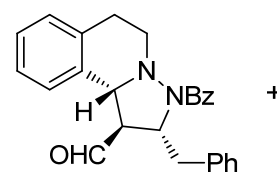

68

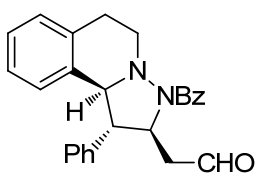

69

Condition A: $73 \%$ yield, 121:122 $\geqslant 98: 2,98 \%$ ee Condition B: $68 \%$ yield, 122:121 $\geqslant 98: 2,94 \%$ ee

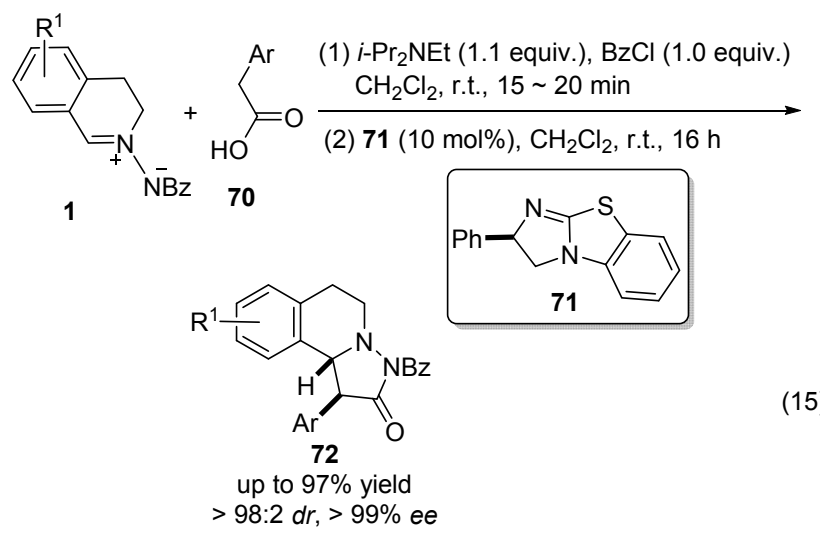

氮次甲基亚胺发生环加成反应, 高效、高立体选择性地 合成了一系列吡唑酮化合物 72. 为了证实吡唑烷酮结 构单元在有机合成中的价值, 作者对产物 73 进行了合 成转换(Eq. 16), 产物中 $N$-苯甲酰基的脱保护可以在二 环[4.3.0]-1,5-二氮-5-十一烯(DBU)/ $\mathrm{LiBr}$ 和 $\mathrm{MeOH}$ 的条 件下实现, 通过 Raney- $\mathrm{Ni} / \mathrm{H}_{2}$ 还原能以较好的收率得到 相应的 $\mathrm{N}-\mathrm{N}$ 断裂产物 74. 这些 $\beta$-氨基酸衍生物在 $\beta$ 肽制备中可能具有一定价值. 作者还对该反应的机理进 行了深入的研究, 结果表明, 反应经过了一个分步的 $\mathrm{C}-\mathrm{C}$ 键和 $\mathrm{C}-\mathrm{N}$ 键形成机理, 其中第一步 $\mathrm{C}-\mathrm{C}$ 键的形 成是反应的决速步骤和立体化学的关键. 反应物通过 exo 型的加成得到了热力学稳定的反式异构体, 这与实 验结果一致.

2015 年, Chi 课题组 ${ }^{[26 a]}$ 报道了手性异硫脲有机催化

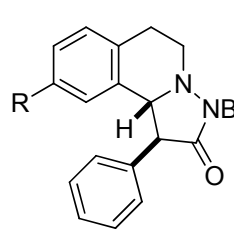

73a: $\mathrm{R}=\mathrm{H}$

73b: $R=O M e$
(1) $\mathrm{DBU} / \mathrm{LiBr}, \mathrm{MeOH}$ (2) Raney-Ni, $\mathrm{H}_{2}, \mathrm{EtOH}$ $50^{\circ} \mathrm{C}, 16 \mathrm{~h}$<smiles>[R]c1ccc2c(c1)[C@H]([C@@H]([14CH3])C(=O)N[13CH3])NCC2</smiles>

74a: $77 \%$ yield 74b: $65 \%$ yield

剂 71 促进的 $\gamma$-氯取代环丁烯酮 70 与 $\mathrm{C}, \mathrm{N}$-环状偶氮次甲 基亚胺 1 的 $[3+2]$ 环加成反应，高对映选择性地合成了吡 唑酮衍生物 76. 有机催化剂对底物 75 的酮片段加成破坏 了其稳定的共轭平面结构, 由此产生了相对不稳定的氧 负离子非平面中间体 77, 该中间体的 $\mathrm{C}-\mathrm{C}$ 键被活化后 极易断裂形成中间体 78, 随后与 $\mathrm{C}, \mathrm{N}$-环状偶氮次甲基亚 胺 1 发生一个 $\alpha$-碳选择性的反应, 再脱催化剂得到目标 化合物 76 (Scheme 11). 值得注意的是, 当底物 75 的氯原 子改为 $\mathrm{H}$ 或者是 $\gamma, \gamma^{\prime}$-二氯取代的环丁烯酮时，在标准反 应条件下，不能得到相应的环加成产物。这些结果表明 在 $\gamma$ 位有一个取代基的环丁酮的反应活性更高，与文献 ${ }^{[266]}$ 报道的计算结果是一致的. 当底物中的 $\mathrm{Cl}$ 原子改为 甲基取代时，相应的甲基化产物在反应中并不活泼，可 能是由于电子效应导致酮片段不够活泼以及异硫艮催化 剂相对较弱的亲核性. 作者通过一系列的合成转换实验 证实了该方法的重要性: 在 $\mathrm{SmI}_{2}$ 和 $\mathrm{EtOH}$ 作用下，产物 76a 的 $\mathrm{N}-\mathrm{N}$ 键断裂得到产物 80; 另外, 产物中的烯基氯 单元是有机合成中广泛使用的官能团，其中的氯原子可 以被 $\mathrm{PhS}$ 基团取代得到产物 81 (Scheme 12).

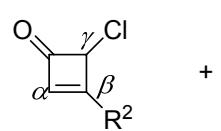

75

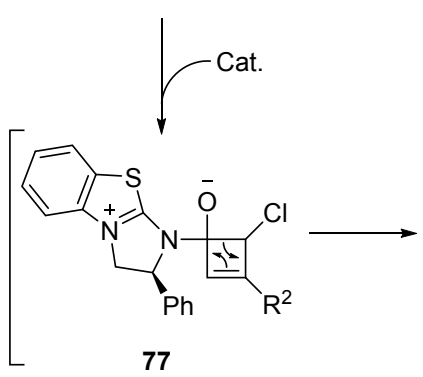

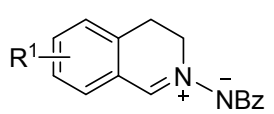

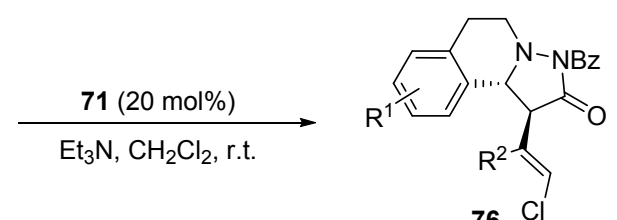

$76 \mathrm{Cl}$

up to $73 \%$ yield

$>20: 1 d r,>99: 1$ er

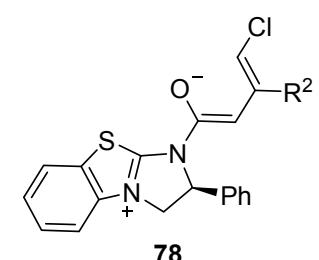

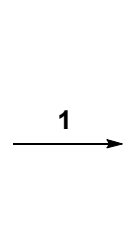

1

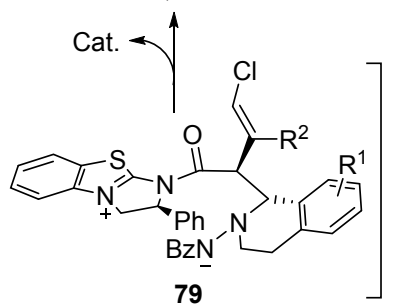

图式 $11 \mathrm{C}, \mathrm{N}$-环状偶氮次甲基亚胺与环丁烯酮[3+2]环加成反应的可能机理

Scheme 11 Proposed mechanism of the $[3+2]$ cycloaddition reaction of C,N-cyclic azomethine imines with cyclobutenones 
<smiles>NC(=O)C(/C(=C/Cl)c1ccccc1)C1NCCc2ccccc21</smiles>

$85 \%$ yield

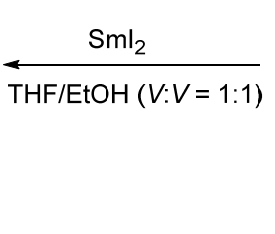

图式 $12 \mathrm{C}(1)$-取代四氢异喹啉衍生物 76a 的合成转换

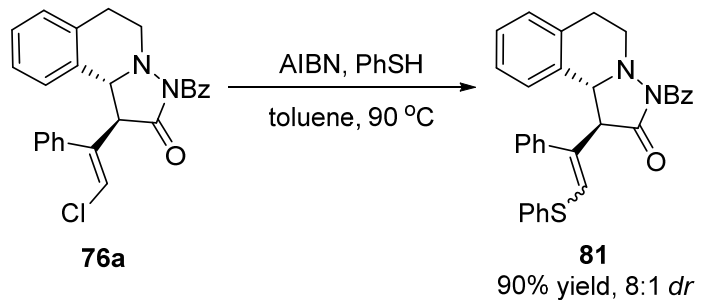

Scheme 12 Synthetic transformations of C(1)-substituted tetrahydroisoquinoline derivatives 76a

在上述工作中, 仅 $\beta$-芳基羧酸应用到了反应体系 中. $\mathrm{N}$-杂环卡宾 $(\mathrm{NHC})$ 在 $\mathrm{C}-\mathrm{H}$ 活化和对映选择性 $\mathrm{C}-\mathrm{C}$ 键形成中有着巨大的潜在作用, 近年也在不对称有机催 化中得到了迅速发展. 2015 年, 廖维林和叶松等 ${ }^{[27]}$ 发展 了 $\mathrm{N}$-杂环卡宾 82a 催化的 $\alpha$-氯醛 83 与 $\mathrm{C}, \mathrm{N}$-环状偶氮次 甲基亚胺的对映选择性 $[3+2]$ 环化缩合反应(Eq. 17). 在 温和的条件下, 高效地合成了相应的吡唑烷酮 84, 其中 $\beta$-芳基、 $\beta$-烷基取代的 $\alpha$-氯醛都能很好地参与反应. 作 者对吡唑烷酮产物 84a 进行了合成转换研究, 84a 在水 合肼作用下可以脱去苯甲酰基保护基以 $85 \%$ 的收率及 95\%的对映选择性得到产物 85 (Scheme 13). 在 $\mathrm{NaOH}$ 的碱性条件下, 通过脱氧芳构化反应可以得到相应的吡 唑啉酮化合物 85'. 如图 3 所示, 作者提出了可能的过渡 态来解释该反应立体选择性: 烯醇中间体和 $\mathrm{C}, \mathrm{N}$-环状 偶氮次甲基亚胺的 $[3+2]$ 环加成反应是经过 endo-过渡 态模式给出了 cis-选择性的目标产物.

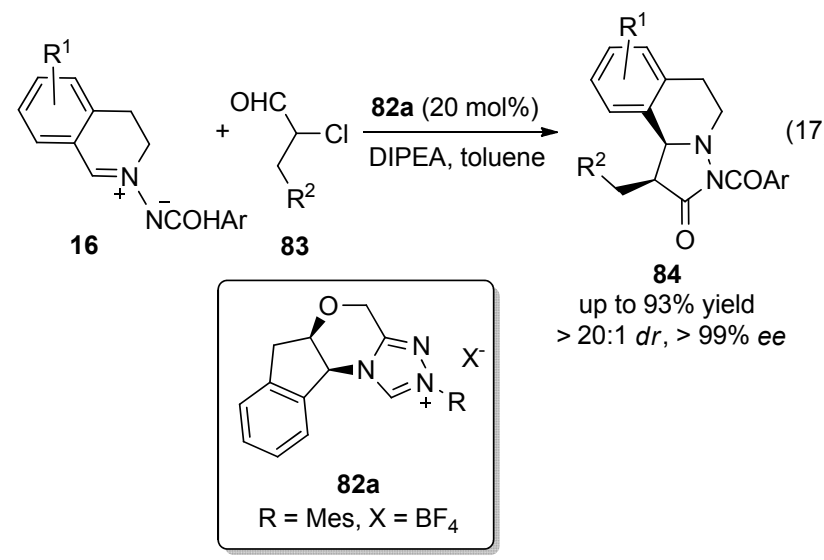

虽然 NHC 催化已被证明在有机合成中能催化多种 反应, 但对反应活性的控制研究确很少被报道. 2015 年, Glorius 团队 ${ }^{[28]}$ 报道了一种通过调节反应条件以控制 $\mathrm{C}, \mathrm{N}$-环状偶氮次甲基亚胺 $87 \mathrm{a}$ 与 $\alpha, \beta$-不饱和烯醛 88 的 [3 $+2]$ 和 $[3+3]$ 两个竞争环加成的反应(Scheme 14): $\alpha, \beta$-不 饱和烯醛 88 和 NHC (89)的结合可形成等物质的量的中 间体 90, 随后如果催化碱的共轭酸具有足够的酸性, 则 可以使烯醇化物中间体 90 在 $\beta$-位发生质子化, 形成等 物质的量的烯醇中间体 91, 再与 $\mathrm{C}, \mathrm{N}-$ 环状偶氮次甲基

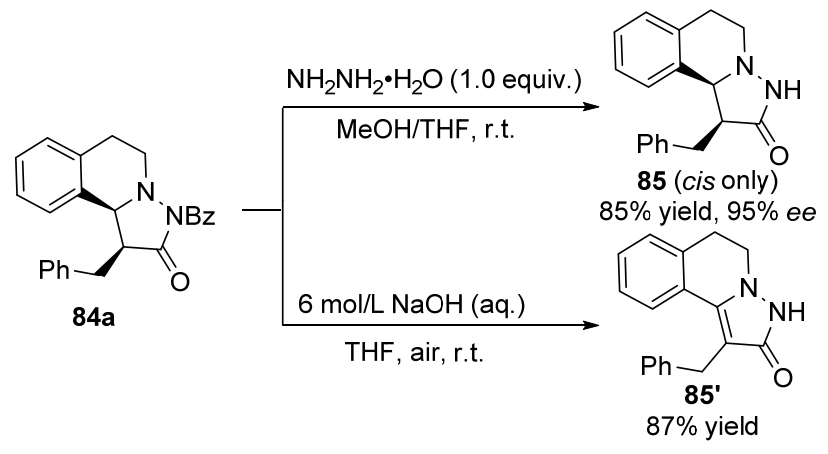

图式 $13 \mathrm{C}(1)$-取代四氢异喹啉衍生物 84a 的合成转换 Scheme 13 Synthetic transformations of C(1)-substituted tetrahydroisoquinoline derivatives $\mathbf{8 4 a}$

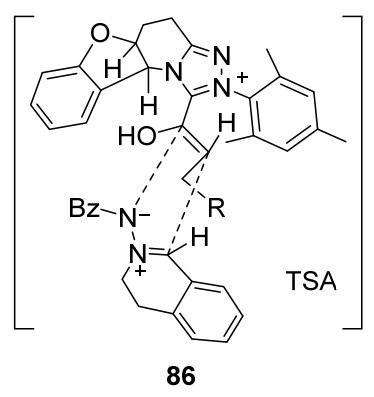

图 3 烯醇与 $\mathrm{C}, \mathrm{N}$-环状偶氮次甲基亚胺可能经历的过渡态 Figure 3 Possible transition states of enol with C,N-cyclic azomethine imine

亚胺 87a 结合完成 $[3+2]$ 环化反应, 以得到吡唑并 [5,1- $a$ ]异喹啉衍生物 93; 否则烯醇化物中间体 90 与 $\mathrm{C}, \mathrm{N}$-环状偶氮次甲基亚胺 87a 结合完成 $[3+3]$ 环化反应 ([3+3]环化反应在下文中讨论). 通过计算和对照实验 研究发现, 中间体 90 和中间体 91 之间的平衡是决定催 化循环性的关键, 故随着有效质子浓度的增加, 反应平 衡从中间体 85 转移到中间体 86 , 促进 $[3+2]$ 环化反应 (Scheme 15). 基于初步的机理研究作者提出了以下的 催化循环(Scheme 16): 发现竞争性 Homoenolate/烯醇途 径之间的选择是由 NHC 催化剂、碱和溶剂决定的. NHC 催化剂与 $\alpha, \beta$-不饱烯醛结合生成 Breslow 中间体 94, 该 中间体可以通过烯醇共振式或经过 $\beta$ 位质子化形成烯醇 中间体 95 , 然后在碱性较弱的条件下, 该中间体 95 与 


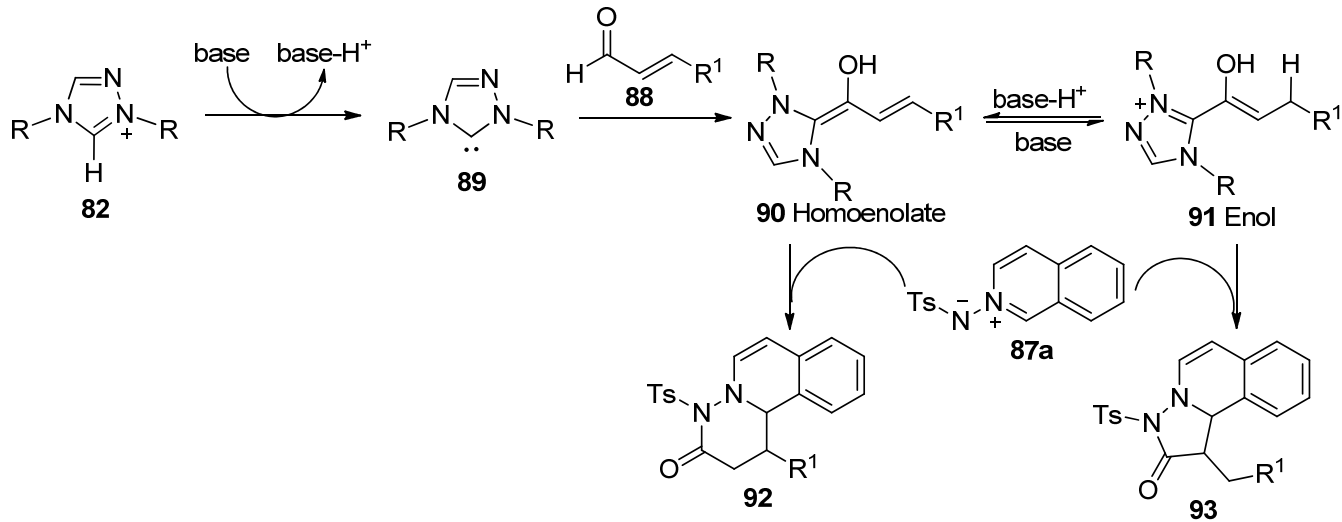

图式 $14 \mathrm{C}, \mathrm{N}$-环状偶氮次甲基亚胺与 $\alpha, \beta$-不饱和烯醛的环加成反应

Scheme 14 Cycloaddition reaction of $\mathrm{C}, \mathrm{N}$-cyclic azomethine imines with $\alpha, \beta$-unsaturated alkenal

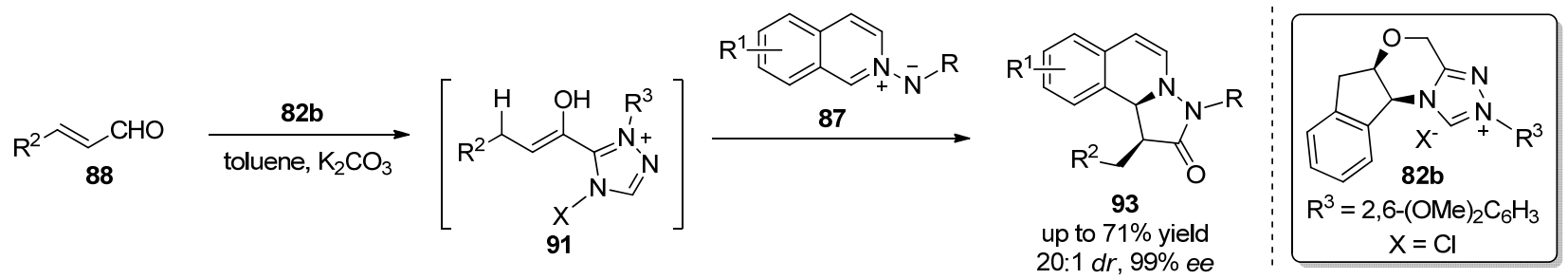

图式 $15 \mathrm{C}, \mathrm{N}$-环状偶氮次甲基亚胺与 $\alpha, \beta$-不饱和烯醛烯醛的 $[3+2]$ 环加成反应

Scheme $15[3+2]$ cycloaddition reaction of $\mathrm{C}, \mathrm{N}$-cyclic azomethine imines with $\alpha, \beta$-unsaturated alkenal

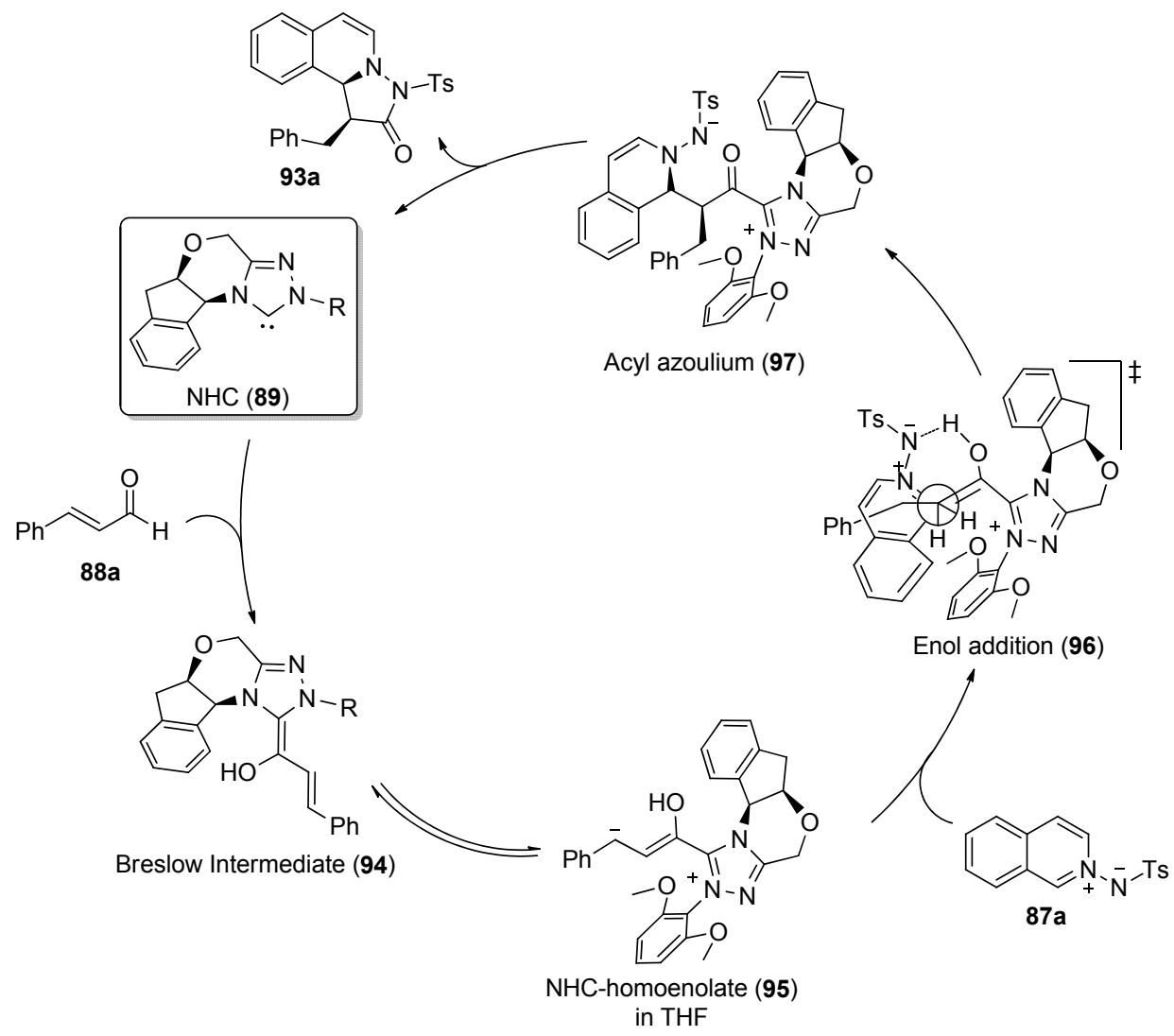

图式 $16 \mathrm{C}, \mathrm{N}$-环状偶氮次甲基亚胺与 $\alpha, \beta$-不饱和烯醛烯醛的 $[3+2]$ 环加成反应的反应机理

Scheme 16 Reaction mechanism of the $[3+2]$ cycloaddition of $\mathrm{C}, \mathrm{N}$-cyclic azomethine imine with $\alpha, \beta$-unsaturated alkenal 
$\mathrm{C}, \mathrm{N}-$ 环状偶氮次甲基亚胺 87a 结合得到中间体 96, 随后 经历加成/ $\mathrm{N}$-酰基化过程, $\mathrm{NHC}$ 再生, 得到[3+2]环化最 终产物 93a.

2018 年, 徐进宜和柳红团队 ${ }^{[29]}$ 同样使用 NHC 催化 实现了饱和羒酸酯 98 与 $\mathrm{C}, \mathrm{N}-$ - 环状偶氮次甲基亚胺 87 的直接活化 $\alpha$-碳的脱芳香化反应, 在温和条件下, 得到 了三环手性产物 99 (Eq. 18). 作者环化产物 99 进行了合 成转换研究, 在 $\mathrm{NaBH}_{3} \mathrm{CN}$ 处理下能一步转化为含吲哚 嗪生物碱片段的 $N$-取代的吲哚并咪唑衍生物 100 (Eq. 19). 对于该反应的过程, 作者提出了可能的反应机理 (Scheme 17): NHC 催化剂与酯基底物 98a 结合得到中间 体 101, 该中间体 101 可以形成带有酸性 $\alpha-\mathrm{CH}$ 的烯醇中 间体 102 共振式. 中间体 102 再去质子化产生 $\alpha$-碳作为 亲核中心的中间体 103 , 然后中间体 103 与底物 87a 结 合得中间体 104, 再进行分子内酰化反应, 最终得到的 环化产物 99c, 并再生 NHC 催化剂.

2007 年, Aoyama 团队 ${ }^{[30]}$ 描述了以三甲基硅烷烯酮 106 作为 $2 \mathrm{C}$ 合成子引入试剂, 与 $\mathrm{C}, \mathrm{N}$-环状偶氮次甲基 亚胺 87 在三乙胺作用下发生 $[3+2]$ 环加成反应意外得 到吡唑并 [5,1- $a$ ] 异喹啉衍生物 23 (Eq. 20)的反应. 对于 该反应过程作者目前尚不清楚怎样发生的脱氧和脱对 甲苯磺酸过程, 但能初步假定了环加成反应中的亲核进 攻过程(Scheme 18).

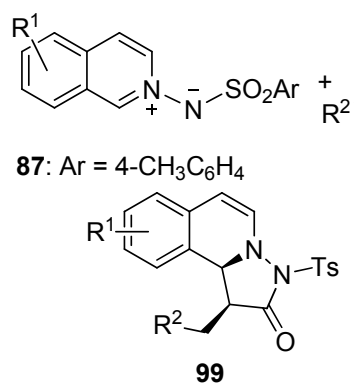

up to $82 \%$ yield, $99 \%$ ee<smiles>[R]CCC(=O)Oc1ccc([N+](=O)[O-])cc1</smiles>

98
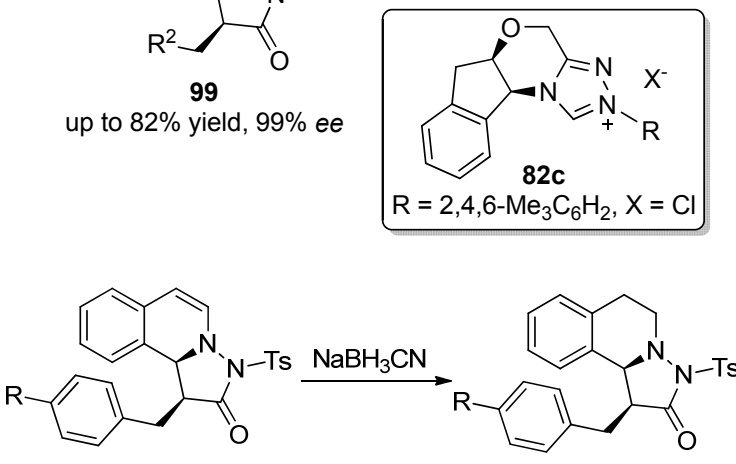

100a: $\mathrm{R}=\mathrm{H}, 60 \%$ yield, 10:1 dr, 95\% ee

100b: $\mathrm{R}=\mathrm{Br}, 62 \%$ yield, $8: 1 d r, 97 \%$ ee

99a: $\mathrm{R}=\mathrm{H}, 99 \%$ ee 99b: $\mathrm{R}=\mathrm{Br}, 96 \%$ ee

2016 年, 刘冬生和苏吴等 ${ }^{[31]}$ 成功地报道了 C,N-环 状偶氮次甲基亚胺 109 与呋内酯 110 反电子需求的 1,3偶极环加成反应. 在金鸡纳碱衍生的三级胺硫脲催化剂 111 的作用下，高效、高立体选择性地实现了吡唑烷酮 112 的构建(Eq. 21). 根据文献调研及实验结果, 作者推

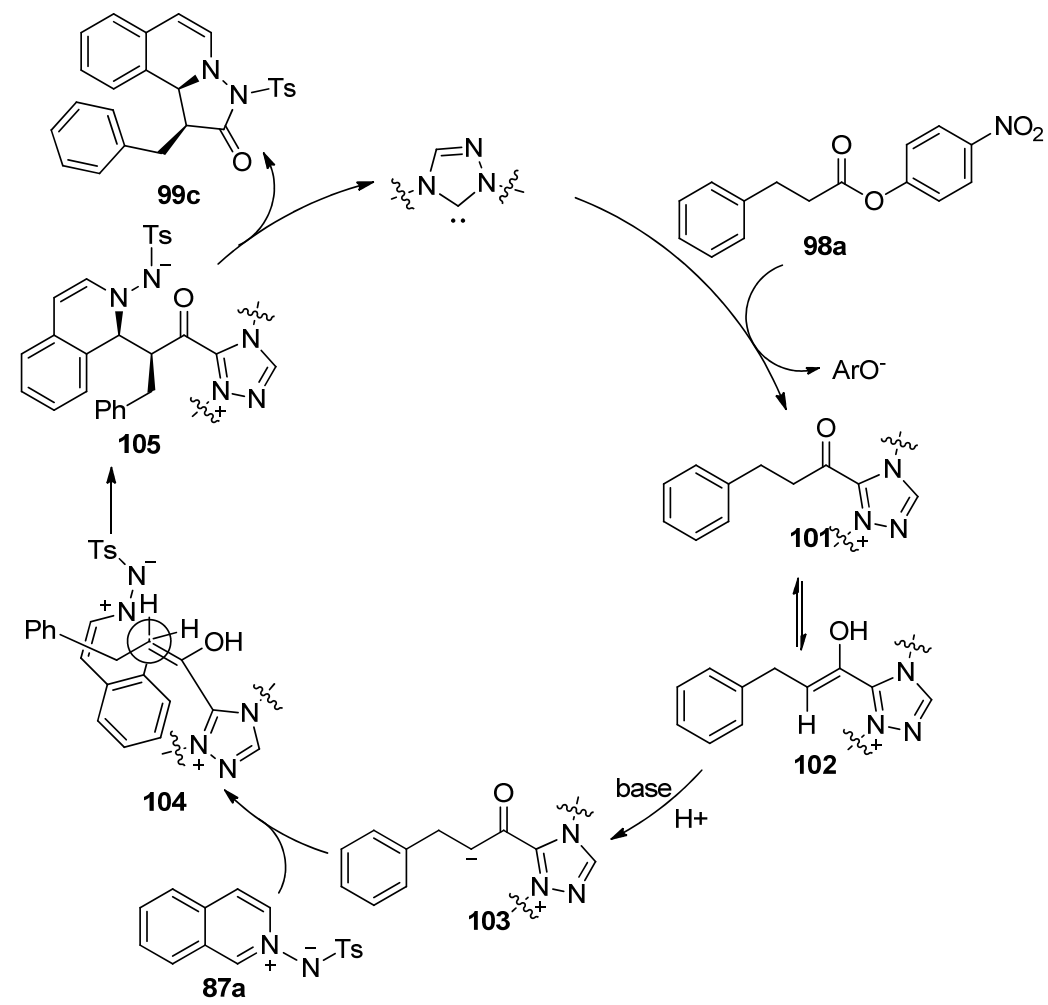

图式 $17 \mathrm{C}, \mathrm{N}$-环状偶氮次甲基亚胺与饱和羧酸酯 $[3+2]$ 环加成反应的反应机理

Scheme 17 Proposed mechanism of the [3+2] cycloaddition of C,N-cyclic azomethine imines with saturated carboxylic esters 


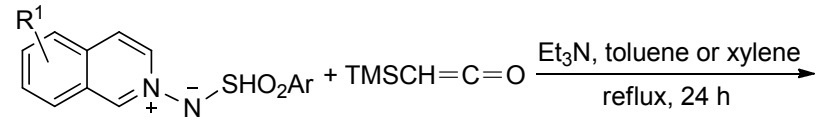
87: $\mathrm{Ar}=4-\mathrm{CH}_{3} \mathrm{C}_{6} \mathrm{H}_{4}$

106

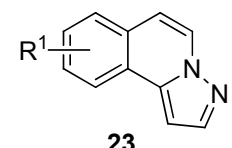

up to $79 \%$ yield

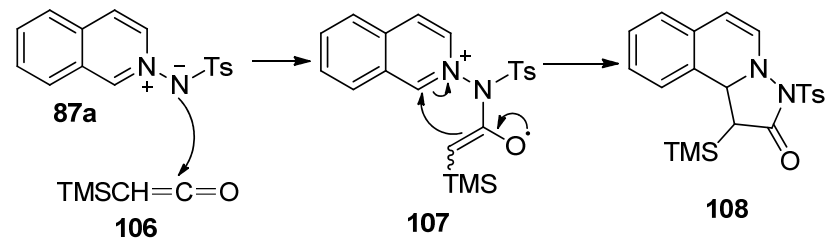

图式 $18 \mathrm{C}, \mathrm{N}$-环状偶氮次甲基亚胺与三甲基硅烷烯酮的 $[3+$ 2]环加成反应的可能机理

Scheme 18 Proposed mechanism of the $[3+2]$ cycloaddition of $\mathrm{C}, \mathrm{N}$-cyclic azomethine imines with trimethylsilylketene<smiles>O=[N+]([O-])[N+]1=Cc2cc[R1]cc2CC1</smiles>

109<smiles>[R]C1=NC([R])C(=O)O1</smiles>

110
测了可能的过渡态解释该反应的立体化学优势, 催化剂 111 的硫艮片段通过氢键活化两个底物, 三级胺片段活 化唤内酯形成烯醇式. 吟内酯烯醇式的 $R e$ 面进攻 C,N环状偶氮次甲基亚胺的 $R e$ 面后环化得到不稳定的中间 体 115, 接着重排为目标产物(Scheme 19). 为了证实该 方法的可拓展性和实用性, 作者对环状产物 $112 \mathrm{a}$ 进行 了一些代表性的转化: 产物 112a 经过 $\mathrm{Pd} / \mathrm{C}$ 催化氢化反 应以 $65 \%$ 的收率得到 116, 再在 $\mathrm{H}_{2}$ 作用下 Raney $\mathrm{Ni}$ 处理 以 73\%的收率转化为产物 117 (Scheme 20).

1,3-偶极子与烯烃的 $[3+2]$ 环加成反应主要分为两 种: 与缺电子烯烃的正电子需求的 1,3-偶极环加成和与 富电子烯烃的反电子需求的 1,3-偶极环加成. 反电子需 求的 1,3-偶极环加成反应发展远不及正电子需求 1,3-偶 极环加成反应的多样性和复杂性. 2011 年, Maruoka 课 题组 ${ }^{[32]}$ 报道了 $\mathrm{C}, \mathrm{N}$-环状偶氮次甲基亚胺 1 与烯基醚 118(或乙烯基氮杂烯胺 119)的不对称反电子需求的 1,3-
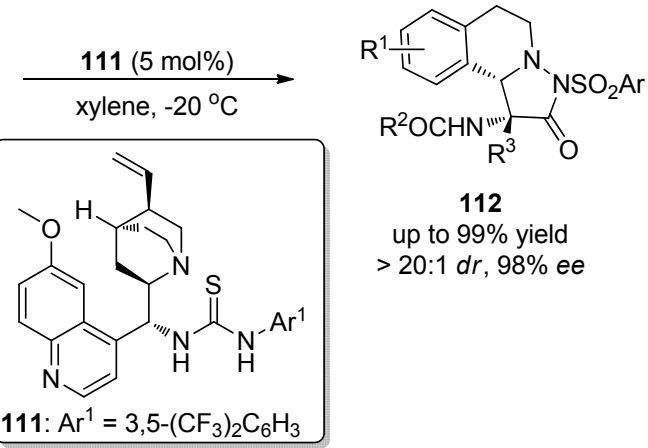

$$
\text { up to } 99 \% \text { yield }
$$

$>20: 1 d r, 98 \%$ ee

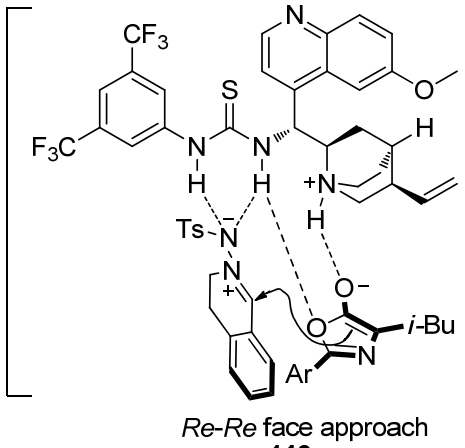

113

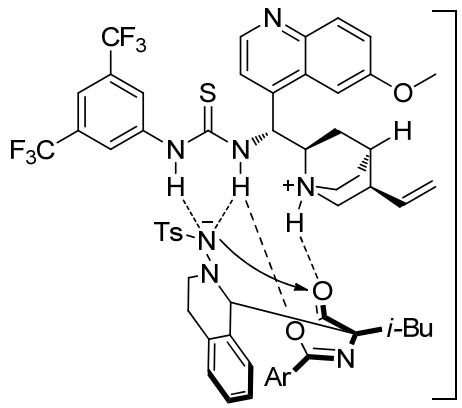

114

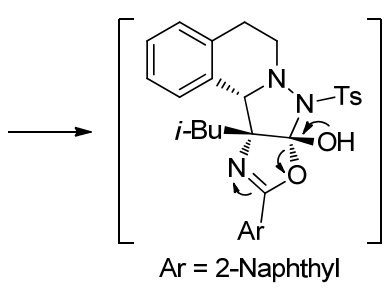

115

图式 19 三级胺硫脲催化的呋内酯与 $\mathrm{C}, \mathrm{N}-$ 环状偶氮次甲基亚胺的 $[3+2]$ 环加成反应的可能机理

Scheme 19 Putative mechanism of tertiary thiosemicarbazide-catalyzed [3+2] cycloaddition of C,N-cyclic azomethine imines with azlactones
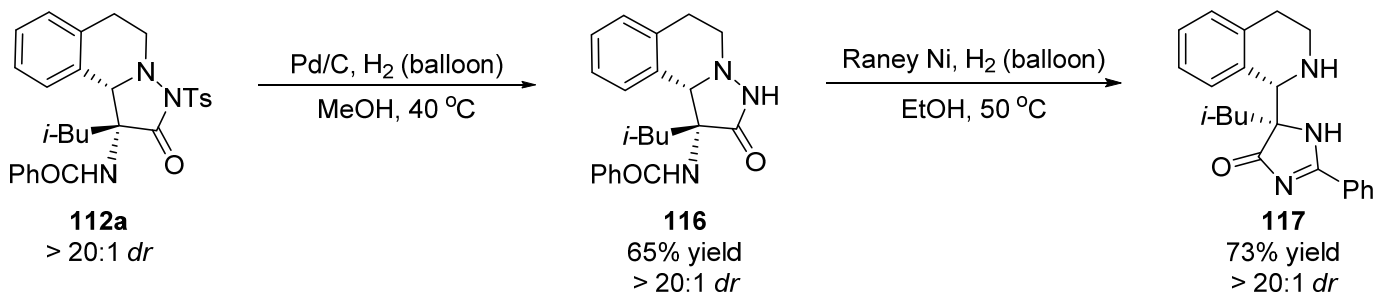

图式 $20 \mathrm{C}(1)$-取代四氢异喹啉衍生物 116 的合成转换

Scheme 20 Synthetic transformations of C(1)-substituted tetrahydroisoquinoline derivatives $\mathbf{1 1 6}$ 
偶极环加成反应. 在该不对称反应中使用 3,3'-位取代的 轴手性二羧酸 120 作为催化剂, 高收率、高对映选择性 地得到了手性四氢异喹啉衍生物 121 和 122 (Eq. 22). 为 了证明该环加成反应产物的有用性，作者对产物 121a 进行了路易斯酸催化氰基化反应和 Mukaiyama-type 的 加成反应，预期设想这些亲核试剂来取代产物中的叔丁 氧基, 但意外地发现反应后叔丁氧基在产物中保留, 以 高非对映选择性得到了产物 123 和 124 (Scheme 21). 环
加成产物 122a 的氮杂烯胺片段通过氧邻苯二甲酸镁 (MMPP)转化为氭基化合物 125, 而不影响立体化学(Eq. 23).

2016 年，朱杰平课题组 ${ }^{[33]}$ 发展了第一例手性磷酸 126 或 127 催化的不对称反转电子需求的 C,N-环状偶氮 次甲基亚胺与烯氨基甲酸芳酯 128 的 1,3-偶极环加成反 应(Eq. 24). 成功实现了含有两个或三个连续手性中心 的异喹啉并吡唑烷化合物的高效、高立体选择性合成.
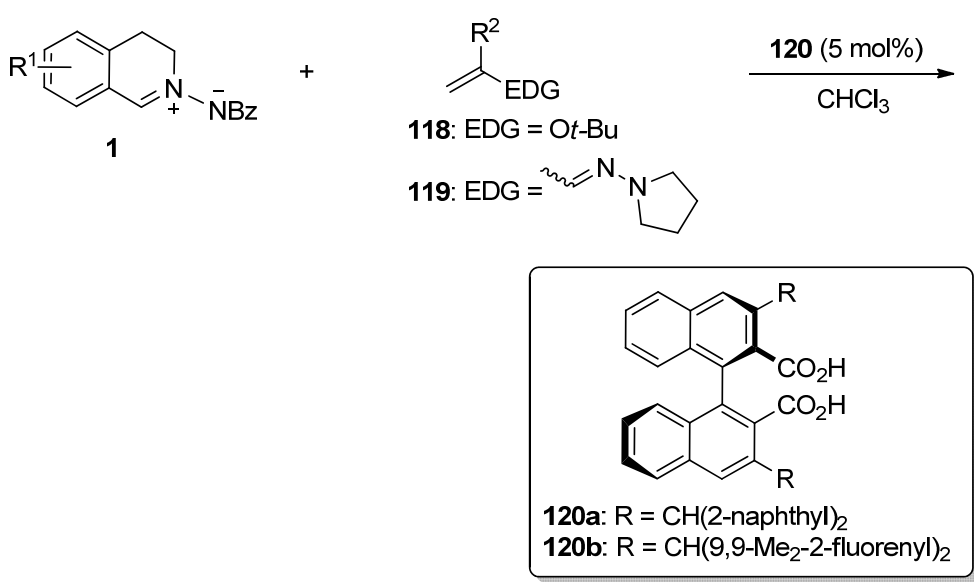



121: $\mathrm{EDG}=\mathrm{O} t-\mathrm{Bu}$

122: $\mathrm{EDG}=\mathrm{z}^{2}=\mathrm{N}$

exo:endo $>95: 5$ up to $>99 \%$ yield $97 \%$ ee<smiles>CCCCN1CCc2ccccc2[C@H]1CC(C#N)OC(C)(C)C</smiles>

123 $81 \%$ yield (major) 5:1 dr

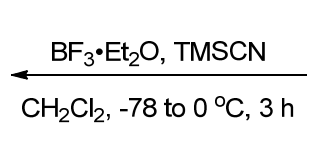<smiles></smiles>

$121 a$
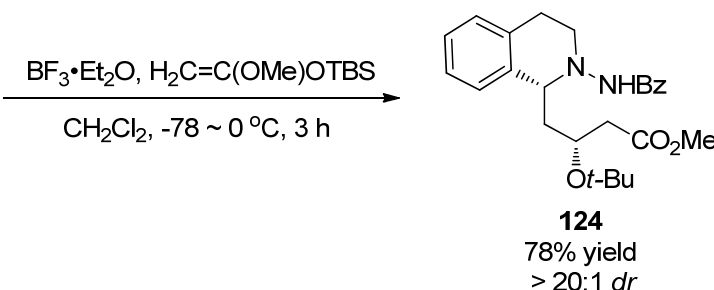

图式 $21 \mathrm{C}(1)$-取代四氢异喹啉衍生物 121a 的合成转换

Scheme 21 Synthetic transformations of C(1)-substituted tetrahydroisoquinoline derivatives 121a<smiles>O=C(c1ccccc1)N1CC[C@H]2c3ccc(Br)cc3CCN21</smiles><smiles>COCCOCCCOCCOCCOC</smiles><smiles>N#CC1C[C@@H]2c3ccc(Br)cc3CCN2N1C(=O)c1ccccc1</smiles>

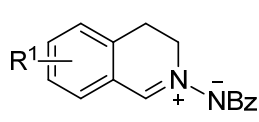<smiles>[R]/C=C\[R]</smiles>

126 or 127 (10 mol\%) $\mathrm{CH}_{2} \mathrm{Cl}_{2},-20^{\circ} \mathrm{C}$
128<smiles>CC1(C)c2c(Br)ccc(Br)c2Cc2ccc(Br)c(OP(=O)(O)O)c21</smiles>

126

126: $\mathrm{Ar}=2,4,6-(c-P e n t)_{3} \mathrm{C}_{6} \mathrm{H}_{2}$ 127: $\mathrm{Ar}=2,4,6-(i-\mathrm{Pr})_{3} \mathrm{C}_{6} \mathrm{H}_{2}$

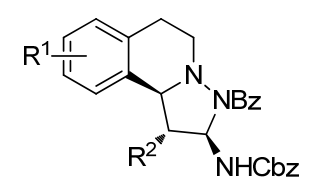

129

up to $95 \%$ yield $>19: 1 d r$ 98.9:1.1 er 
当使用反式的烯烃时, 相应的环加成产物的产率和对映 选择性都非常低, 由此排除了在环化反应过程中顺式烯 烃向反式烯烃异构化的可能性. 另外, 将环加成产物 129 重新置于标准条件下并未导致缩醛胺片段手性中心 的差向异构化. 因此观察到的环加成产物 129 中 $\mathrm{R}^{2}$ 基团 和 $\mathrm{NHCbz}$ 基团的反式关系表明 1 和 128 的这一反电子 需求的 1,3-偶极环加成可能是经过一个分步的反应过 程, 所以作者推测了反应可能的过渡态 130 来解释立体 化学的产生: 手性磷酸作为一个双功能催化剂, 同时活 化亲核和亲电试剂, 烯胺片段进攻 $\mathrm{C}, \mathrm{N}$-环状偶氮次甲 基亚胺的 $S i$ 面(Scheme 22). 在反应的标准条件下, 使用 $N$-甲基烯氨基甲酸苄酯时, 由于缺乏 $\mathrm{N}-\mathrm{H}$ 官能性, 导 致并未与 $\mathrm{C}, \mathrm{N}$-环状偶氮次甲基亚胺反应得到相应的环 化产物, 这一实验现象与上述过渡态的推测是一致的. 为了证实这一环加成反应的有用性, 作者对产物 129a 进行了合成转换研究, 得到了结构多样的四氢异喹啉衍 生物: 在 $\mathrm{SmI}_{2}$ 和 $\mathrm{MeOH}$ 条件下, 环化产物 129a 可以经 过选择性的 $\mathrm{N}-\mathrm{N}$ 键断裂得到手性 $\mathrm{C}(1)$-取代四氢异喹 㕲化合物 132; 在路易斯酸 $\mathrm{BF}_{3} \cdot \mathrm{Et}_{2} \mathrm{O}$ 作用下, $129 \mathrm{a}$ 与三 甲基硅氧( $\mathrm{TMSCN}$ )反应得到 $\alpha$-氨基腈 133 ; 利用烯丙基 三甲基硅烷作为亲核试剂与 129a 反应合成烯丙基胺
元的 C(1)-取代四氢异喹啉化合物 135，此外 135 可一锅 转化为氨基苯并喹唑嗪 136, 这对治疗 II 型糖尿病的选 择性 $\alpha 2$-肾上腺受体拮抗剂和二肽基肽酶(DDP-IV)抑制 剂的研制具有重要意义(Scheme 23).

\section{3 过渡金属催化}

2010 年, Charette 团队 ${ }^{[34-35]}$ 报道了银参与的 Pd 催化 直接烯基化的 C,N-环状偶氮次甲基亚胺 19a 与烯烃 137 的 $[3+2]$ 环化反应，以良好的收率得到了吡唑并 $[5,1-a]$ 异喹啉衍生物 23a (Eq. 25). 对该反应过程作者提出了 以下的反应机理(Scheme 24): 第一步 Pd 催化剂氧化加 成到烯基碘中，随后协同金属化/去质子化(CMD)发生 碳钯化反应，将催化剂插入到 C,N-环状偶氮次甲基亚 胺中得到中间体 138, 然后 $\mathrm{Ag}$ 插入得到烯基化吡啶 139, 再经过环化得到 140; 进一步发生歧化反应消除 Ag 得 到 141，最后脱去苯甲酰基得到目标产物.

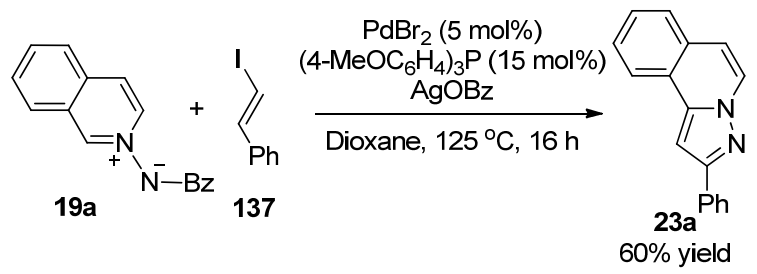

134; 随后 $\mathrm{SmI}_{2}$ 促进 $\mathrm{N}-\mathrm{N}$ 键断裂得到带有 1,3-二胺单

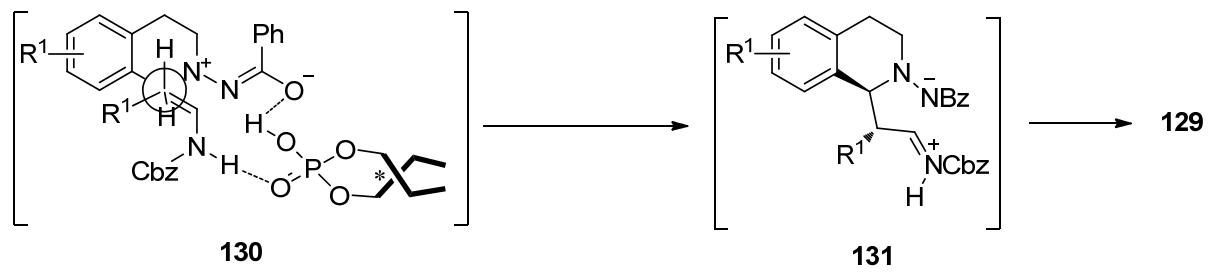

图式 $22 \mathrm{C}, \mathrm{N}-$ 环状偶氮次甲基亚胺与烯氨基甲酸苠酯的 $[3+2]$ 环加成反应可能经历的过渡态

Scheme 22 Proposed transition state of the $[3+2]$ cycloaddition of $\mathrm{C}, \mathrm{N}$-cyclic azomethine imines with enecarbamates

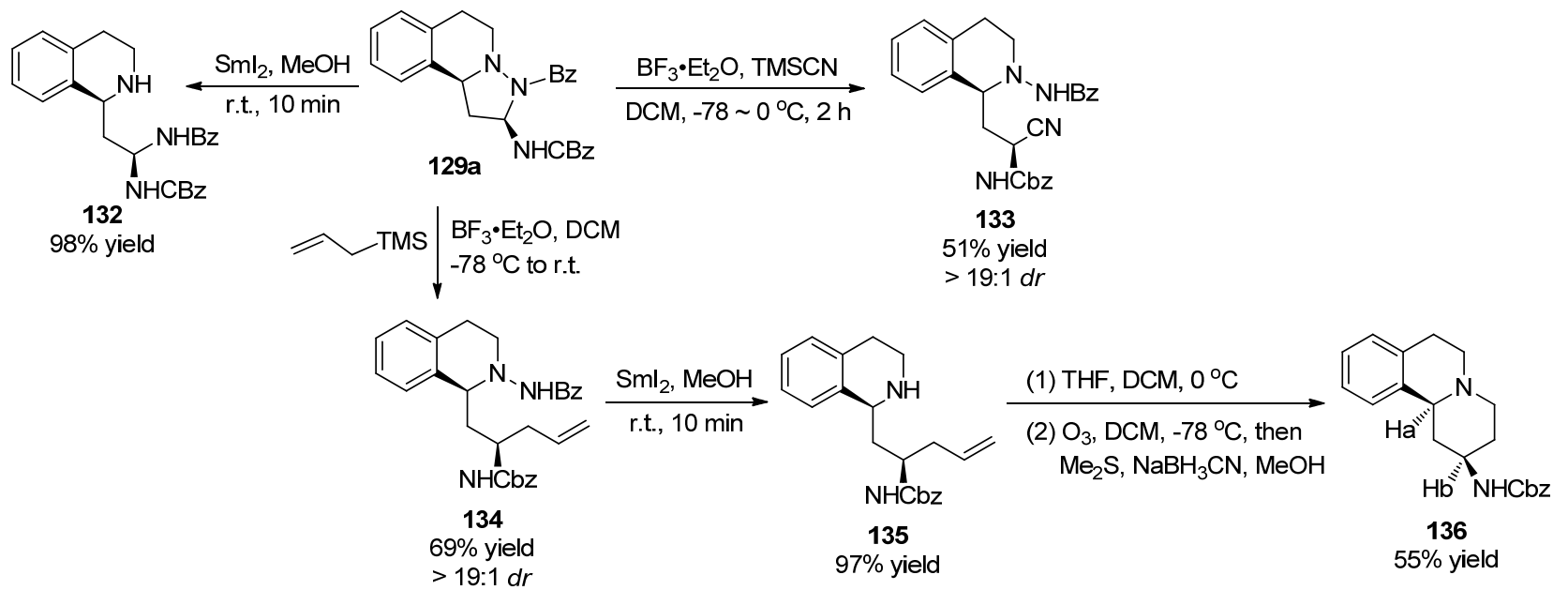

图式 23 C(1)-取代四氢异喹啉衍生物 129a 的合成转换

Scheme 23 Synthetic transformations of C(1)-substituted tetrahydroisoquinoline derivatives 129a 


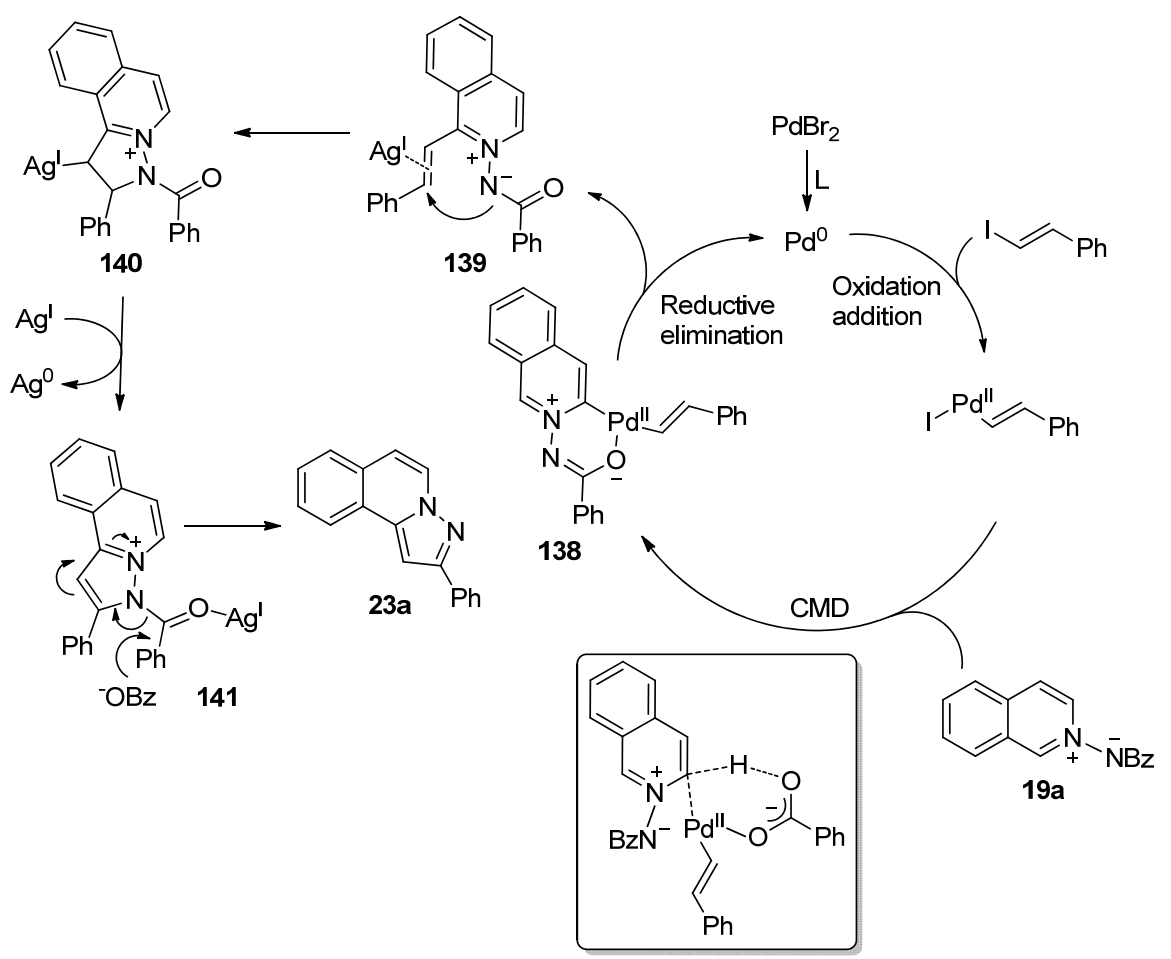

图式 24 铜催化的 $\mathrm{C}, \mathrm{N}$-环状偶氮次甲基亚胺与烯基碘的[3+2]环加成反应的可能机理

Scheme 24 Proposed mechanism of the $[3+2]$ cycloaddition of the palladium-catalyzed C,N-cyclic azomethine imines with alkenyl iodides

当累积二烯都连有吸电子基团(EWG)时，它可作为缺电 子烯烃或者与膦催化剂作用形成两性离子中间体 142(图 4), 而当累积二烯连有给电子取代基(EDG)时, 可以与 $\mathrm{Au}$ 催化剂作用形成中间体 143 , 这两个中间体 的反应性不同，导致它们在反应中的区域选择性不同. 2013 年, 陈自立课题组 ${ }^{[36]}$ 报道了 $\mathrm{Au}(\mathrm{I})$ 催化的 $N$-累积二 烯酰胺 144 与 $\mathrm{C}, \mathrm{N}-$ 环状偶氮次甲基亚胺 $1 \mathbf{a}$ 的 $[3+2]$ 环 加成反应，可以顺利得到 1-亚甲基吡唑[5,1- $a$ ]异喹啉类 化合物 145 (Eq. 26).



图 4 累积二烯可能的中间体

Figure 4 Proposed intermediates of cumulative dienes

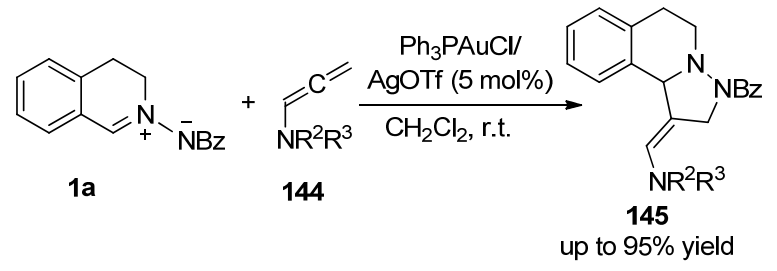

在 $P d$ 催化作用下，亚甲基三甲基甲烷 146 通常作为 一个 $3 \mathrm{C}$ 合成子和一系列受体发生 $[3+n]$ 环加成反应 (Scheme 25). 郭红超课题组 ${ }^{[37]}$ 使用 $\mathrm{C}, \mathrm{N}$-环状偶氮次甲
基亚胺 1,3-偶极子作为受体，Pd-亚甲基三甲基甲烷的 $\mathrm{C}=\mathrm{C}$ 双键作为 1,3-偶极环加成的亲偶极子, 报道了 $\mathrm{Pd}$ 催化的亚甲基三甲基甲烷和 $\mathrm{C}, \mathrm{N}$-环状偶氮次甲基亚胺 的不对称 $[3+2]$ 环加成/烯丙基化串联反应(Eq. 27), 高 产率、高对映选择性地构建了官能化的手性六氢吡唑 [5,1- $a]$ 异喹啉衍生物 150. 在探索产物进一步转化的过 程中，作者发现在 $\mathrm{K}_{2} \mathrm{CO}_{3}$ 作用下，产物可以顺利发生着 基化反应. 受此结果的鼓舞, 作者进一步研究了串联/差弪 基化一锅法合成烯丙基醇衍生物的反应(Eq. 28). 该一 锅法产率较好, 对映选择性没有任何损失, 且产物仅为 反式异构体. 为了深入了解该环加成反应机理, 作者开 展了一系列对照实验. 基于此, 作者提出了可能的催化 循环(Scheme 26). 在 Pd 催化剂的作用下，亚甲基取代

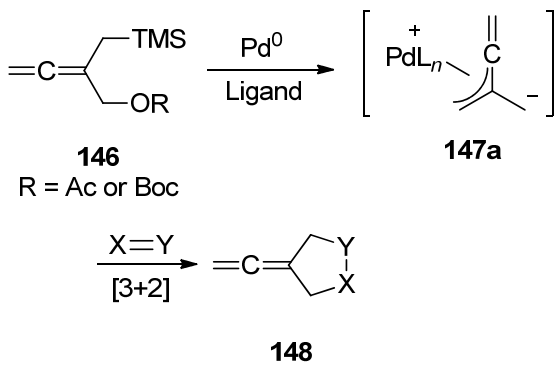

图式 $25 \mathrm{Pd}$ 催化的亚甲基三甲基甲烷的 $[3+2]$ 环化反应 Scheme 25 Pd catalyzed [3+2] cyclization of methylene trimethyl methane 
<smiles>[R14]CC(=C=C)CO[R2]</smiles>

16

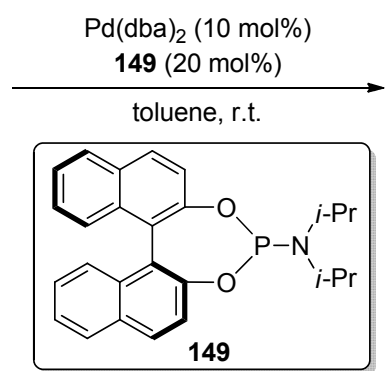

(1) $\mathrm{Pd}(\mathrm{dba})_{2}(10 \mathrm{~mol} \%), 149(20 \mathrm{~mol} \%)$ toluene, r.t.

(2) $\mathrm{K}_{2} \mathrm{CO}_{3}, \mathrm{MeOH}$, r.t.

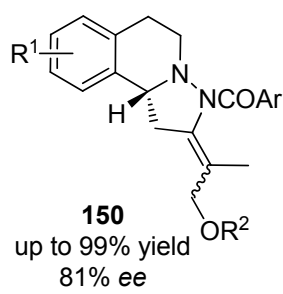

16

$146 a$<smiles>C=CC(CO)COC(C)C</smiles>

$146 a$
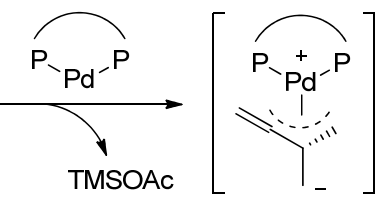

$147 b$

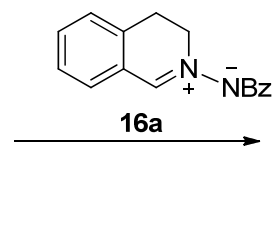

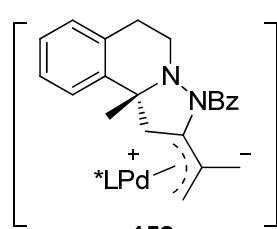

152

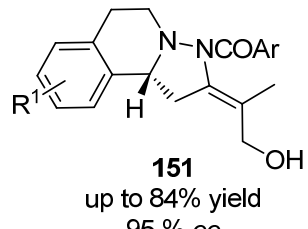

$95 \%$ ee

图式 $26 \mathrm{Pd}$ 催化的亚甲基三甲基甲烷的 $[3+2]$ 环化反应的可能机理

Scheme 26 Proposed mechanism of the [3+2] cycloaddition of the pd-catalyzed methylene trimethyl methane

的三甲基甲烷受体转化为 $\mathrm{Pd}-$ 亚甲基-三甲基甲烷络合 物 152b，同时释放出 TMSOAc，络合物 147b 与 C,N-环 状偶氮次甲基亚胺 16a 发生环加成反应形成中间体 $\mathbf{1 5 2}$, 随 OAc 负离子对中间体 152 的烯丙基化得到产物 150a.

该课题组 ${ }^{[38]}$ 又继续实现了 $\mathrm{Pd}$ 催化的累积二烯基甲 醇酸酯 153 和 $\mathrm{C}, \mathrm{N}-$ 环状偶氮次甲基亚胺 16 的串联 $[3+$ 2]环加成反应, 高产率、高立体选择性地得到了四氢吡 咯异喹啉衍生物 155 (Eq. 29). 作者还研究了该反应的 不对称过程, 使用 149 作为手性配体, 甲苯作溶剂可以 得到 $87 \%$ 的产率和 $80 \%$ ee 值. 产物 $\mathbf{1 5 5 a}$ 的衍生化反应, 在 $\mathrm{Pd} / \mathrm{C}$ 氢化的条件下可分别以 $54 \%$ 和 $15 \%$ 产率得到产 物 156 和 $157, \mathrm{SmI}_{2}$ 促进开环 $\mathrm{N}-\mathrm{N}$ 键断裂以 $58 \%$ 的产 率得到四氢异喹啉产物 158 (Scheme 27). 基于对照实验 及前期工作基础, 作者提出了一个机理(Scheme 28): Pd 催化剂和累积二烯基甲醇醋酸酯形成 Pd-丁二烯基中间 体 159, 再与 $\mathrm{C}, \mathrm{N}$-环状偶氮次甲基亚胺发生 $[3+2]$ 环加 成得中间体 160, 随后 OAc 负离子的烯丙基化反应产生 中间体 161, 最后消除 HOAc 得到产物 155a. 作者对反 应体系开展了质谱分析. 关键中间体 160 和 161 的成功 检测进一步阐明了该路径的合理性.

\section{4 自身协同反应}

在 Maruoka 小组 ${ }^{[11]}$ 工作的启发下, C,N-环状偶氮次 甲基亚胺开始真正地受到化学家们的关注, 它可以与一 系列缺电子烯烃发生 $[3+2]$ 环加成反应. 2010 年,
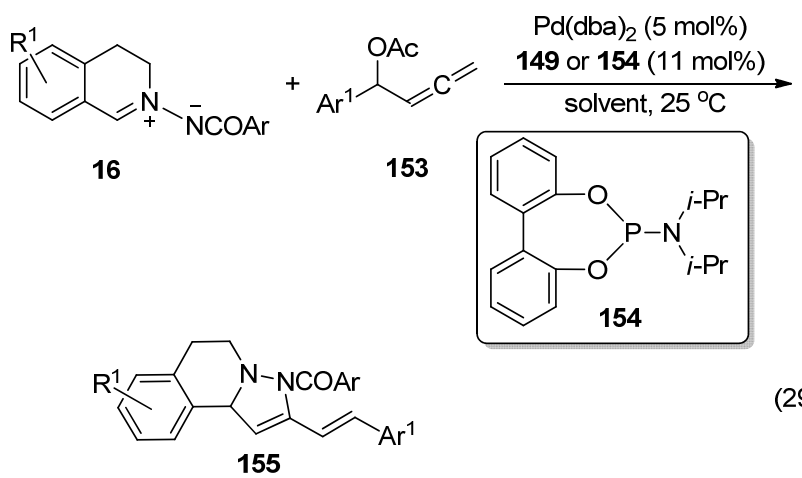

(29)

149: tolunene, $\mathrm{R}^{1}=\mathrm{H}, \mathrm{Ar}=\mathrm{Ph}, \mathrm{Ar}^{1}=\mathrm{Ph}: 87 \%$ yield, $80 \%$ ee 154: AcOEt: up to $99 \%$ yield

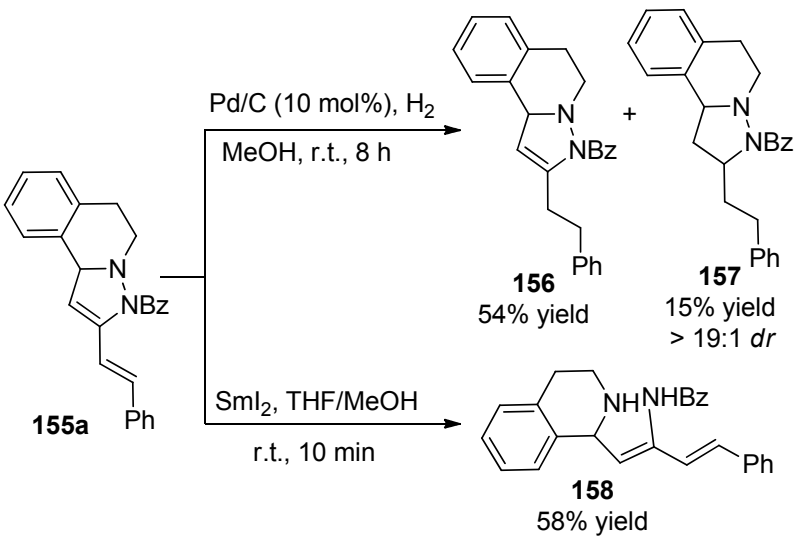

图式 $27 \mathrm{C}(1)$-取代四氢异喹啉衍生物 155a 的合成转换

Scheme 27 Synthetic transformations of C(1)-substituted tetrahydroisoquinoline derivatives $\mathbf{1 5 5 a}$ 




160

$\mathrm{m} / \mathrm{z}[\mathrm{M}+\mathrm{H}]^{+}$calcd 1175.4 found 1175.5<smiles></smiles>

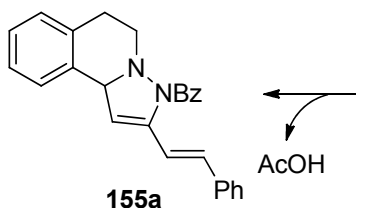<smiles>O=C(O)C1(/C=C/c2ccccc2)CC2c3ccccc3CCN21</smiles>

161

$\mathrm{m} / \mathrm{z}[\mathrm{M}+\mathrm{Cl}]^{+}$calcd 473.2 , found 473.2

图式 $28 \mathrm{Pd}$ 催化的累积二烯基甲醇酸酯与 $\mathrm{C}, \mathrm{N}-$ 环状偶氮次甲 基亚胺的 $[3+2]$ 环加成反应的可能机理

Scheme 28 Proposed mechanism of the [3+2] cycloaddition of palladium-catalyzed allenyl carbinol acetates with $\mathrm{C}, \mathrm{N}$-cyclic azomethine imines

Koptelov 课题组 ${ }^{[39]}$ 报道了 $\mathrm{C}, \mathrm{N}$-环状偶氮次甲基亚胺 16 和 $N$-芳基马来酰亚胺 34 的 1,3-偶极环加成反应(Eq. 30). 在该反应中, 当使用 $N$-均三甲苯基马来酰亚胺为亲偶 极子时, 反式产物和顺式产物的比例高达 7:1; 当 $N$ 芳基马来酰亚胺的芳基上没有邻位取代基时, 反应以顺 式产物为主, 反式产物和顺式产物的比例可达 1:10. 根据实验和 DFT 计算结果, 作者推测, 在与空间位阻较 大的 $N$-均三甲苯基马来酰亚胺反应中, 反式产物的优 先形成取决于 $\mathrm{C}, \mathrm{N}$-环状偶氮次甲基亚胺的不稳定的但 更具有活性的反式异构体和亲偶极子 exo 途径的参与. 在苯环邻位没有取代基的 $N$-芳基马来酰亚胺的环加成 反应中, 对占主导地位的 $\mathrm{C}, \mathrm{N}$-环状偶氮次甲基亚胺顺 式构型的 endo 途径加成比 exo 途径的空间位阻更小, 因 此, 得到的主要产物是相应的顺式产物. 2015 年, 该课 题组 ${ }^{[40]}$ 又报道了 $\mathrm{C}, \mathrm{N}$-环状偶氮次甲基亚胺 16 与 $N$-芳基 甲酰亚胺 162 的环加成反应(Eq. 31). 在 $130 \sim 135{ }^{\circ} \mathrm{C}$ 的 反应温度下, 区域选择性和非对映选择性都很优异, 能 得到单一的非对映体产物.

近年来, 由于三氟甲基的独特物理性质, 含有三氟 甲基的化合物在医药和农药领域应用广泛. 因此在化合 物中引入 $\mathrm{CF}_{3}$ 的报道越来越多, 通过使用商业可得的含 $\mathrm{CF}_{3}$ 的底物是得到含 $\mathrm{CF}_{3}$ 目标化合物的通用有效方法之 一. 2012 年, Shibata 课题组 ${ }^{[41]}$ 使用了三氟甲磺酰基炔烃 164 作为亲偶极子和 $\mathrm{C}, \mathrm{N}$-环状偶氮次甲基亚胺 1 反应,

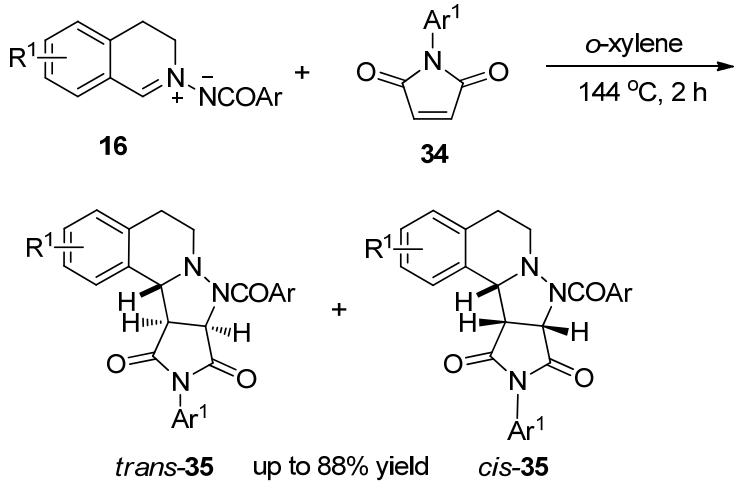

(30)



up to $76 \%$ yield

实现了具有生物吸引力的吡唑并 $[5,1-a]$ 异喹啉三氟甲磺 酸酯 166 的合成(Scheme 29). 反应过程包括区域选择性 的 1,3-偶极环加成得到不稳定的环加成产物 165 , 再在 DDQ 作用下发生氧化芳构化得到最终目标产物 166.

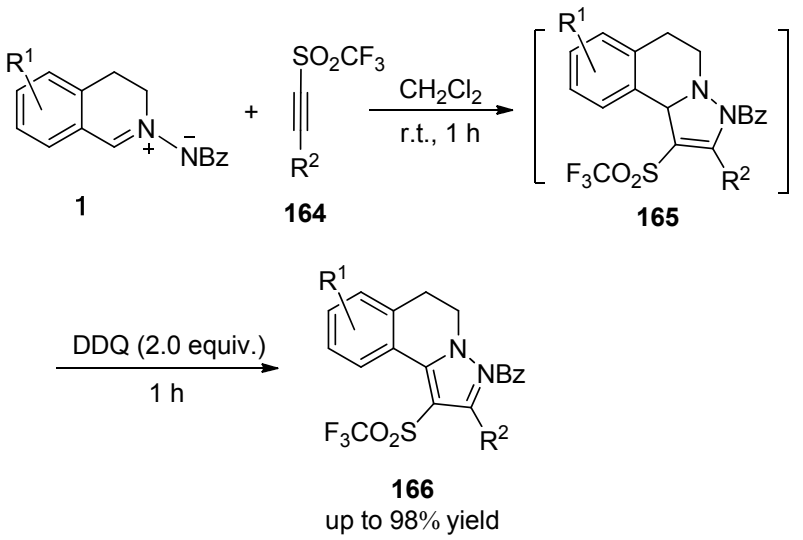

图式 29 吡唑并 $[5,1-a$ ]异喹啉三氟甲磺酸酯的合成 Scheme 29 Synthesis of pyrazolo[5,1-a]isoquinoline triflones

2013 年, 施敏小组 ${ }^{[42]}$ 发展了含 $\mathrm{CF}_{3}$ 的烯烃 167 与 $\mathrm{C}, \mathrm{N}$-环状偶氮次甲基亚胺 1 的 $[3+2]$ 环加成反应，得到 了一系列含 $\mathrm{CF}_{3}$ 的吡唑 $[5,1-a]$ 异喹啉衍生物 168, 反应 的产率和非对映选择性非常高(Eq. 32). 作者还使用了 $\alpha-\mathrm{CF}_{3}-\beta$-芳基取代的 $\alpha, \beta$-不饱和羧酸酯作为 $\mathrm{CF}_{3}$ 来源, 相 应的环加成产物以 $66 \%$ 的收率和 $>19: 1$ 的非对映选择 性得到(Eq. 33)

2016 年, 王锐课题组 ${ }^{[43]}$ 发展了一种简洁的 C,N-环 状偶氮次甲基亚胺与 3-硝基吲哚 171 的[3+2]环加成反 

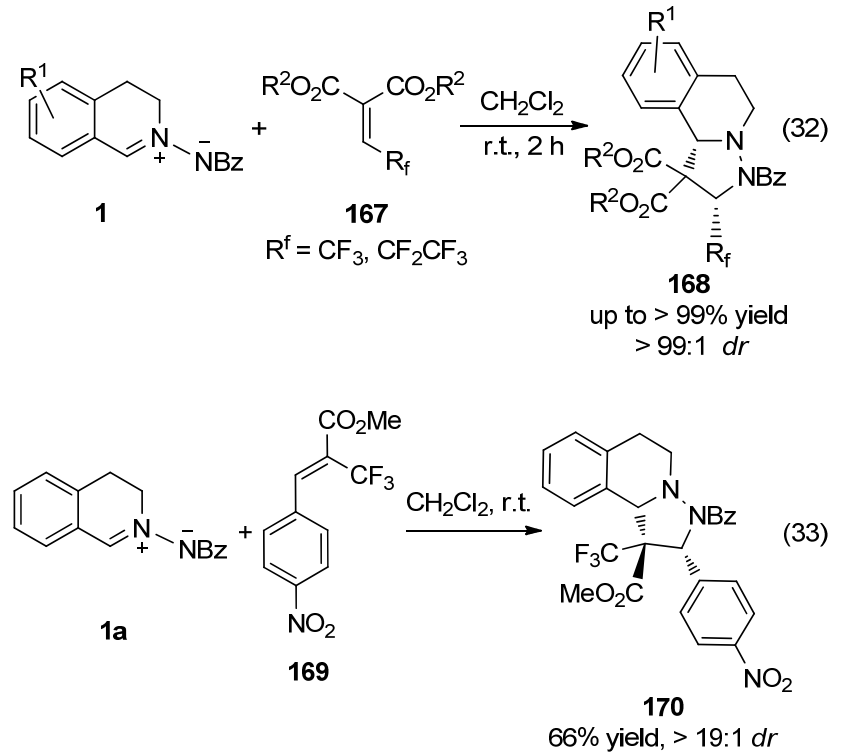

应(Eq. 34). 反应可以以中等至较好的收率得到一系列 五元环并四氢异喹啉和吲哚骨架的单一非对映异构体 172. 反应条件温和, 无需任何添加剂. 作者还将此策略 应用到了其他的亲偶极子, 如亚烷基二氢噁唑酮 173 和 3-烯基氧化吲哚 174, 相应的螺环产物都顺利地以中等 到高产率和较好 $d r$ 获得(Eq. 35). 作者提出了可能的优 势过渡态来解释反应的立体专一性. 如图 5 所示, 该优 势过渡态可能是由 $\mathrm{C}, \mathrm{N}$-环状偶氮次甲基亚胺与 3-硝基 吲哚的 $\pi-\pi$ 相互作用导致的.

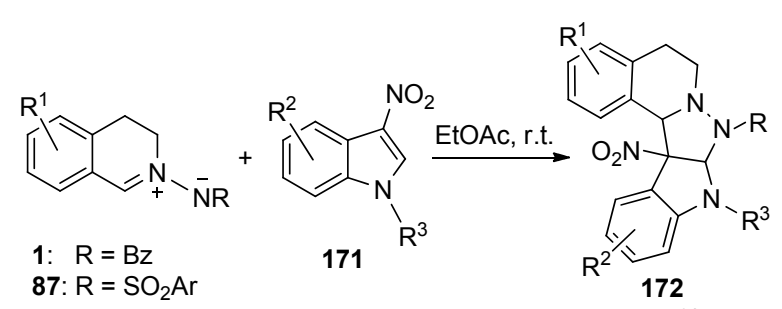

up to $>94 \%$ yield

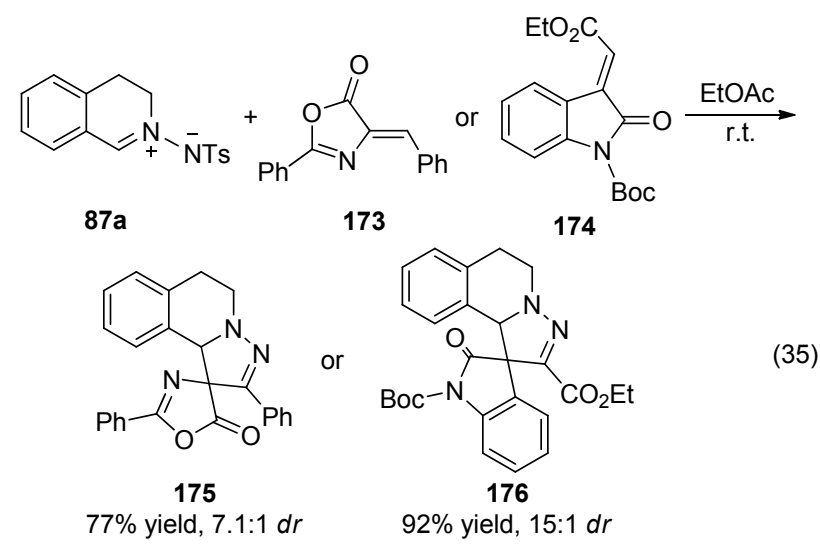

2017 年, 张晓梅小组 ${ }^{[4]}$ 详细研究了 3-烯基氧化吲 哚 179 作为亲偶极子与 $\mathrm{C}, \mathrm{N}$-环状偶氮次甲基亚胺 16 的
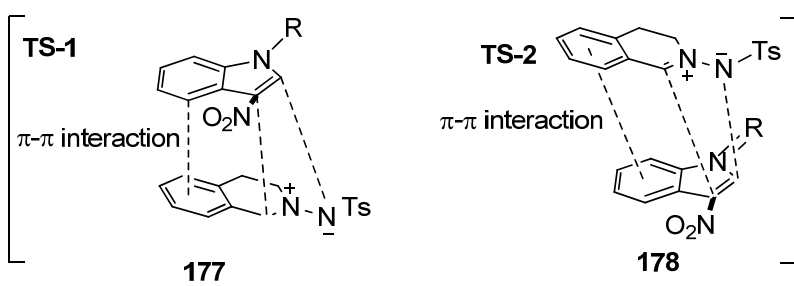

图 $5 \mathrm{C}, \mathrm{N}$-环状偶氮次甲基亚胺与 3-硝基吲哚可能的过渡态 Figure 5 Proposed transition state for $\mathrm{C}, \mathrm{N}$-cyclic azomethine imines with 3-nitroindole

1,3-偶极环加成反应(Eq. 36). 相比王锐课题组的工 作 ${ }^{[43]}$, 作者改变了底物上 $\mathrm{N}$ 的保护基和烯烃的取代基, 通过条件篮选后，反应的产率提升到了 $99 \%$ ，非对应选 择性也非常高 $(>20: 1)$. 基于产物的单晶衍射和前期 工作 ${ }^{[45]}$, 作者提出了一种可能的过渡态模型来解释反 应的立体化学(Eq. 37). C,N-环状偶氮次甲基亚胺中的活 性氮负离子进攻缺电子的 3-烯基氧化吲哚形成了反式 的非对映异构产物。
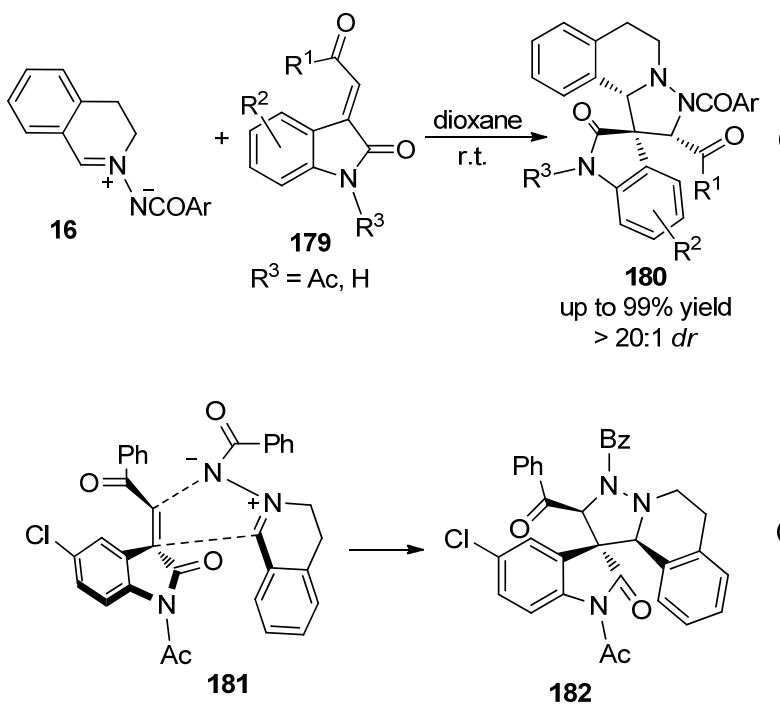

$2 H$-氮丙啶是一个常用的结构单元，它可以作为一个氮 杂 $2 \mathrm{C}$ 合成子, 可以发生 $[3+2] 、[4+2]$ 环加成反应. Hashmi 小组 ${ }^{[46]}$ 利用 $2 \mathrm{H}$-氮丙啶和 $\mathrm{C}, \mathrm{N}$-环状偶氮次甲基 亚胺发生 $[3+2]$ 环加成反应(Scheme 30). 当 C,N-环状偶 氮次甲基亚胺的 $\mathrm{R}$ 基团为 $\mathrm{Bz}$ 时，反应得到的是 $[3+2]$ 环加成产物 $N$-桥稠环三唑衍生物 $\mathbf{1 8 5}$ 产物. 当 $\mathrm{R}$ 基团为 Ts 时, 这个 $[3+2]$ 环加成产物会发生一个开环反应脱掉 Ts 基团消去一份子亚磺酸, 得到 1,2,4-三嗪 $\mathbf{1 8 6}$, 是形式 上的 $[3+3]$ 环加成产物(此部分将不在 $[3+3]$ 环加成中讨 论). 同时, 它可以被空气作为氧化剂氧化形成相应的 酮 187 (Eq. 38).

累积二烯含有特别有用的 1,2-丙二烯体系，两个 $\mathrm{C}=\mathrm{C}$ 键都是偶极进攻的活性位点, 因此可以从两个相 


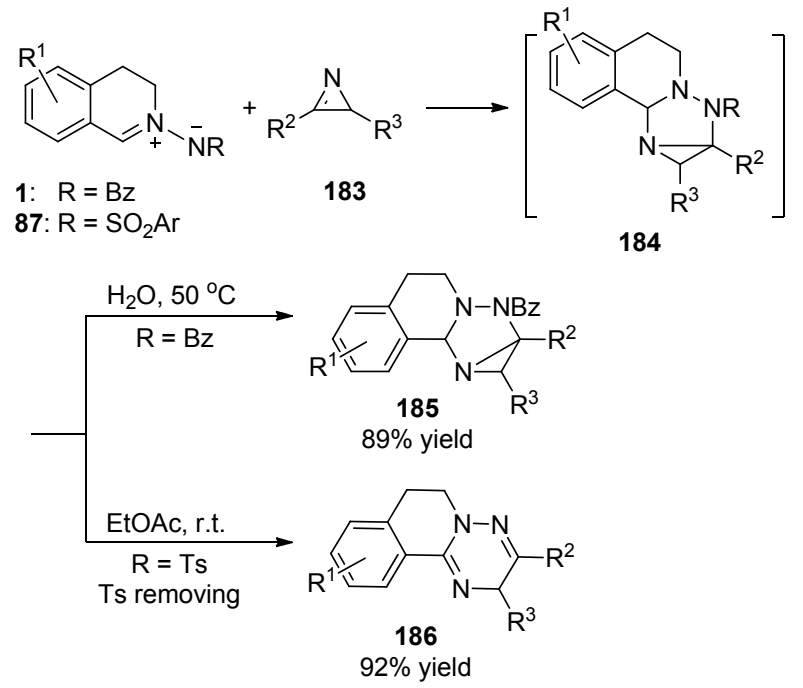

图式 $302 H$-氮丙啶和 $\mathrm{C}, \mathrm{N}$-环状偶氮次甲基亚胺的反应 Scheme 30 Reaction of $2 \mathrm{H}$-aziridine and $\mathrm{C}, \mathrm{N}$-cyclic azomethine imines

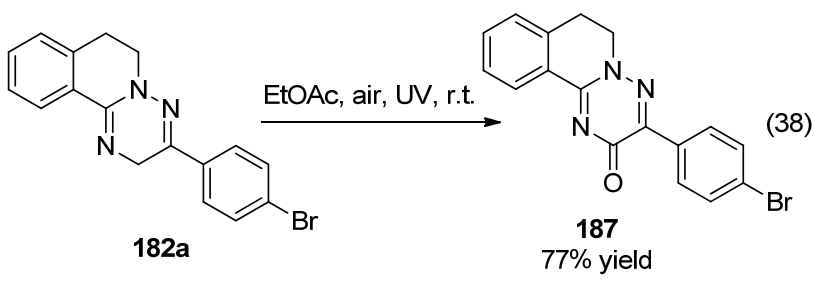

反的方向进攻发生偶极环加成反应, 尤其是含吸电子基 团的累积二烯. 2012 年, 郭红超课题组 ${ }^{[47-48]}$ 首次使用了 累积二烯酸酯 188 作为亲偶极子, 与 $\mathrm{C}, \mathrm{N}$-环状偶氮次甲 基亚胺 1 或 19 在 $80{ }^{\circ} \mathrm{C}$ 条件下发生 1,3-偶极环加成反应 (Eq. 39), 该反应有三种可能的途径(Scheme 31). 然而, 该反应具有非常高的区域选择性, 作者并未观察到环加 成产物 190a 和 191a, 带有 2 个手性中心的 2-环外双键 产物是唯一的区域异构体, 以非对映异构体混合物的形 式分离得到，反应操作简便高效. $\alpha$-取代的累积二烯酸 酯和 $\gamma$-取代的累积二烯酸酯作为反应底物也能应用到 该环加成反应中, 与前者相比, 该反应的产率略低, 最 高以 71\%的产率得到相应的环外双键产物 193 (Eq. 40).

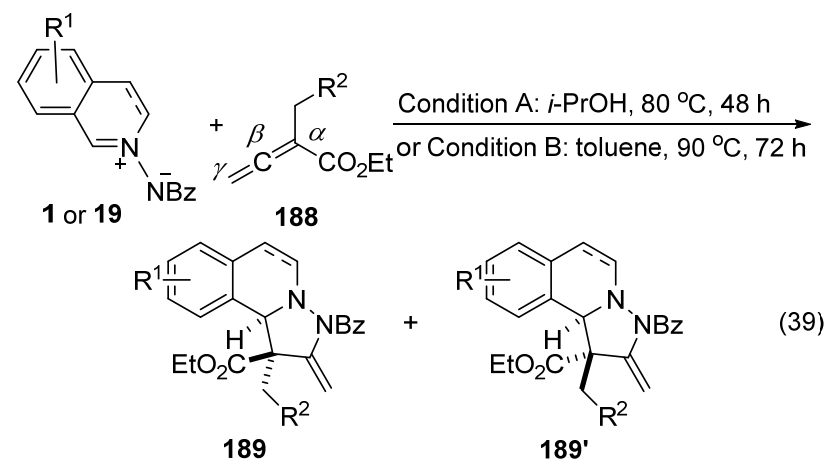

Ref [47]: Condition A, up to $93 \%$ yield, $92: 8$ (189:189') Ref [48]: Condition B, up to $98 \%$ yield, $28: 72$ (189:189')

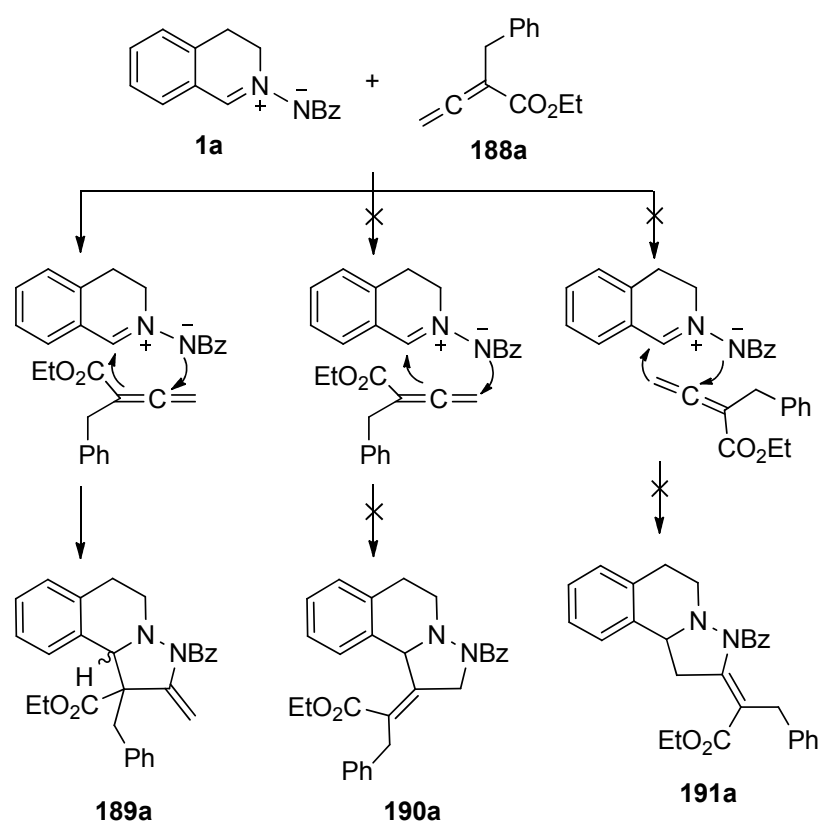

图式 $31 \mathrm{C}, \mathrm{N}-$ 环状偶氮次甲基亚胺与累积二烯酸酯可能的反 应途径

Scheme 31 Possible reaction pathways of C,N-cyclic azomethine imines with cumulative dienoate

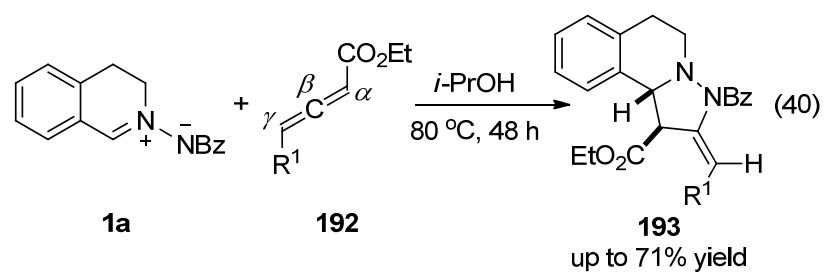

2015 年, Tong 课题组 ${ }^{[49]}$ 也报道了 $\gamma$-取代的累积二烯 酸酯 194 和 C,N-环状偶氮次甲基亚胺 1 在加热条件下的 1,3-偶极环加成反应(Scheme 32). 该累积二烯酸酯的 $\delta$

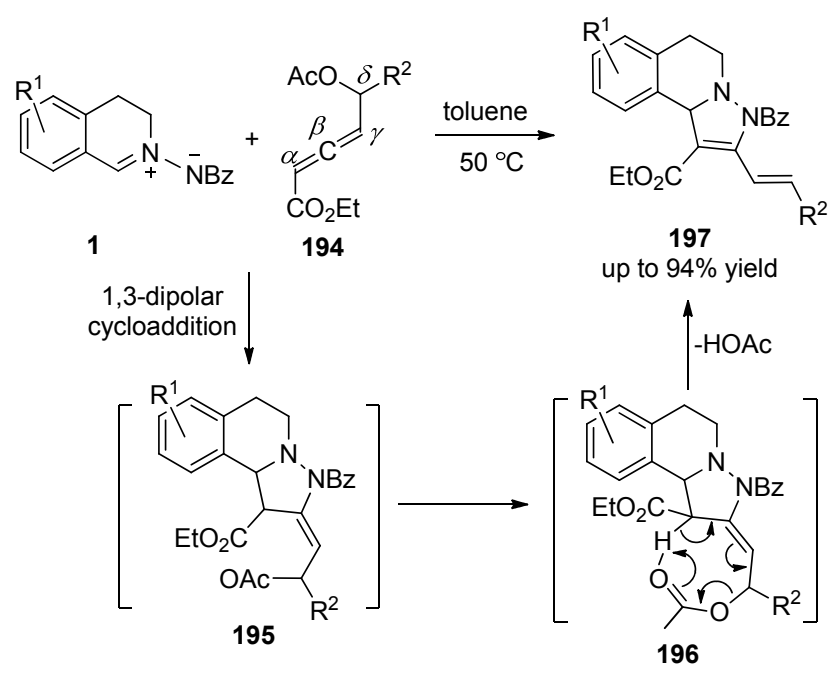

图式 32 二氢异喹啉 $\delta$-OAc 取代的累积二烯酸酯的反应机理 Scheme 32 Proposed mechanism of dihydroisoquinoline $\delta$-OAc substituted cumulative dienoates 
位有乙酰氧基 $(\mathrm{OAc})$, 在 1,3-偶极环加成反应完成后, 随 后以 HOAc 的形式消除, 以非常优异的收率得到四氢异 喹啉并 2,3-二氢吡唑衍生物 197.

2016 年, 厍学功课题组 ${ }^{[50]}$ 报道了活化的酯衍生物 198 与 $\mathrm{C}, \mathrm{N}$-环状偶氮次甲基亚胺 1 在加热条件下发生 1,3-偶极环加成反应, 以中等至高的收率得到了一系列 的活性吡唑烷酮 196 (Eq. 41). 基于实验结果, 作者提出 了可能的反应机理(Scheme 33): 首先酯 198a 与 $\mathrm{C}, \mathrm{N}$-环 状偶氮次甲基亚胺 $\mathbf{1 a}$ 反应产生了中间体 200, 接着经过 内酰胺反应形成中间体 201, 最终得到了产物 199a, 同 时 202 经过质子转移形成副产物 203.
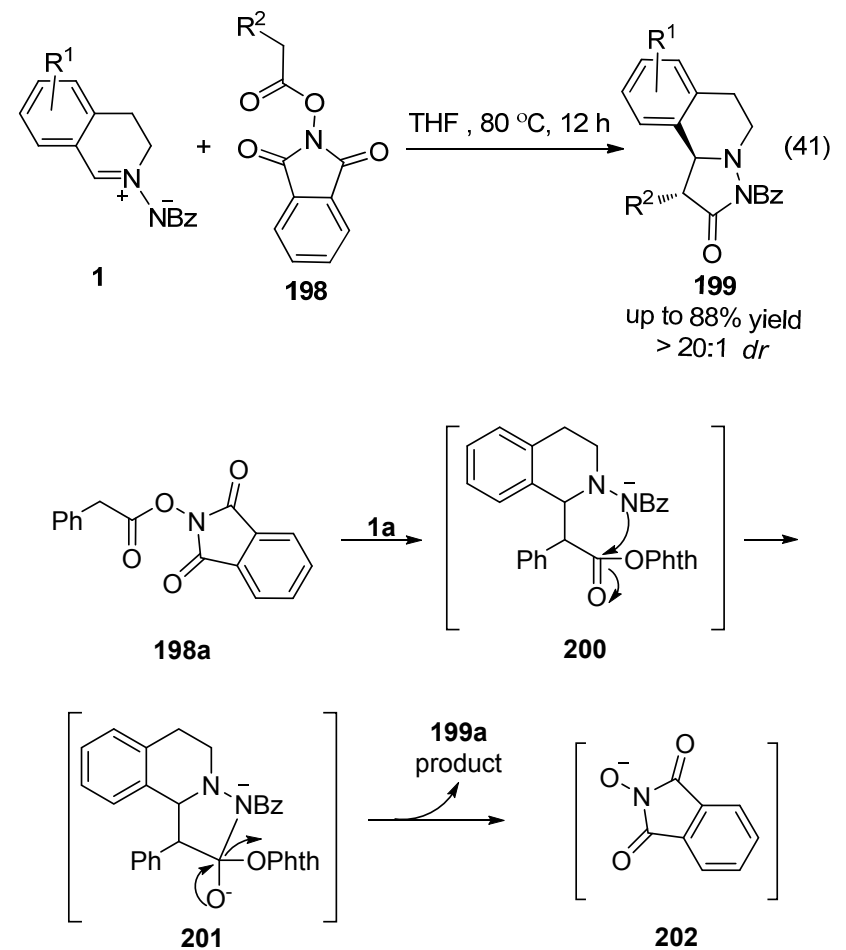

202

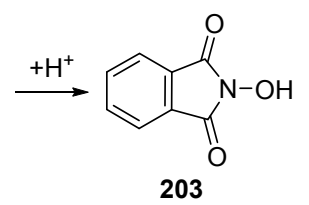

图式 $33 \mathrm{C}, \mathrm{N}-$ 环状偶氮次甲基亚胺与活化酯的 $[3+2]$ 环加成 反应的可能机理

Scheme 33 Proposed mechanism of the [3+2] cycloaddition of $\mathrm{C}, \mathrm{N}-\mathrm{cyclic}$ azomethine imines with active esters

2012 年, 石峰团队 ${ }^{[51]}$ 报道了邻三甲基硅三氟甲磺 酸酯作为苯炔 204a 前体与 $\mathrm{C}, \mathrm{N}-$ 环状偶氮次甲基亚胺 $\mathbf{8 7} \mathbf{a}$ 的 $[3+2]$ 环加成反应, 以高收率的得到吲唑并 [3,2- $a]$ 异喹啉 205a (Eq. 42).

2019 年, 沙风和伍新燕等 ${ }^{[52]}$ 也发展了邻三甲基硅 三氟甲磺酸酯 204 与 $\mathrm{C}, \mathrm{N}-$ 环状偶氮次甲基亚胺 1 或 19 的[3+2]环加成策略, 构建了 $N$-取代吲唑[3,2-a]异喹啉

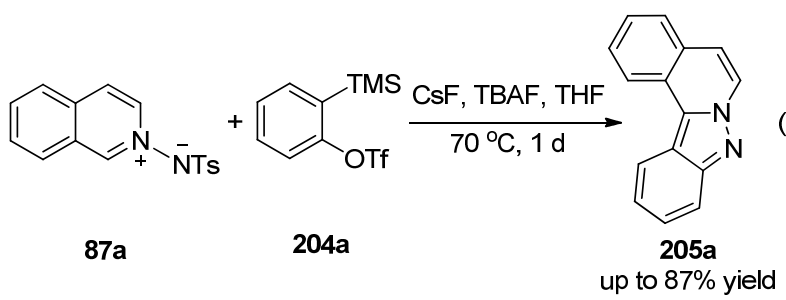

206 (Eq. 43). 产物 206a 在 $\mathrm{LiBHEt}_{3}$ 的作用下, 脱去苯甲 酰基得到产物 207 (Eq. 44), 更重要的是, 在生物活性方 面, 对癌细胞系显示出好的抗增殖活性.

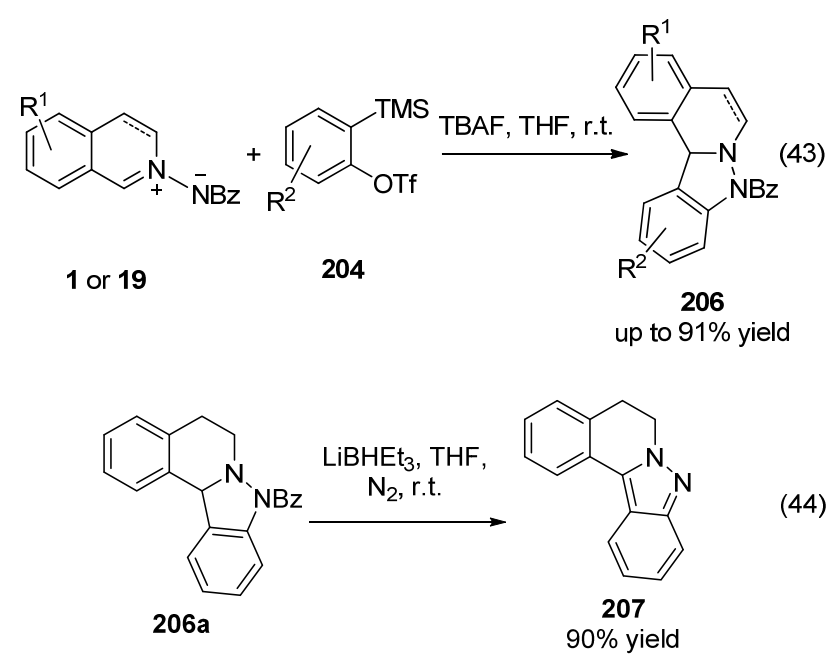

\section{$2 \mathrm{C}, \mathrm{N}-$ 环状偶氮次甲基亚胺参与的 $[3+3]$ 环加 成反应}

与上述发展较好的 $\mathrm{C}, \mathrm{N}$-环状偶氮次甲基亚胺与各 种 $2 \pi$ 亲偶极子的 $[3+2]$ 环加成相比, C,N-环状偶氮次甲 基亚胺的 $[3+3]$ 环加成反应合成六元氮杂环的发展较为 落后, 这也是非常值得期望的.

\section{1 有机催化}

在亲核膦催化中, 由 Morita-Baylis-Hillman (MBH) 羧酸酯形成的烯醇化磷两性离子作为一个 $3 \mathrm{C}$ 合成子能 参与到一系列的膦催化环加成反应中, 如 $[3+2] 、[3+$ 3]、 $[3+4] 、[3+6]$ 环化, 可构建一系列碳杂环化合物和 天然产物. 基于这些反应, 郭红超小组 ${ }^{[33]}$ 在 2015 年报 道了第一例对映选择性的 $\mathrm{MBH}$ 羒酸酯 $\mathbf{2 0 8}$ 与 $\mathrm{C}, \mathrm{N}$-环状 偶氮次甲基亚胺 109 的 $[3+3]$ 环加成反应, 以螺环手性 膦 209 作为催化剂, 高产率、高立体选择性地合成了一 类新颖的双氮稠杂环哒嗪 $[6,1-a]$ 异喹啉化合物 210 (Eq. 45). 作者对所得的环加成产物进行了相应的合成转换, 产物可以进一步转化为其它合成上或生物学上有用的 杂环化合物: DIBAL-H 处理产物 210a 可以将酯基还原, 以 $75 \%$ 的产率，>99\%的对映选择性得到醇化物 211 (Eq. 46); 在 $\mathrm{Pd}\left(\mathrm{PPh}_{3}\right)_{4}$ 存在下, 环加成产物 210b 中芳环 
上的 $\mathrm{Br}$ 原子可以与芳基嗍酸发生偶联反应，以 $66 \%$ 产 率，>99\% ee 得到手性联苯取代的杂环化合物 212 (Eq. 47).
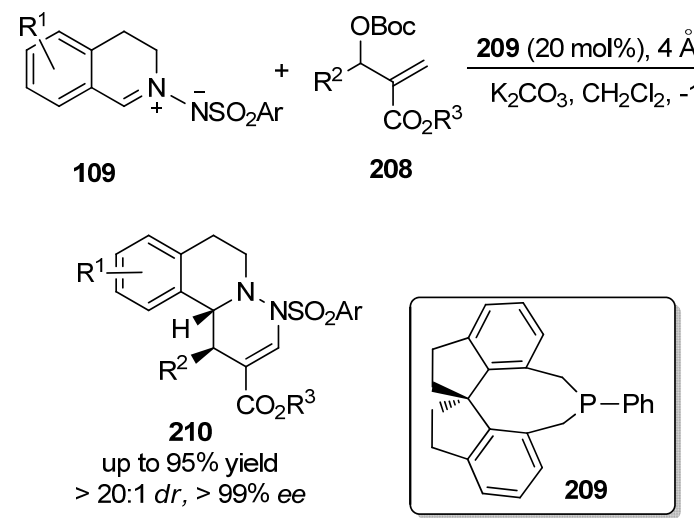

(45)

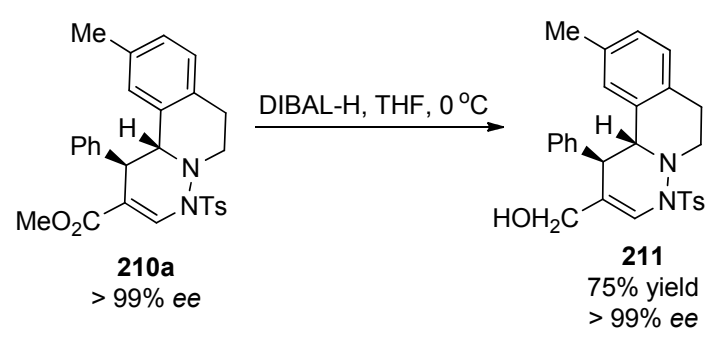

(46)
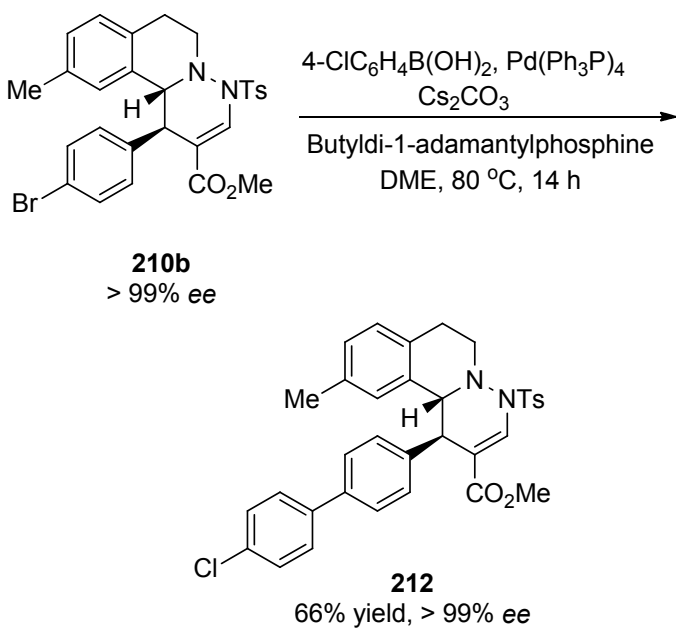

最近几年, 炔酮作为一个新的膦烷接受体受到广泛 关注. 在膦催化的条件下, 炔酮也可以作为 $3 \mathrm{C}$ 合成子 进行一些环化反应. 2016 年, 郭红超团队 ${ }^{[54]}$ 发展了第一 例膦烷催化的 C,N-环状偶氮次甲基亚胺 1 与炔酮 213 的 $[3+3]$ 环化反应, 在温和的反应条件下, 以中等至优 异的产率和立体选择性得到了三环双氮稠杂环化合物 214 (Eq. 48). 通过使用一些手性磷烷, 作者尝试了该反 应的不对称过程, 但遗憾的是并没有得到好的结果. 作 者提出了可能的机理来解释产物的形成(Scheme 34): $\mathrm{PPh}_{3}$ 作为一个亲核试剂对炔酮加成得到两性离子中间 体 215, 随后质子转移, 接着对 $1 \mathrm{a}$ 进行共轭加成得到的 中间体 217, 发生分子内加成得中间体 218, 随后质子转
移，再消除 $\mathrm{PPh}_{3}$ 形成最终产物 214a. 基于文献 ${ }^{[55]}$ 报道, 同位素标记实验和计算结果证明了水或其它质子源可 以促进累积二烯酸酯的膦催化环化反应中的 [1,2]-和 $[1,3]$-质子转移, 从而有助于 $[1,2]$-和 $[1,3]$-氢迁移. 在该 反应中, 苯酚通过辅助 [1,2]-和[1,3]-氢迁移可能有利于 中间体 215 到 216 的形成和 218 到 219 的形成.

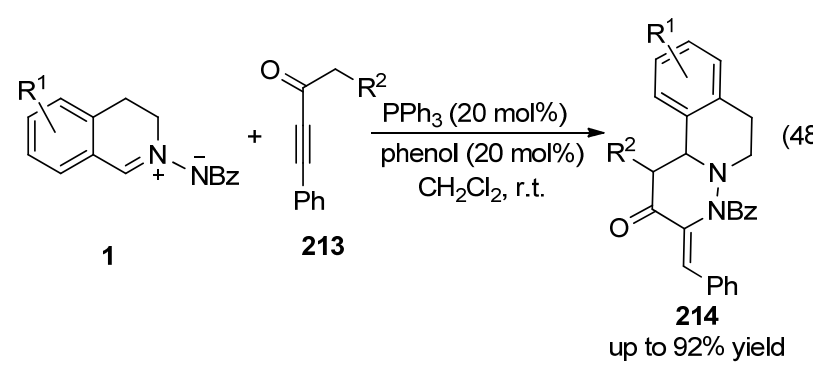

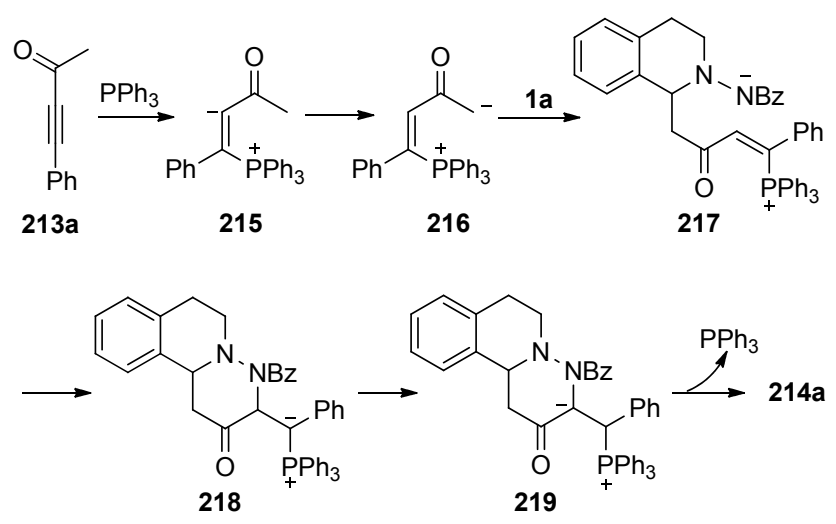

图式 34 膦催化的炔酮与 $\mathrm{C}, \mathrm{N}$-环状偶氮次甲基亚胺的 $[3+3]$ 环加成反应可能的机理

Scheme 34 Proposed mechanism of the phosphane-catalyzed $[3+3]$ cyclization of $\mathrm{C}, \mathrm{N}$-cyclic azomethine imines with ynones

2015 年, Glorius 团队 ${ }^{[28]}$ 发现当使用 $\mathbf{8 2 c}$ 作为 $\mathrm{NHC}$ 催化剂时, $\mathrm{C}, \mathrm{N}$-环状偶氮次甲基亚胺 87 与烯醛 88 反应 以优异的收率、高对映选择性以及高区域选择性的完成 $[3+3]$ 环加成反应, 得到哒嗪并 $[6,1-a]$ 异喹啉 92 环加成 产物(Scheme 35). 为探究该反应的使用性, 作者对环加 成产物做了合成转化研究(Scheme 36). 根据反应过程 的研究作者提出了可能的反应机理(Scheme 37): NHC 催化剂与 $\alpha, \beta$-不饱烯醛 88a 结合生成 Breslow 中间体 94, 该中间体以共振式或经过 $\beta$-质子化形成中间体 223 ; 在 强碱性条件下, Homoenolate 反应占优势, Breslow 中间 体在互变异构后与 $\mathrm{C}, \mathrm{N}$-环状偶氮次甲基亚胺 $88 \mathrm{a}$ 反应 生成 224, 224 在异构化为酰基偶氮中间体 225, 通过分 子内酰化以产生目标产物 92a, 从而促进催化剂的转化.

\section{2 金属催化}

以上报道是关于 $\mathrm{C}, \mathrm{N}$-环状偶氮次甲基亚胺作为一 个氮杂 $3 \mathrm{C}$ 合成子(aza-3C)与 $3 \mathrm{C}$ 合成子的环加成反应, 但对于 $\mathrm{C}, \mathrm{N}$-环状偶氮次甲基亚胺与一些氮杂 $3 \mathrm{C}$ 合成 


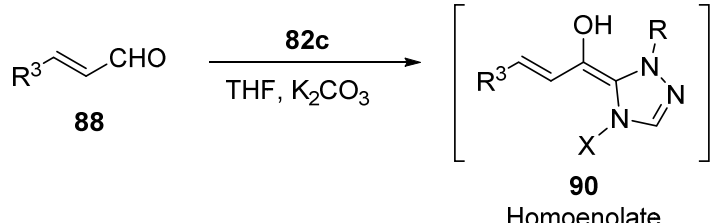<smiles>[R]N[n+]1ccc2c[R1]ccc2c1</smiles>
87

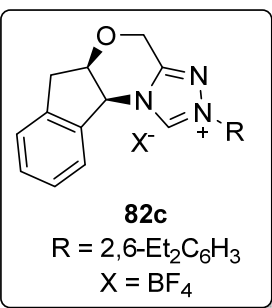

图式 $35 \mathrm{C}, \mathrm{N}$-环状偶氮次甲基亚胺与 $\alpha, \beta$-不饱和烯醛的 $[3+$ 3]环加成反应

Scheme $35[3+3]$ cycloaddition reaction of $\mathrm{C}, \mathrm{N}-\mathrm{cyclic}$ azomethine imines with $\alpha, \beta$-unsaturated alkenal

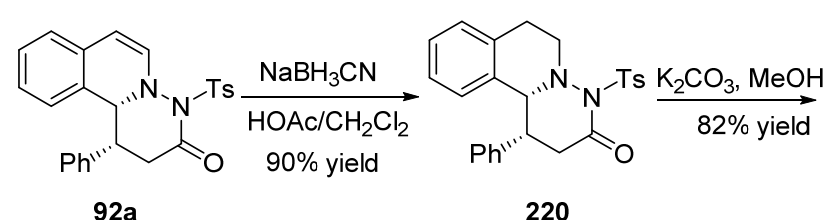

92a<smiles>O=C1C[C@H](c2ccccc2)[C@H]2c3ccccc3CCN12</smiles>

222

$90 \%$ ee

图式 $36 \mathrm{C}(1)$-取代四氢异喹啉衍生物 92a的合成转换

Scheme 36 Synthetic transformations of C(1)-substituted tetrahydroisoquinoline derivatives 92a

子的环加成反应也有一些报道，可以合成一系列结构多 样性的氮杂六元环化合物. 烯基氮杂环丙烷是一类重要 的氮杂环丙烷衍生物, 可以作为一个活化的氮杂 $3 \mathrm{C}$ 合 成子发生一系列环加成反应. 如[3+1]、[3+2]和[3+4], 但是将它作为氮杂 $3 \mathrm{C}$ 合成子发生 $[3+3]$ 环加成反应目 前还未见报道. 2017 年, 冯见君和张俊良等 ${ }^{[56]}$ 报道了第
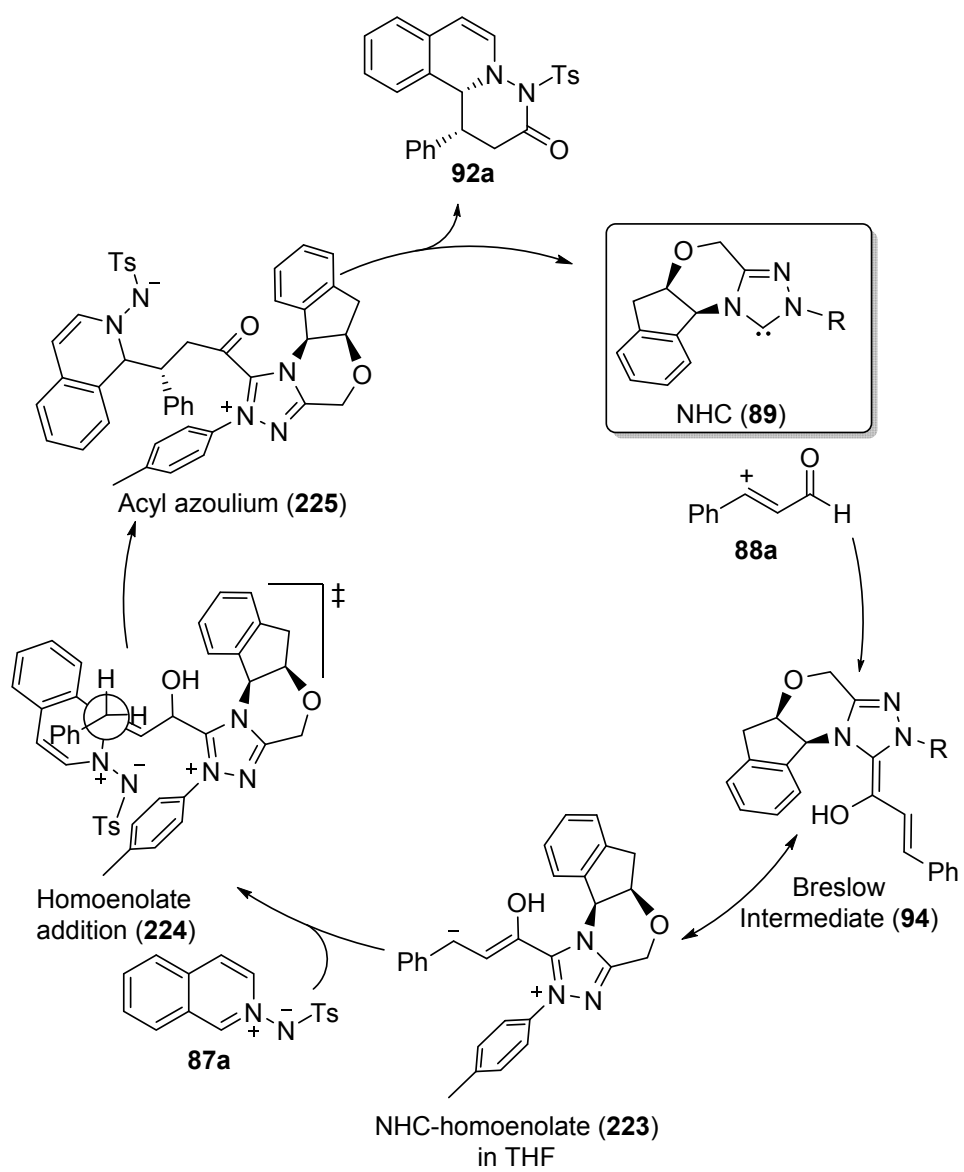

图式 $37 \mathrm{NHC}$ 催化的 $\alpha, \beta$-不饱和醛与 $\mathrm{C}, \mathrm{N}$-环状偶氮次甲基亚胺的[3+3]环加成反应可能的机理

Scheme 37 Proposed mechanism of the NHC-catalyzed [3+3] cyclization of C,N-cyclic azomethine imines with $\alpha, \beta$-unsaturated alkenal 
一例 $\mathrm{Rh}$ 催化的烯基氮杂环丙烷 226 和 $\mathrm{C}, \mathrm{N}$-环状偶氮次 甲基亚胺 16 的 $[(a z a-3 C)+(a z a-3 C)]$ 环加成反应，以中等 至高收率和极好的非对映选择性得到了 1,2,4-六氢三嗪 227 (Eq. 49). 这是首次将烯基氮杂环丙烷用作 1,3-偶极 子 $\mathrm{C}, \mathrm{N}$-环状偶氮次甲基亚胺的反应搭档, 该过程具有 原子经济性、条件温和及底物范围广泛等特点. 另外, 作者在反应中使用的是手性氮杂环丙烷, 手性可以有效 地转移到 $[3+3]$ 环加成产物中, 为 $1,2,4$-六氢三嗪的对 映选择性合成提供了一个新方法. 基于实验研究结果和 作者前期工作的机理探究, 他们提出了一个可能的机理 来解释该反应过程: 烯基氮杂环丙烷中的烯烃和氮原子 都能与铑催化剂配位形成络合物 228 , 发生氧化加成形 成烯基 $(\sigma+\pi)$ 铑物种 229 , 随后，该铑物种 229 的 $\mathrm{NR}^{4}$ 基 团亲核进攻 C,N-环状偶氮次甲基亚胺 16 的 $S i$ 面形成中 间体 230, 最后, 经过中间体 230 中的 $N$-酰基片段对铑 复合物从背面亲核进攻, $[3+3]$ 环加成产物 $(S, S)-227$ 形 成, 铑催化剂再生(路径 A); 或者如路径 B 所示, 可能先 发生 16 的 $N$-酰基片段对铑复合物 229 的背面亲核进攻, 产生构型反转的中间体 231, 催化剂再生. 最后, 通过 $\mathrm{NR}^{4}$ 基团对甲亚胺亚胺 $S i$ 面的亲核进攻得到 [3+3]环加 成产物(Scheme 38).<smiles>[R1][N+](=O)[O-]</smiles>

16

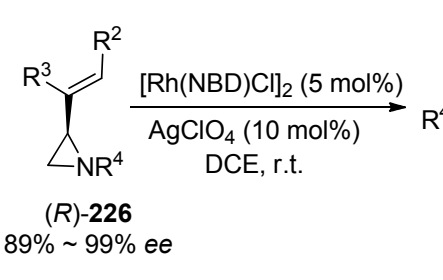

$\mathrm{R}^{4}$<smiles>[R]c1ccc2c(c1)CCN1CN(CCCO1)CCN2C(=O)O</smiles><smiles>[R]/C=C(/[R])C</smiles>

227

up to $93 \%$ yield $>20: 1 d r, 97 \%$ ee
蒋先兴等 ${ }^{[57]}$ 报道了 $\mathrm{Cu}$ 催化 3-取代吲哚 229 和 C,N环状偶氮次甲基亚胺 87 的需氧氧化/[3+3]环加成反应, 反应中使用氧气作为唯一的氧化剂, 条件温和, 产率较 好, 非对映选择性优异(Eq. 50). 通过同位素标记等一系 列机理探究实验, 作者提出了该需氧氧化/[3+3]环化加 成反应的机理(Scheme 39). 首先, $\mathrm{Cu}$ (II) 被 $\mathrm{O}_{2}$ 氧化为高 价态的 $\mathrm{Cu}(\mathrm{III})$ 并产生氧自由基负离子, 随后吲哚氮原子 的一个电子被 $\mathrm{Cu}(\mathrm{III})$ 捕获形成氮正离子自由基中间体 234, $\mathrm{Cu}(\mathrm{III})$ 回到 $\mathrm{Cu}(\mathrm{II})$, 中间体 234 很容易和氧自由基 负离子结合, 产生吲哚啉过氧化物中间体 235 , 在反应 中这一中间体的分子量可以采用液质联用(LC-MS)技术 检测到. 在 $\mathrm{Cu}(\mathrm{II})$ 的还原作用下, 中间体 235 转变为中 间体 236, $\mathrm{Cu}$ (II)变为 $\mathrm{Cu}$ (III)-氧自由基, 这个 $\mathrm{Cu}(\mathrm{III})$-氧 自由基也可以和 3-取代吲哚反应产生中间体 236 和 $\mathrm{Cu}$ (II). 另外, 由于中间体 $\mathbf{2 3 6}$ 氧原子上孤对电子的给电

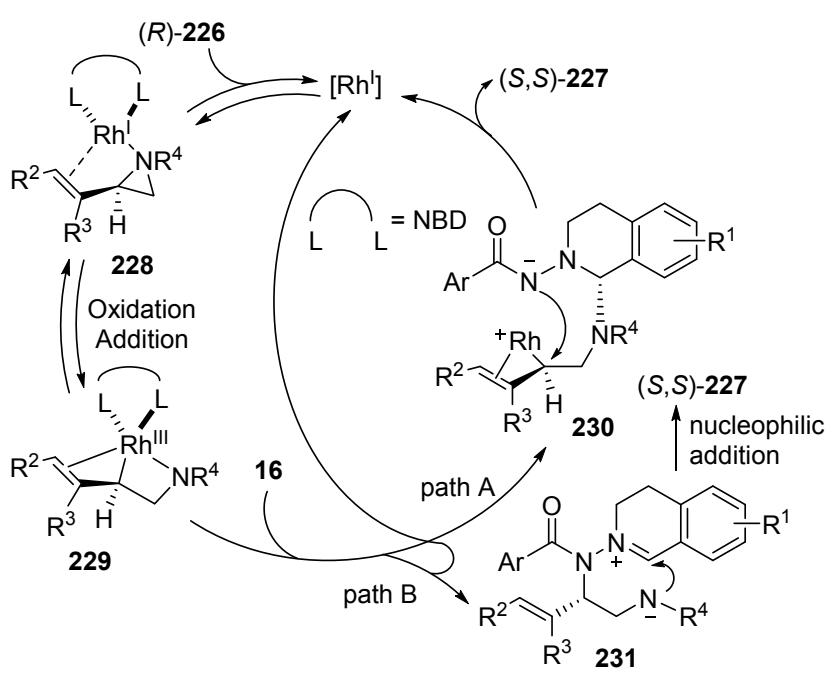

图式 $38 \mathrm{Rh}$ 催化的烯基氮杂环丙烷与 $\mathrm{C}, \mathrm{N}$-环状偶氮次甲基 亚胺的 $[3+3]$ 环加成反应可能的机理

Scheme 38 Proposed mechanism of the phodium-catalyzed $[3+3]$ cyclization of $\mathrm{C}, \mathrm{N}$-cyclic azomethine imines with vinyl aziridines

子效应，2-位的 $\mathrm{C}-\mathrm{O}$ 键很容易断裂形成两极型中间体 237, 最后，它作为一个氧杂 $3 \mathrm{C}$ 合成子和 C,N-环状偶氮 次甲基亚胺 87a 发生 $[3+3]$ 环加成反应，产生目标产物 233a. 如图 6 所示, 高非对映选择性产生主要是由于 $\pi-\pi$ 堆积 $\mathrm{Ts}$ 基团和 $\mathrm{N}$-保护基团 $\mathrm{R}$ 的空间位阻作用.
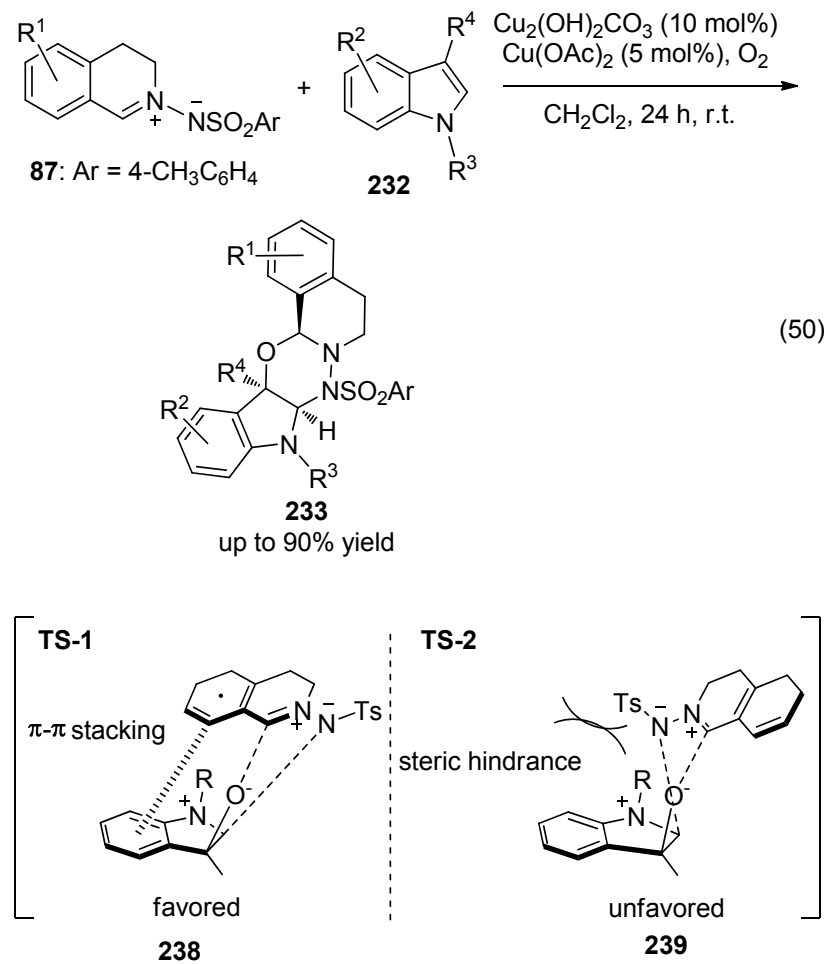

图 63 -取代吲哚与 $\mathrm{C}, \mathrm{N}$-环状偶氮次甲基亚胺反应可能的过 渡态

Figure 6 Proposed transition state of the reactions between 3 -substituted indoles with $\mathrm{C}, \mathrm{N}$-cyclic azomethine imines 
<smiles>[R16]c1cn([R])c2ccccc12</smiles>

232a

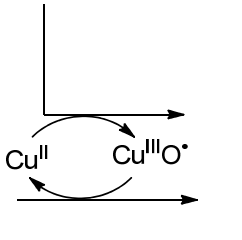<smiles>[R]N1c2ccccc2C2(C)OC12</smiles>

236
234

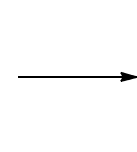

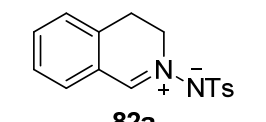

82a

图式 $39 \mathrm{Cu}$ 催化 3-取代吲哚的需氧氧化/[3+3]环加成反应的可能机理

Scheme 39 Proposed mechanism of the copper-catalyzed aerobic oxidation/[3+3] cycloaddition of 3-substituted indoles

2013 年, 唐勇、孙秀丽和李玉学等 ${ }^{[58]}$ 报道了使用侧 壁修饰的 $\mathrm{In}-\mathrm{TOX} / \mathrm{Ni}^{\mathrm{II}}$ 复合物催化 $\mathrm{C}, \mathrm{N}$-环状偶氮次甲基 亚胺 16 与环丙烷 240 的高对映选择性的 [3+3] 环加成反 应(Eq. 51), 并通过 M06 方法进行了密度泛函计算和对 照实验. 研究表明, 侧壁的 $\pi-\pi$ 相互作用的定向效应在 反应中对立体化学的控制起着至关重要的作用. 在计算 研究中获得了如图 7 所示的 $\mathrm{TOX} / \mathrm{Ni}^{\mathrm{II}}$ 配位优化模型, 该 模型是六配位的 $\mathrm{Ni}^{\mathrm{II}}$ 配合物, 其中 $\mathrm{C}, \mathrm{N}-$ 环状偶氮次甲基 亚胺与镍中心配位.

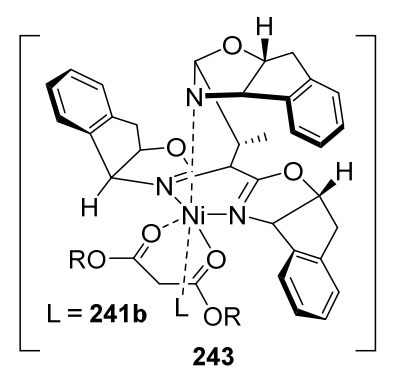

图 $7 \mathrm{TOX} / \mathrm{Ni}^{\mathrm{II}}$ 复合物的优化模型
在 2013 年和 2018 年, Doyle 课题组 ${ }^{[59-60]}$ 分别报道了 使用手性 dirhodium 催化剂和手性铜(I)催化剂, 催化 $\mathrm{C}, \mathrm{N}-$ 环状偶氮次甲基亚胺 19a 与烯丙基重氮羰基化合物 244 的 $[3+3]$ 环加成反应, 以良好的收率和化学选择性 得到异喹啉衍生物 247 (Eq. 52).

\section{3 自身协同反应}

$N$-芳基取代的化合物 $\mathbf{2 4 8}$ 被证实是原位产生高活性 的甲亚胺叶立德的一个有用前体，它作为一个氮杂 $3 \mathrm{C}$ 合成子，被广泛用于 $[3+2]$ 或 $[3+3]$ 环加成反应，可合 成具有生物活性的氮杂环衍生物. 2019 年, 王凯凯课题 组 ${ }^{[61]}$ 报道了化合物 $\mathbf{2 4 8}$ 与 $\mathrm{C}, \mathrm{N}-$ 环状偶氮次甲基亚胺 $\mathbf{1 6}$ 的 $[3+3]$ 环加成反应, 高产率地合成了 1,2,4-六氢三嗪 化合物 250 (Eq. 53). 作者对产物 250a 进行了合成转换, 在 $\mathrm{Pd} / \mathrm{C}$ 催化氢化反应中, 以甲醇作为溶剂, 室温下脱去 芐基，以 75\%的产率得到 $N$-甲基取代产物 251; 若反应 溶剂为乙酸乙酯, 脱去茮基以 $90 \%$ 的产率形成 $\mathrm{N}-\mathrm{H}$ 产 物 252 (Scheme 40).

Figure 7 Coordination model of TOX/Ni ${ }^{\mathrm{II}}$ complex<smiles></smiles>

16<smiles>[R]OC(=O)C1(O[R])CC1[R]</smiles>

240 $\mathrm{R}^{2}=$ aryl, heteroaryl, styryl, vinyl
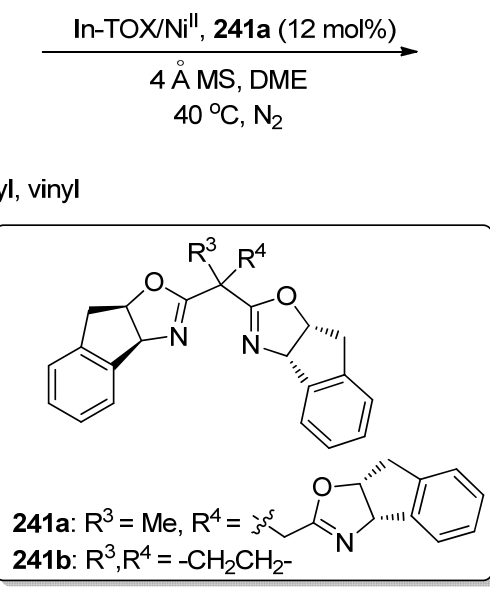

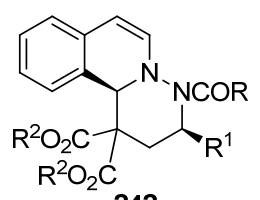

242

up to $99 \%$ yield $>20: 1 d r, 99 \%$ ee 
<smiles>[R14]NC(=C)C(=O)O[SiH3]</smiles>

Ref. [59]: $\mathrm{Si}=$ OTIPS, $\mathrm{R}^{1}=\mathrm{O}^{t} \mathrm{Bu}$ Ref. [60]: $\mathrm{Si}=$ OTBS, $\mathrm{R}^{1}=\mathrm{Me}$<smiles></smiles>

$19 a$


$6 \mathrm{~mol} \% 246$, DCM, r.t., $4 \mathrm{~h}$

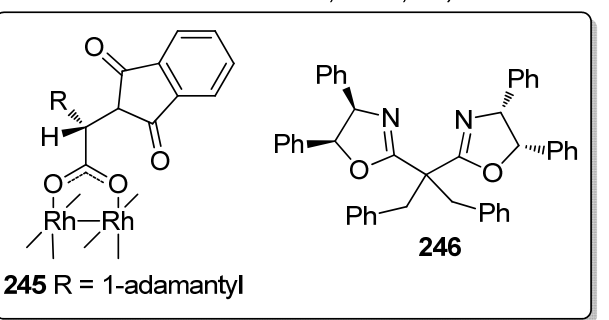

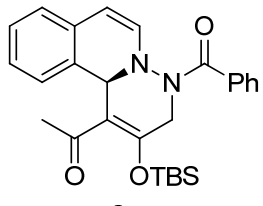

247

Ref. [59]: $71 \%$ yield, $97 \%$ ee Ref. [60]: $94 \%$ yield, $58 \%$ ee
(52)
16<smiles>COc1ccccc1</smiles>

251

$75 \%$ yield<smiles>[R1]c1ccc2c(c1)C1CN(Cc3ccccc3CCCCCC)CN(C(=O)OCC)N1CC2</smiles>

250 up to $96 \%$ yield<smiles></smiles>

249 in situ generation

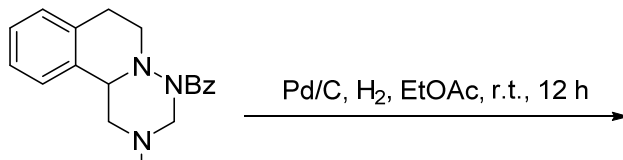

$\mathrm{Bn}$

250a

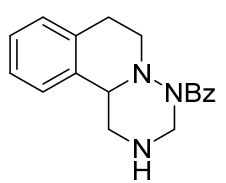

252

$90 \%$ yield

图式 $40 \mathrm{C}(1)$-取代四氢异喹啉衍生物 250a 的合成转换

Scheme 40 Synthetic transformations of C(1)-substituted tetrahydroisoquinoline derivatives 250a

\section{$3 \mathrm{C}, \mathrm{N}-$-环状偶氮次甲基亚胺参与的 [3+4]环加}

\section{成反应}

累积二烯是一类重要的反应底物, 它在亲核性的膦 催化剂作用下被活化, 对不同的亲电试剂显示出多样的 反应活性. 累积二烯可以做 2C 合成子与 1,3-偶极子 $\mathrm{C}, \mathrm{N}$-环状偶氮次甲基亚胺发生 $[3+2]$ 环加成反应, 也可 以作为 4C 合成子与 1,3-偶极子 $\mathrm{C}, \mathrm{N}$-环状偶氮次甲基亚 胺发生 $[3+4]$ 环加成反应.

\section{1 有机催化}

郭红超课题组 ${ }^{[20,62]}$ 报道了膦催化的 $\alpha$-取代累积二 烯酸酯 36 与 $\mathrm{C}, \mathrm{N}$-环状偶氮次甲基亚胺 1 的环化反应. 通过调节膦催化剂和累积二烯酸酯的性质, 可以分别得 到 $[3+2]$ 和 $[3+4]$ 环化反应产物. 当使用 $\alpha$-苄基取代的 累积二烯酸酯时, 反应途径受所使用的膦催化剂的控 制, 即使用大位阻的 $\mathrm{PBu}_{3}$ 作催化剂时, 反应可以得到 [3+4]环加成产物 253 (Eq. 54). 作者对该过程提出了一 个可能的机理(Scheme 41): 催化剂 $\mathrm{PBu}_{3}$ 对累积二烯酸 酯的 $\beta$-碳原子加成形成两性离子中间体 38, 然后中间 体 38 的 $\gamma$-碳原子进攻 $\mathrm{C}, \mathrm{N}$-环状偶氮次甲基亚胺形成中
间体 39, 当累积二烯酸酯取代的 $\mathrm{R}$ 基团为芳基时，由于 中间体 39 的 $\gamma$-质子酸性更强，容易异构化为中间体 256, 分子内的 7-endo 环化, 形成中间体 257, 通过叶立德-烯 醇酯的转换释放出催化剂, 形成 $[3+4]$ 产物 253a. 当使 用 $\mathrm{PBu}_{3}$ 作为催化剂时, $\beta$-碳原子的位阻增大, 不利于得 到[3+2]产物 37 .

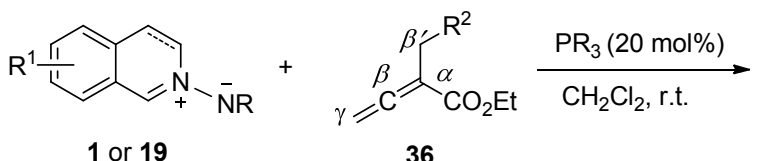

Ref. [20]: $R=B z$ Ref. [62]: $R=A c$ Ref. [20]: $R^{2}=A r$

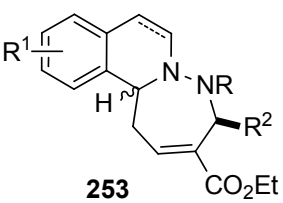

Ref. [20]: up to $93 \%$ yield

Ref. [62]: up to $93 \%$ yield, $>20: 1 d r$

\section{2 金属催化}

2018 年, 蒋先兴和许兆青等 ${ }^{[63]}$ 实现了催化不对称 $[3+4]$ 环加成反应合成手性含四氢异喹啉的苯并三氮杂 环化合物 260 (Eq. 55). 反应利用 $\mathrm{Cu}(\mathrm{OAc})_{2}$ 和手性 $\mathrm{NHC}$ 


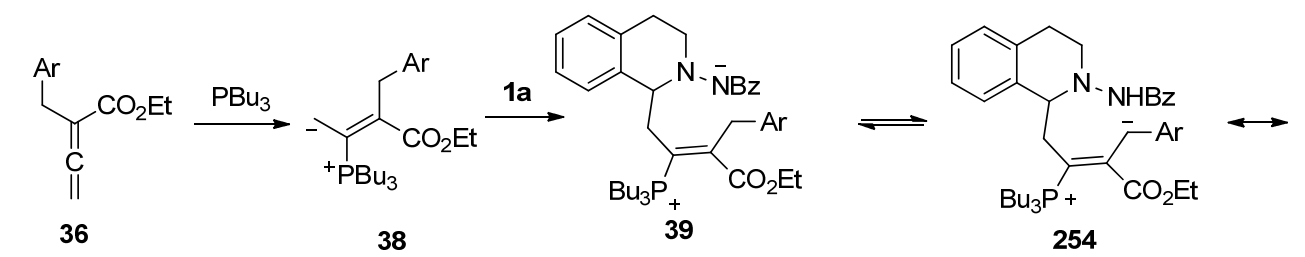<smiles>CCCNN1CCc2ccccc2C1CC(=CC(C)C)C(=O)OCC</smiles>

255<smiles>CCOC(=O)C(=CC(=O)NC(=O)c1ccccc1)CC1c2ccccc2CCN1C(C)(C)C</smiles>

256

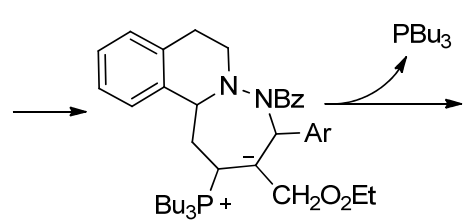

257

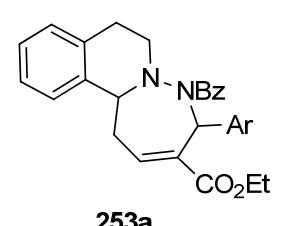

253a

图式 41 膦催化的 C,N-环状偶氮次甲基亚胺与烯丙酸酯[4+3]环化反应的可能机理

Scheme 41 Proposed mechanism of the phosphine-catalyzed [4+3] annulation reactions between C,N-cyclic azomethine imines with allenoates<smiles>[R1]c1ccc2c(c1)C(=C)OC(=O)N2[Y6]</smiles>

1

258

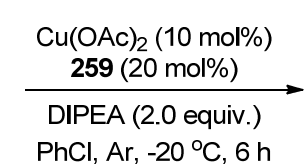

$\mathrm{PhCl}, \mathrm{Ar},-20^{\circ} \mathrm{C}, 6 \mathrm{~h}$





260

up to $95 \%$ yield, $>20: 1 d r$
配体作为催化体系, 能有较好的产率和优异的立体选择 性. 手性产物 260a 的炔基片段可以在 CuTc 的作用下, 与 $\mathrm{TsN}_{3}$ 经过 Huisgen 环化反应转变为三唑产物 261 (Eq. 56). 基于实验结果和最近的研究, 作者提出了一个可 能的催化循环(Scheme 42): 首先, $\mathrm{Cu}(\mathrm{OAc})_{2}$ 和 $\mathrm{NHC}$ 配 体形成 $\mathrm{Cu}(\mathrm{II})-\mathrm{NHC}$ 络合物, 活化底物 258a 的炔基片段 产生一个 $\pi$ 络合物 $262^{[64]}$, 去质子化形成中间体 $\mathbf{2 6 3}$, 中 间体 263 脱羧可以顺利地产生 $\mathrm{Cu} \pi$-炔基络合物 264'或 是它的共振结构 264, 接着, 该中间体可以作为一个 1,3-偶极子和 C,N-环状偶氮次甲基亚胺反应产生中间体 265 和 266, 最后, 中间体 266 的顶端被 NHC 的取代基 挡住, 经过一个质子化产生手性的四环产物 260a, 同时 释放出活性的 $\mathrm{Cu}$ 催化剂. 由于 $\mathrm{NHC}$ 的取代基的 $\pi-\pi$ 堆 积和空间位阻产生的主要立体化学控制, 高 $R e$ 面和 endo 非对映选择性使得反应得到目标手性产物, 与实 验结果是一致的.

\section{3 碱促进的自身协同反应}

2013 年, 肖文精和陈加荣等 ${ }^{[6]}$ 报道了首例无催化剂 的 $\alpha$-卤代酰腙 267 与 $\mathrm{C}, \mathrm{N}$-环状偶氮次甲基亚胺 $\mathbf{1}$ 的 [3+ 4]环加成反应. 在碱的作用下, $\alpha$-卤代酰腙脱卤化氢原 位生成的 1,2-二氮-1,3-二烯 269 与 1 反应, 高产率地合

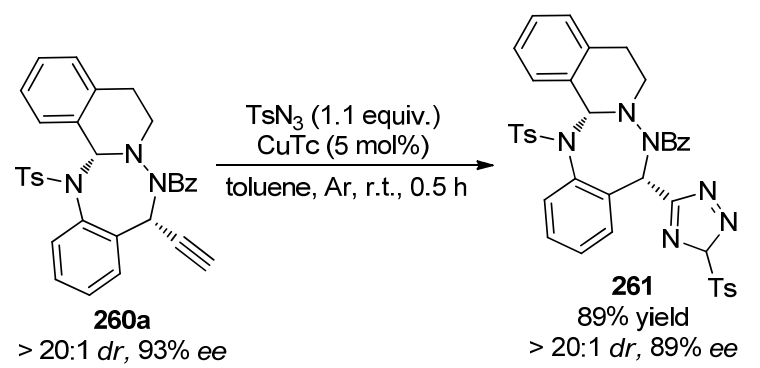

(56)

成了多官能团化的 1,2,4,5-四氮杂环庚烷衍生物 270 (Eq. 57), 反应的条件温和, 底物范围非常广. 值得注意的 是, $\alpha$-卤代腙的 $\mathrm{N}$ 上保护基对反应途径有着显著的影响: 比如, 当使用 $N$-苯甲酰胺时, 反应经过[3+3] 环加成的 途径以 $62 \%$ 的产率得到了相应的环化产物 270 (Eq. 58).

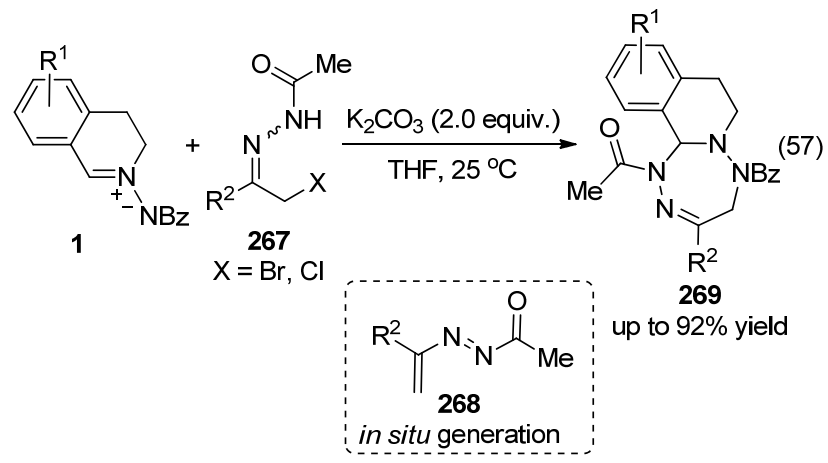




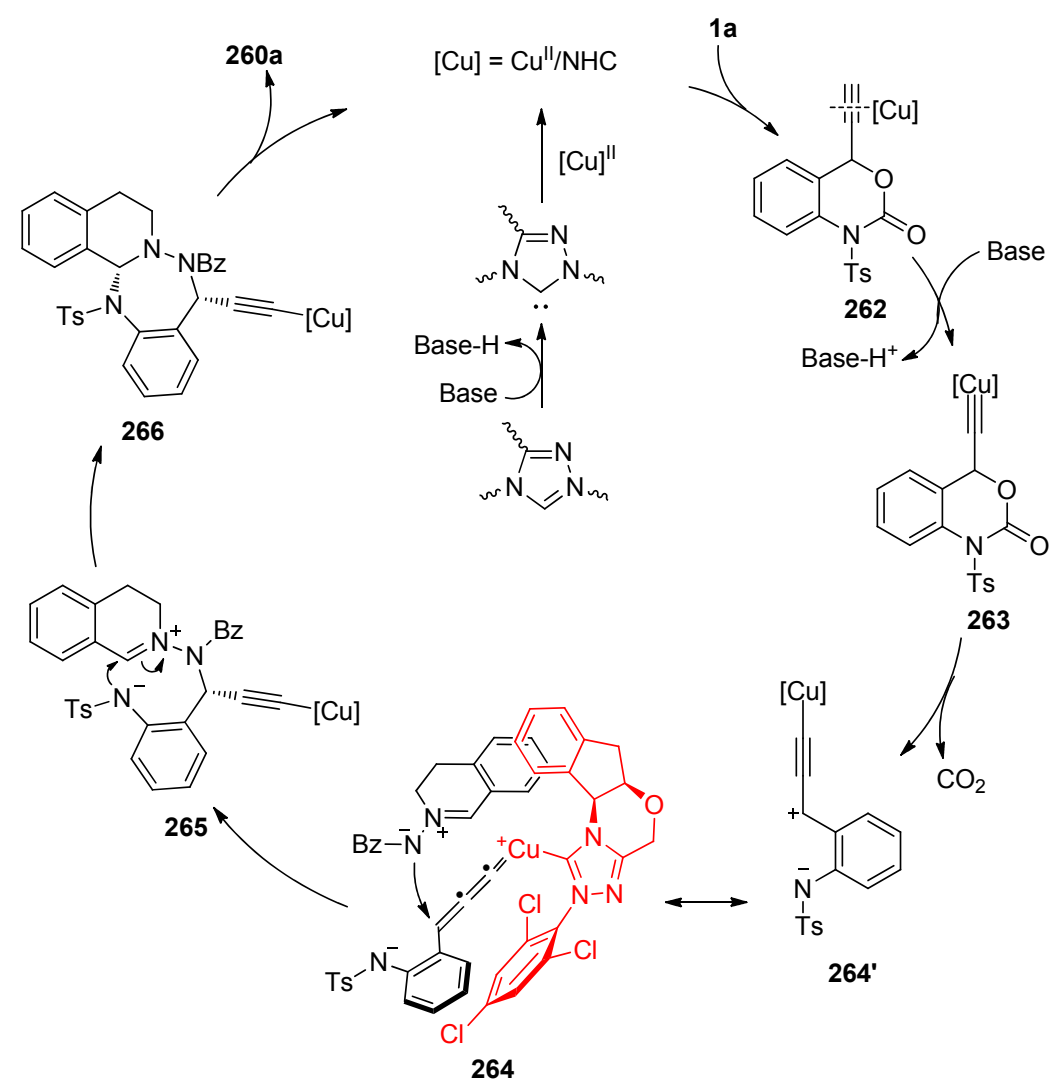

图式 42 铜催化不对称的[4+3]环加成反应的可能机理

Scheme 42 Proposed mechanism for $\mathrm{Cu}$-catalyzed asymmertric [4+3] annulation

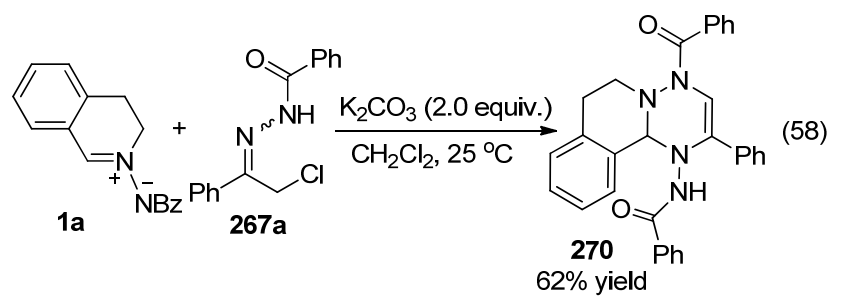

邻氯甲基- $N$-甲苯磺酰基苯胺 271 在碱性条件下也 可以脱卤化氢原位产生氮杂邻醌甲基化物的高活性中

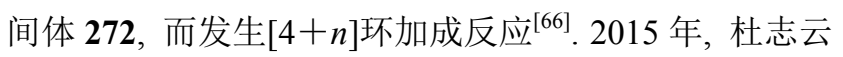
课题组 ${ }^{[67]}$ 和 Enders 课题组 ${ }^{[68]}$ 同时报道了邻氯甲基- $N$-甲 苯磺酰基苯胺和 $\mathrm{C}, \mathrm{N}-$ 环状偶氮次甲基亚胺 1 在温和条 件下的 $[3+4]$ 环化反应, 以非常好的收率得到了含四氢 异喹啉的苯并三氮杂环骨架的有用衍生物 273 (Eq. 59).

2017 年, 徐建峰和任红军等 ${ }^{[69]}$ 报道了在温和的碱 性条件下, 2-(1-甲苯磺酰基)苯酚 274 原位生成邻醌甲基 化合物 275 $(o-\mathrm{QMs})$ 与 $\mathrm{C}, \mathrm{N}-$ 环状偶氮次甲基亚胺 16 的 $[3+4]$ 环化反应, 以中等至良好的产率和优异的非对映 选择性得到目标产物 276 (Eq. 60). 作者提出了可能的 过渡态以合理解释七元杂环化合物优异的非对映选择 性：大位阻的对氯苯基和苯甲酰基的空间排斥作用使

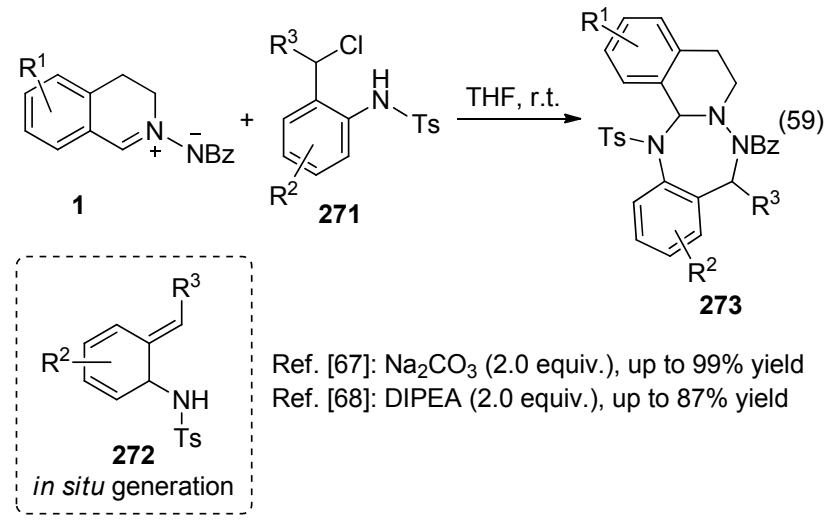

得 E-o-QM 异构体会与 $\mathrm{C}, \mathrm{N}$-环状偶氮次甲基亚胺经过优 势的过渡态发生 $[3+4]$ 环加成反应, 形成了主要的非对 映异构体 cis-278a 产物(Scheme 43).

\section{$4 \mathrm{C}, \mathrm{N}-$ 环状偶氮次甲基亚胺参与的 $[3+1]$ 环加 成反应}

3 -氯氧化吲哚是一类常用的 $1 \mathrm{C}$ 合成子, 陈应春小 组 ${ }^{[70]}$ 基于前期工作, 研究了 3-氯氧化吲哚 279 和 $\mathrm{C}, \mathrm{N}-$ 环状偶氮次甲基亚胺 16 的[3+1]反应(Eq. 61). 在 Brønsted 碱作用下, 意外发现 $[3+1]$ 环加成/重排串联反 
<smiles>[R1]c1ccc2c(c1)C=[N+]([N+](=O)O[Na])CC2</smiles>

16<smiles>[R][R]1ccc(O)c(C([R])[18F])c1</smiles>

274
(60)

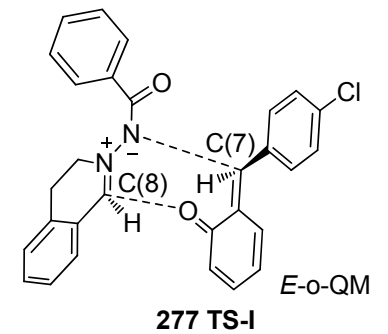

favored

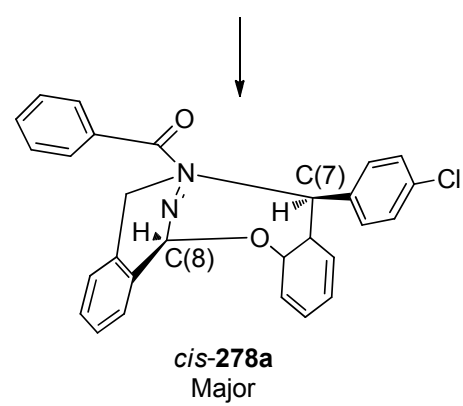

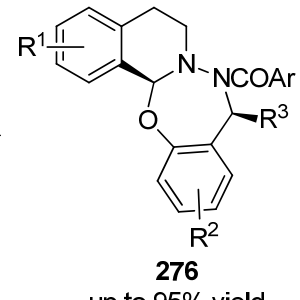

up to $95 \%$ yield

$>20: 1 d r$

图式 $43 \mathrm{C}, \mathrm{N}-$ 环状偶氮次甲基亚胺与原位生成邻醌甲基化物反应可能的过渡态

Scheme 43 Proposed transition state of the reaction between C,N-cyclic azomethine imines with in situ generated ortho-quinone methides

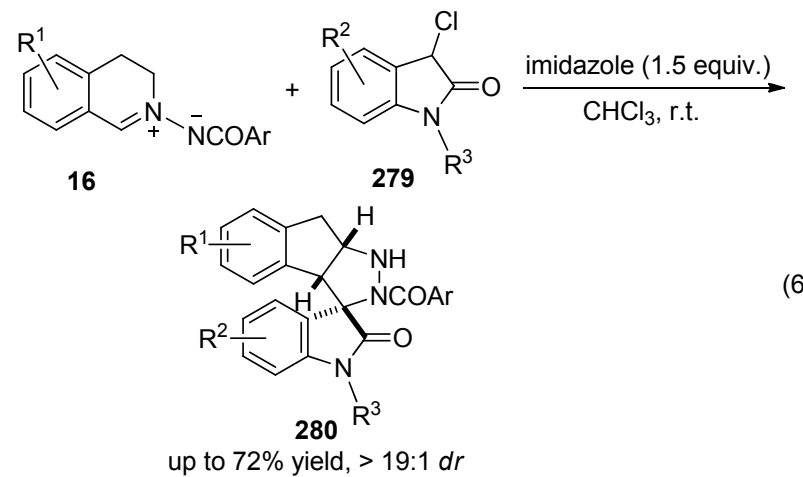

应, 有效构建了一个复杂的带有螺环氧化吲哚骨架的六 氢狮[2,1-c]吡咯结构 280. 作者也尽力实现这一反应的 不对称过程, 经过一系列条件筛选, 作者发现多功能催 化剂 281、添加剂 282 和 2-氨基-3-甲基吡啶(283)作碱、 $\mathrm{CH}_{3} \mathrm{Cl}_{3}$ 和 $\mathrm{PhCF}_{3}$ 为混合溶剂的条件下, 底物 $1 \mathrm{a}$ 和 279a 的反应可以很成功地实现高的非对映选择性和对映选 择性(Eq. 62). 但是, 反应产物在溶剂中很容易发生消旋 化, 可能是由于 1,3 -偶极子环加成的可逆过程导致的.
${ }^{1} \mathrm{H}$ NMP 实验和 DFT 计算研究也进一步说明了消旋化过 程. 作者提出了可能的机理(Scheme 44): 3-氯氧化吲哚 279a 在碱的作用下去质子化得到烯醇中间体 284, 它可 以进攻 $\mathrm{C}, \mathrm{N}$-环状偶氮次甲基亚胺 $1 \mathrm{a}$ 产生中间体 285, 随 后以 $\mathrm{S}_{\mathrm{N}} 2$ 的方式分子内 $\mathrm{N}-$ 烷基化产生 $[3+1]$ 环加成中间 体 287, 由于四元环结构的环张力, 可能会重排产生八 元环中间体 288, 接着 287 非对映选择性的跨环 Mannich 型反应得到中间体 $\mathbf{2 8 9}$, 最后该中间体质子化形成产物 280a. DFT 计算显示中间体 287 可以经过一个很小的能 垒 $(22.6 \mathrm{~kJ} / \mathrm{mol})$ 转化为 $\mathbf{2 8 8}$, 这也表明新的 $\mathrm{C}-\mathrm{C}$ 键形成 很快, 同时, 产物 $280 \mathrm{a}$ 比 $280 \mathrm{a}^{\prime}$ 的能量要低, 这说明 280a 很容易产生.

\section{$5 \mathrm{C}, \mathrm{N}-\mathrm{x}$ 环状偶氮次甲基亚胺参与的 $[5+1]$ 环加 成反应}

在上述工作中, C,N-环状偶氮次甲基亚胺作为 1,3偶极子发生 $[3+n]$ 环加成反应. $\mathrm{N}$ 上的酰基官能团作为延 长的共轭体系, 使得它可以作为 1,5-偶极子(Scheme 45). 

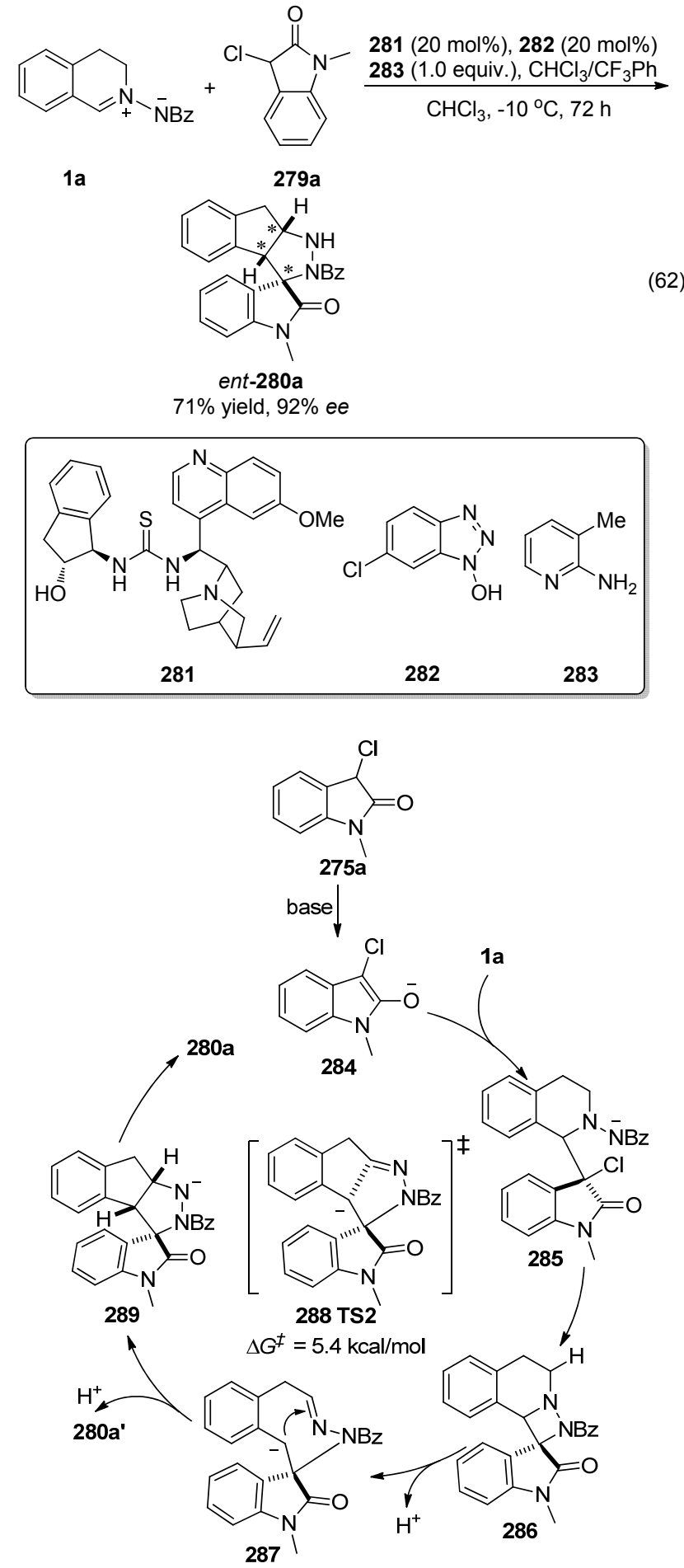

图式 $44 \mathrm{C}, \mathrm{N}$-环状偶氮次甲基亚胺与 3-氯氧化吲哚串联反应 的可能机理

Scheme 44 Proposed mechanism of the cascade reaction process of $\mathrm{C}, \mathrm{N}$-cyclic azomethine imines and 3 -chlorooxindoles

2012 年, Soeta 和 UKaji 等 ${ }^{[71]}$ 报道了 C,N-环状偶氮次甲 基亚胺 1 作为 1,5-偶极子与异腈 290 的[5+1]环加成反 应(Eq. 63). 在该反应中异腈既充当了亲核试剂又充当 了亲电试剂 $(\mathrm{C}=\mathrm{N})$ 的角色, 反应无需催化剂, 快速合成 了 1,3,4-噁二嗪衍生物 291, 反应产率非常高.

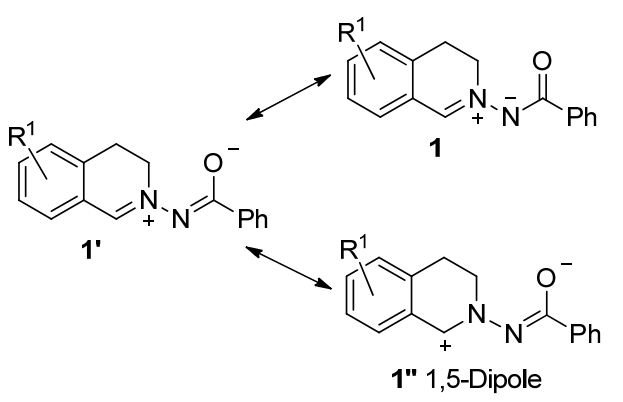

图式 $45 \mathrm{C}, \mathrm{N}$-环状偶氮次甲基亚胺的共轭结构

Scheme 45 Resonance structures of $\mathrm{C}, \mathrm{N}$-cyclic azomethine imines

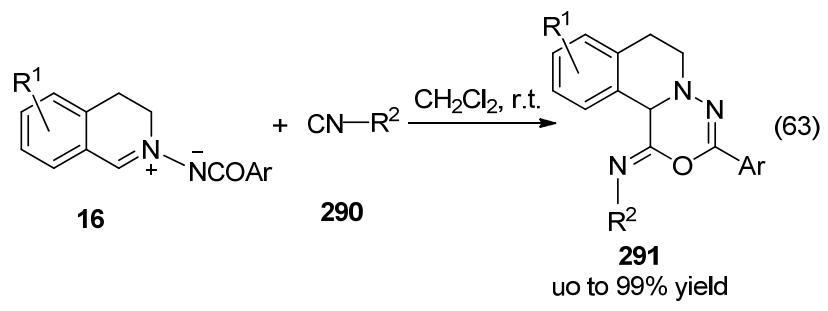

2013 年, 该小组 ${ }^{[72]}$ 继续将这一环加成反应拓展到 了三组分反应，通过向体系中加入同时含亲电试剂和亲 核试剂的一个两性试剂 $\mathrm{TMSCl}$ ，可以抑制分子内 $N$-酰 基基团对腈正离子中间体的分子内进攻，两性试剂中亲 核试剂部分 $\mathrm{Cl}^{-}$对腈正离子中间体的亲核进攻可以实现 多组分反应，以 $93 \%$ 产率得 1-酰胺四氢异喹啉衍生物 293 (Scheme 46). 在这一成功结果的基础上, 作者将体 系中 $\mathrm{TMSCl}$ 替换为 $\mathrm{TMSN}_{3}$ 时，能快速地以 $93 \%$ 的产率 得到含四氢异喹啉酰骨架的 1,5-二取代四唑 297a (Eq. 64). 使用 $\mathrm{TMSCl}$ 和 $\mathrm{NaN}_{3}$ 结合产生 $\mathrm{TMSN}_{3}$ 比直接用 $\mathrm{TMSN}_{3}$ 更经济, 并成功将 $\mathrm{TMSCl}$ 和 $\mathrm{NaN}_{3}$ 应用到 C,N环状偶氮次甲基亚胺 1 和异腈 292 反应体系中, 高产率 地得到四唑衍生物 297. 通过一系列实验, 作者提出了 可能的机理: C,N-环状偶氮次甲基亚胺和异腈的 $[5+1]$ 环加成反应非常快, 所得的六元环会被 $\mathrm{TMSCl}$ 打开原 位产生相应的腈正离子中间体 299 , 随后与 $\mathrm{N}_{3}$ 负离子 1,3-偶极环加成反应得到相应的四唑产物 297 (Scheme 47).

\section{$6 \mathrm{C}, \mathrm{N}-\mathrm{x}$-环状偶氮次甲基亚胺参与的其他反应}

\section{1 路易斯酸催化}

在有机合成中, 一个杂环在其他杂环的存在下很难 再一次高效地发生化学区域选择性官能化，但 2008 年, Charette 课题组 ${ }^{[73]}$ 报道了在钯催化下 C,N-环状偶氮次甲 基亚胺 19a 的新型反应，使得芳基溴化物直接发生 $\mathrm{C}-\mathrm{H}$ 偶联的反应，以良好的收率合成了 $( \pm)$ 木薯碱 302 (Eq. $65)$, 该反应证明了, 在吡啶环存在下也能进一步选择性 


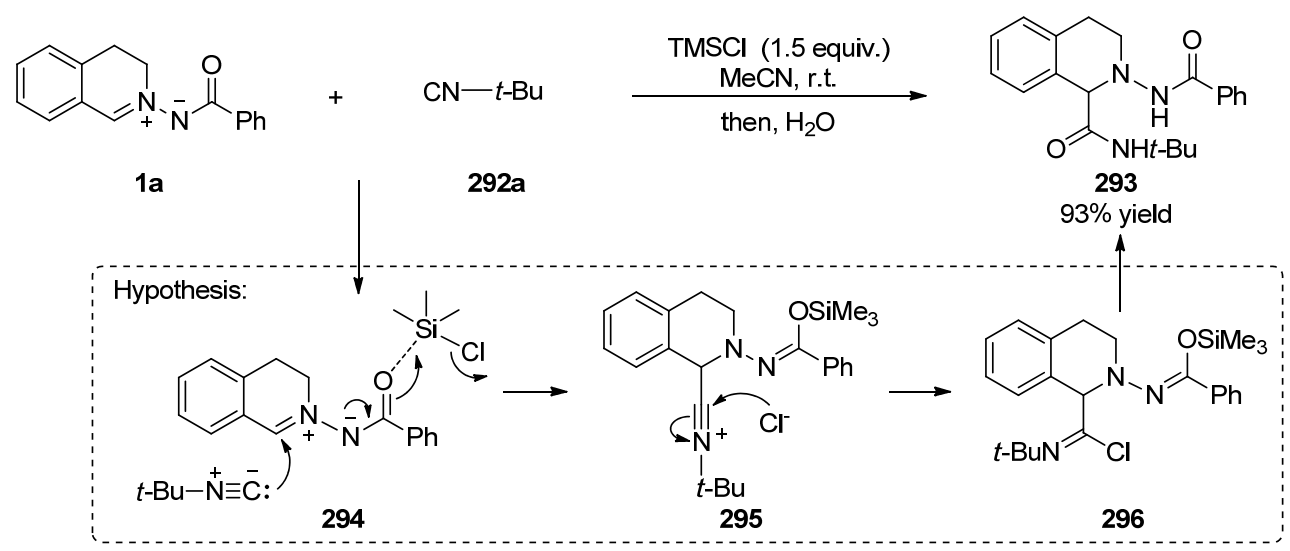

图式 $46 \mathrm{C}, \mathrm{N}$-环状偶氮次甲基亚胺、叔丁基异腈和三甲基氯硅烷的三组分反应及设想

Scheme 46 Working hypothesis for a three-component reaction of C,N-cyclic azomethine imines, tert-butyl isocyanide with TMSCl<smiles></smiles>

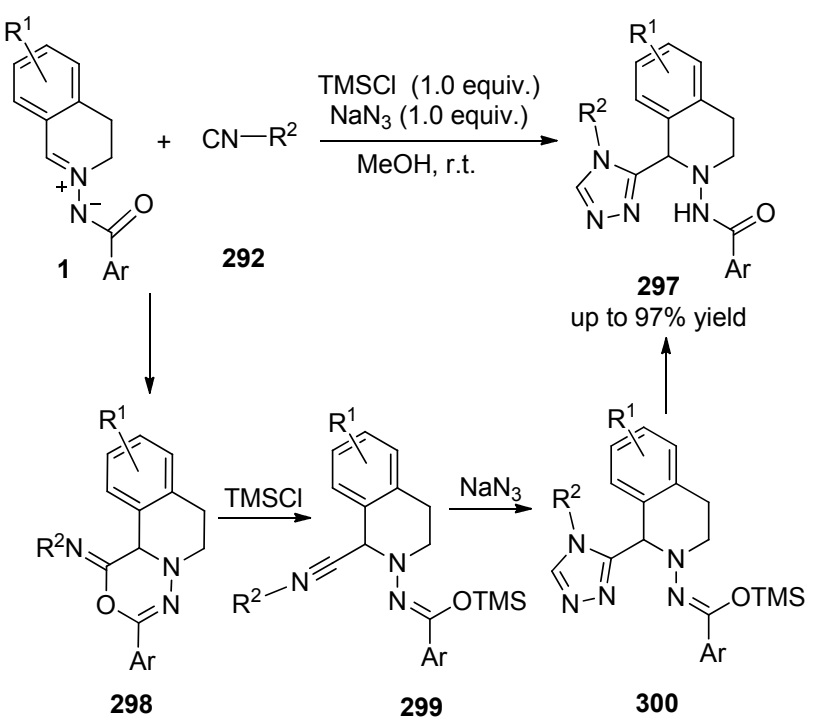

图式 47 C,N-环状偶氮次甲基亚胺、叔丁基异腈、三甲基氯 硅烷和叠氮钠的多组分反应及机理

Scheme 47 A multicomponent reaction of C,N-cyclic azomethine imines and isocyanide in the presene of TMSCl and $\mathrm{NaN}_{3}$ and mechanisms

地使 $\mathrm{C}, \mathrm{N}$-环状偶氮次甲基亚胺官能团化.

\section{2 有机催化}

赵梅欣等 ${ }^{[74]}$ 利用手性双功能三级胺硫艮催化剂 303 也实现了从 $\mathrm{C}, \mathrm{N}$-环状偶氮次甲基亚胺 109 合成手性 1-

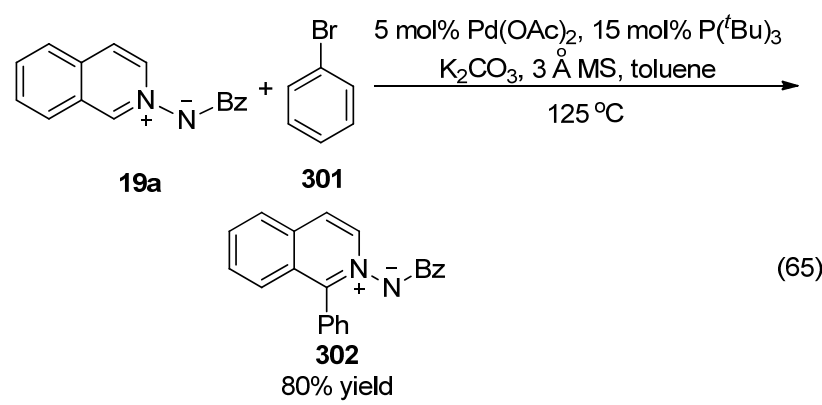

啞唑异喹啉 306, 产率高达 93\%，对映选择性高达 98\% (Eq. 66). 为了解释立体化学的产生, 作者认为四方酰胺 作为一个双功能催化剂活化反应的两个底物, 异氧酸酯 去质子化, 再异氰酸酯烯醇化产生的 $\mathrm{OH}$ 和三级胺片段 的氢键作用，同时， C,N-环状偶氮次甲基亚胺通过四方 酰胺片段的氢键作用活化. 烯醇化的异㲵酸酯对甲亚胺 亚胺的 $S i$ 面的伪分子内亲核加成产生腈正离子中间体, 进一步环化产生了目标产物 5-甲氧基啞唑 $(R)-305 a$ (Scheme 48).

2015 年, 王利民团队 ${ }^{[75]}$ 报道了催化量的过氧苯甲 酰(BPO)引发的 $\mathrm{C}, \mathrm{N}$-环状偶氮次甲基亚胺 19a 与烷烃 308 的交叉脱氢偶联反应，以良好的收率生成具有高区 域选择性的 2-烷基异喹啉类化合物 309, 并且不需要额 外的还原步骤来除去活化的基团(Eq. 67).

\section{3 金属催化}

2011 年, Maruoka 小组 ${ }^{[76]}$ 报道了 $\mathrm{Cu}(\mathrm{I})$ 催化的 C,N环状偶氮次甲基亚胺 1 与末端不对称炔烃 310 的反应, 高产率、高对映选择性地得到了相应的炔基化合物 312, 而不是 $[3+2]$ 环加成产物(Eq. 68). 作者成功地实现了 $\mathrm{C}, \mathrm{N}$-环状偶氮次甲基亚胺作为新型的潜在手性亲电试 剂得到手性 C(1)-取代四氢异喹啉衍生物, 反应的底物 范围非常广, 更重要的是 C(1)-取代的 C,N-环状偶氮次 甲基亚胺也能成功地用于该催化剂体系中, 从而实现四 
<smiles></smiles>

109<smiles>[R]OC(=O)C([Al])Br</smiles>

304

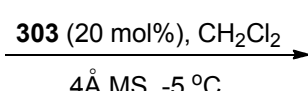

$4 \AA \mathrm{MS},-5^{\circ} \mathrm{C}$

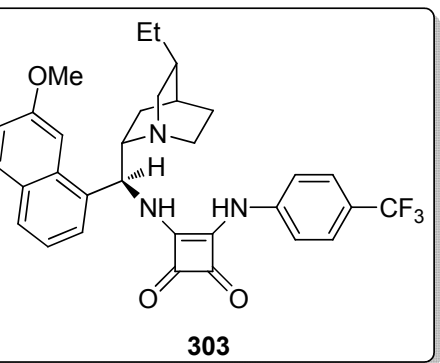<smiles>[R]Oc1oc(C2c3cc[R]([R])cc3CCN2[N+](=O)[O-])nc1Br</smiles>

305

up to $93 \%$ yield $98 \%$ ee
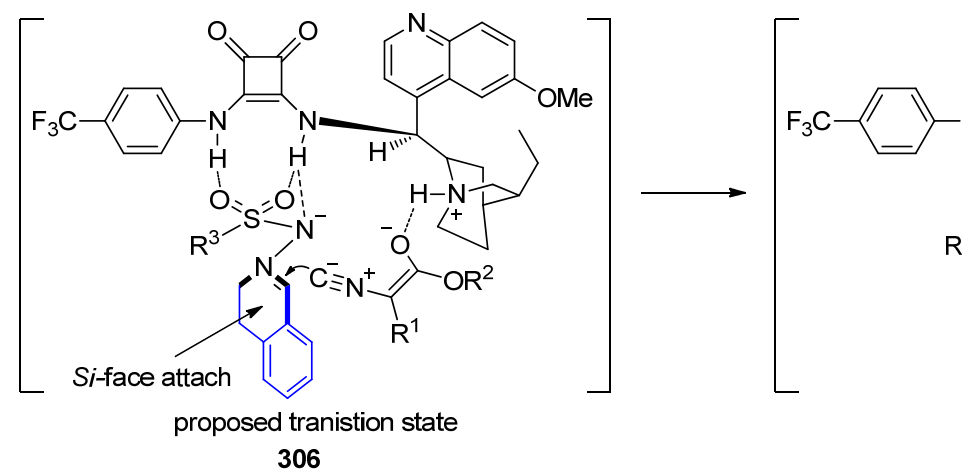

三级

309

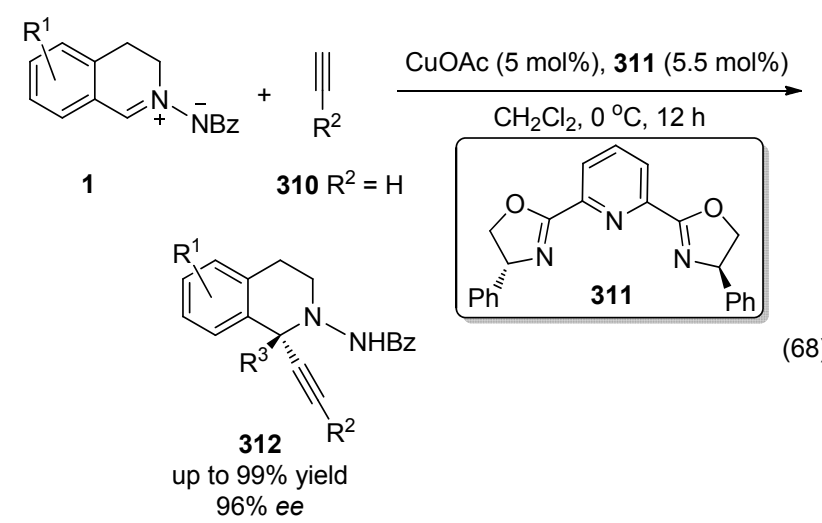

氢异喹啉 $\mathrm{C}(1)$ 位季碳中心的构建. 当使用上述反应条件 时, 并未得到同样高的对映选择性. 在加入一个轴手性 二羧酸 120c 作为共催化剂时, 这一难题被攻破(Eq. 69). 这一关键策略考虑到了反应的催化循环, 末端炔烃和乙
酸酮形成炔基铜会释放出乙酸, 游离的乙酸会将 $\mathrm{C}, \mathrm{N}-$ 环状偶氮次甲基亚胺 1 质子化(Scheme 49), 这样活化的 亲电酰亚胺会与亲核的炔基铜反应, 基于这样设想的催 化循环, 用手性 Brønsted 酸替代乙酸, 并获得高的对映 选择性. 这也是第一例末端炔烃直接对 $\mathrm{C}=\mathrm{N}$ 双键加成 构建高对映选择性的季碳中心反应. 为了除去产物 312a 中的苯甲酰胺基团，作者进行了两步合成应用 (Scheme 50): 产物中炔基片段氢化和 $\mathrm{SmI}_{2}$ 促进 $\mathrm{N}-\mathrm{N}$ 键 断裂以 $69 \%$ 产率得到手性四氢异喹啉 315. 在对产物 312b 的应用中, 作者进行了一步 $\mathrm{Cu}$ 催化的环化反应得 到二氢吡唑产物, 两步氢化得非对映选择性吡唑啉产 物, 随后 $\mathrm{N}-\mathrm{N}$ 断裂产生 318, 同时在产物中引入了另 一立体中心.

2016 年，王利民团队 ${ }^{[77]}$ 报道了在温和条件下，铜催 化的 $\mathrm{C}, \mathrm{N}-$ 环状偶氮次甲基亚胺 19a 与仲胺 319 的交叉脱 氢偶联反应, 高收率、高区域选择性地得到了邻氨基取 代的异喹啉衍生物 320 (Eq. 70). 这种直接的 $\mathrm{C}-\mathrm{H}$ 键胺 化反应采用 $\mathrm{CuI}$ 作为催化剂, 无需添加配体、氧化剂和 碱, 并且脱去 $N$-苯甲酰基也不需要额外的步骤.

王锐课题组 ${ }^{[78]}$ 报道在 $\mathrm{Ni}$ 催化下 $\mathrm{C}, \mathrm{N}$-环状偶氮次甲 基亚胺 $\mathbf{1}$ 和异氰酸酯 321 反应生成噁唑的 Ugi 反应, 其 


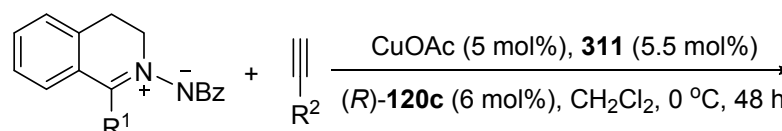

313

310

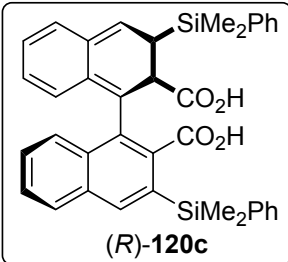

(R)-120c

(69)

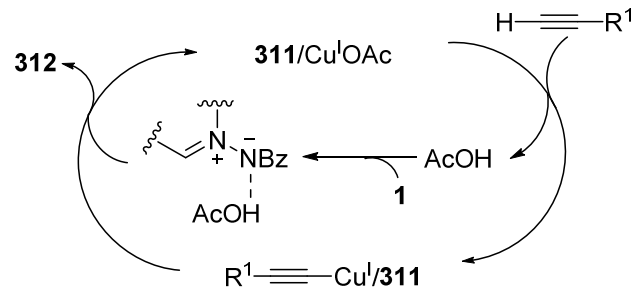

图式 $49 \mathrm{CuI} /$ 手性 Brønsted 酸共催化的不对称炔化反应机理 Scheme 49 Proposed mechanism of catalytic asymmetric alkynylation of $\mathrm{CuI} /$ chiral Brønsted acid Co-catalyst

up to $>99 \%$ yield $95 \%$ ee

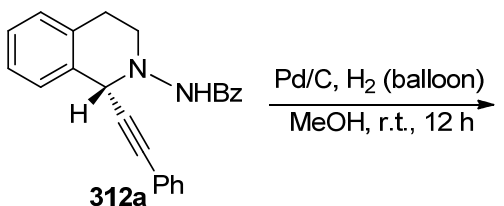

$312 a^{\mathrm{Ph}}$<smiles>c1ccc(CNN2CCc3ccccc3C2)cc1</smiles>

314

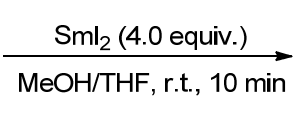<smiles>c1ccc(CC[C@@H]2NCCc3ccccc32)cc1</smiles>

315

$69 \%$ yield

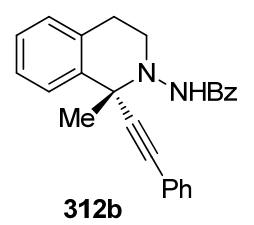

312b

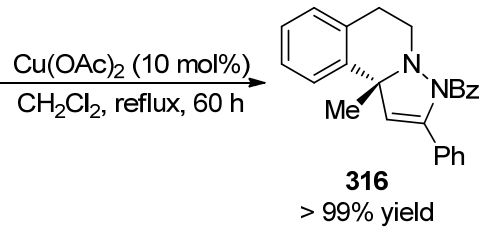

$\mathrm{Pd} / \mathrm{C}, \mathrm{H}_{2}$ (balloon) $\mathrm{MeOH}, 0^{\circ} \mathrm{C}, 48 \mathrm{~h}$

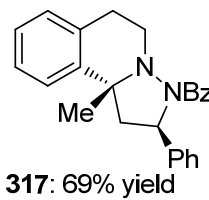
epi-317: $26 \%$ yield ( 2 steps)

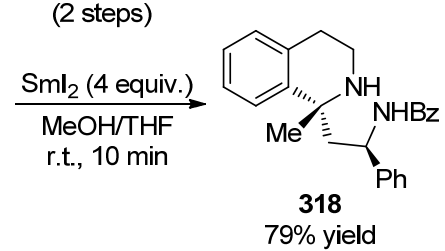

图式 $50 \mathrm{C}(1)$-取代四氢异喹啉衍生物 312a 和 312b 的合成转换

Scheme 50 Synthetic transformations of C(1)-substituted tetrahydroisoquinoline derivatives 312a and 312b

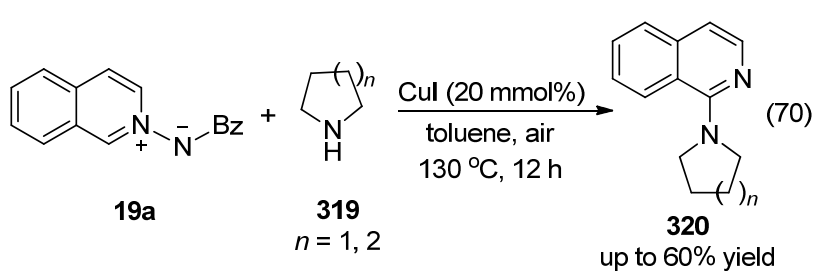

中使用了简单易得的手性二胺配体 322, 非常顺利地得 到了含两个重要骨架(四氢异喹啉和噁唑)的产物 323 , 产率较好, 对映选择性优异(Eq. 71). 对这个 $\mathrm{Ni}$ 催化不 对称形成噁唑的 Ugi 反应作者提出了一个可能的机理 (Scheme 51): 异㲵酸酯的 $\alpha$-取代基在反应是否发生方 面起着关键作用 ( $\alpha$-取代基为芳基), 因此, 酯基能否烯 醇化是噁唑环的形成和加成反应完成的重要因素. 首 先, 异腈和 $N$-二胺络合物通过一个二齿配体结合在一 起, 然后 C,N-环状偶氮次甲基亚胺 $\mathbf{1 a}$ 被 $\mathrm{Ni}$ 中心配位活 化, 通过异腈片段对亚胺的加成形成噁唑, 得到手性噁 唑一四氢异喹啉化合物. 作者设想产生高对映选择性的 一个关键因素是金属中心和底物的配位次序, 因此不同 的金属会产生不同的结果.

邱晃小组 ${ }^{[79}$ 报道了 $\mathrm{Rh}$ 催化的苯胺 328 、重氮化合物
329 ${ }^{[80]}$ 和 $\mathrm{C}, \mathrm{N}-$ 环状偶氮次甲基亚胺 $\mathbf{1 6}$ 的三组分反应(Eq. 72). 原位产生的氮叶立德作亲核试剂, 被 C,N-环状偶氮 次甲基亚胺捕获, 在温和条件下, 快速构建重要的 C(1)取代四氢异喹啉衍生物, 产率中等, 非对映选择性非常 好. 作者还研究了用手性磷酸作为手性源来实现不对称 反应(Eq. 73), 对映选择性中等, 反应的产率和非对映选

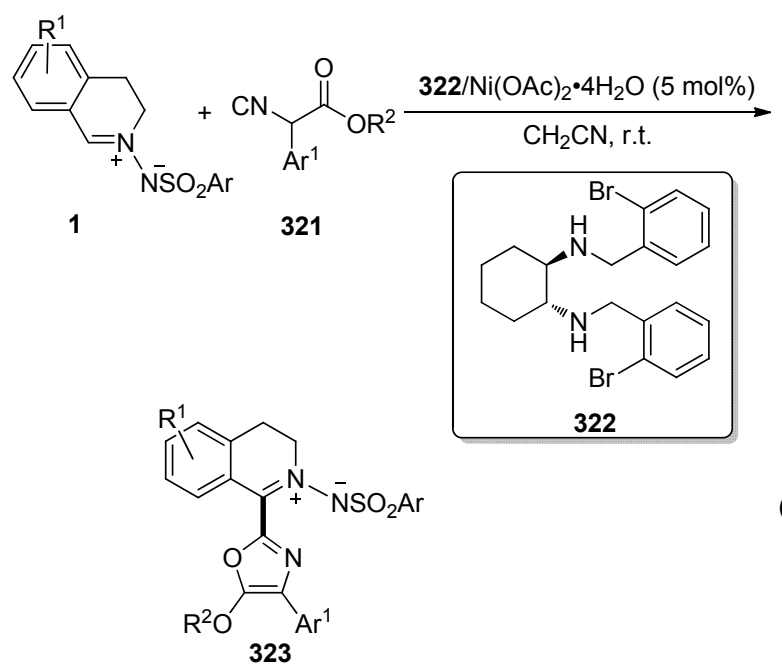

up to $85 \%$ yield, $97 \%$ ee 
<smiles>[R]C([N+]=[C-])C(=O)OC</smiles>

321

$\mathrm{R}=$ aryl, reaction

$\mathrm{R}=$ alkyl, no reaction

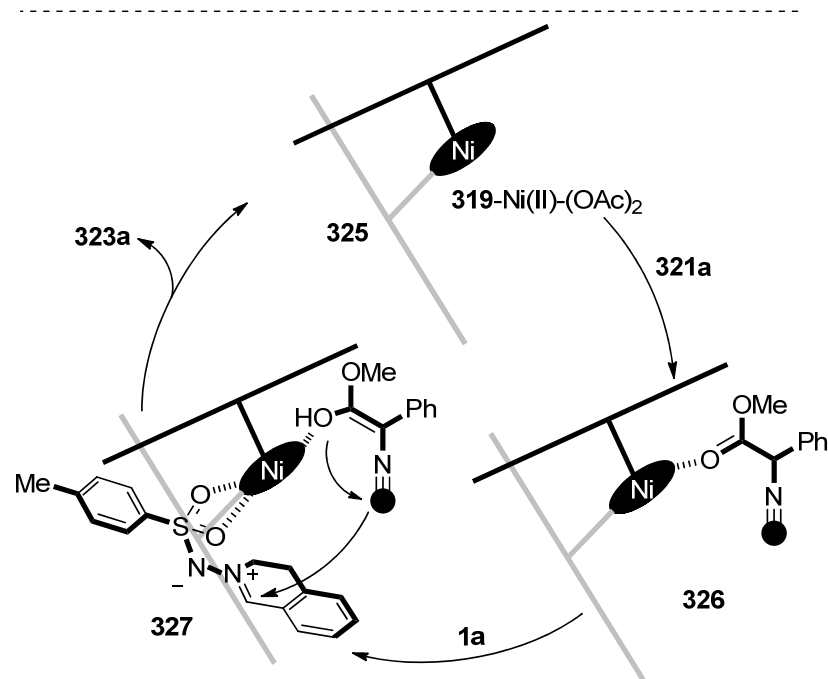

图式 51 不对称噁唑形成 Ugi 反应的机理

Scheme 51 Proposed mechanism of the asymmetric oxazoleforming Ugi-type reaction

择性却有所降低, 可能是由于手性磷酸催化剂重氮化合 物与 $\mathrm{C}, \mathrm{N}$-环状偶氮次甲基亚胺的直接加成是该过程的 主要副反应, 降低了目标反应的产率. 使用一些手性铑 催化剂能得到几乎消旋的结果. 目前这个不对称三组分 反应仍是具有挑战性的, 其中如何抑制副产物的形成是 一个关键问题. 基于一系列对照实验和前期工作基础,
作者提出了一个可能的反应机理(Scheme 52): 首先, $\mathrm{Rh}$ 催化的重氮酸酯分解产物 $\mathrm{Rh}$ 卡宾 333 , 苯胺对 $\mathrm{Rh}$ 卡宾 的亲核进攻产生氮叶立德 334 和烯醇物 335, C,N-环状 偶氮次甲基亚胺对这些活性中间体的捕获可得 $\mathrm{C}(1)$-取 代四氢异喹啉衍生物, 释放出 $\mathrm{Rh}$ 催化剂. 另外非金属 连接的烯醇 336 也是这个过程中一个可能的中间体.

2016 年, 邓辰亮团队 ${ }^{[81]}$ 报道了 $\mathrm{Rh}(\mathrm{II}) / \mathrm{Cu}(\mathrm{II})$ 共同催 化 $\mathrm{C}, \mathrm{N}$-环状偶氮次甲基亚胺 337 通过邻位 $\mathrm{C}-\mathrm{H}$ 氧化以 中等至良好的收率得到各种异喹啉-1-酮产物 338 (Eq. 74). 对于该氧化反应作者提出了可能的反应机理 (Scheme 53): $\mathrm{Rh}_{2}(\mathrm{OAc})_{4}$ 与配体结合生成铑物种, 该铑 物种与底物 337a 配位, 在 $\mathrm{NaO} t-\mathrm{Bu}$ 的协助下形成中间 体 339. 铑物种插入到中间体 339 分子内的 1 位 $\mathrm{C}-\mathrm{H}$ 键中，生成中间体产物 340. 随后，中间体 340 被 $\mathrm{H}_{2} \mathrm{O}$ 亲 核进攻, 得到中间体 341; 同时, 以铜盐为氧化剂的铑 物种再生完成催化循环. 最后, 可以通过互变异构从中 间体 337 中获得目标产物 338. 另一个可能的途径是 $\mathrm{H}_{2} \mathrm{O}$ 作为亲核试剂直接进攻亚胺中间体 339, 形成水加 成产物 342, 经铜/空气进一步氧化得到产物 338a.

\section{4 碱促进的自身协同反应}

2012 年, UKaji 小组 ${ }^{[82]}$ 实现了 C,N-环状偶氮次甲基 亚胺 $1 \mathrm{a}$ 的 Strecker 反应, 在 $n-\mathrm{BuMgCl}$ 作用下, 使用丙 酮氰醇 344 作为氰基来源，它稳定，相对低毒，操作简 单，易得. 以 $93 \%$ 的产率得到 $\alpha$-氰基四氢异喹啉 344 (Eq. 75).

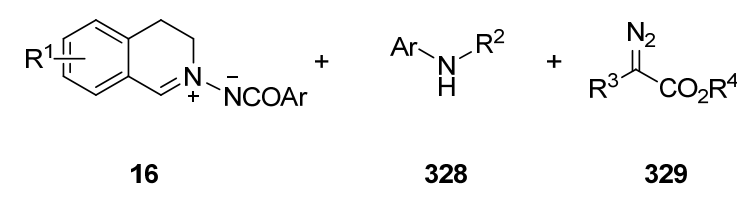

MTBE, r.t., $3 \mathrm{~h}$

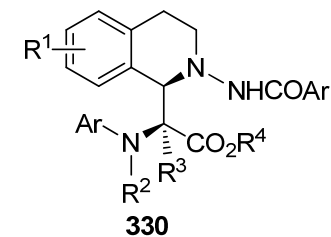

up to $81 \%$ yield 95:5 $d r$


$328 a$

$329 a$

$330 \mathrm{a}$

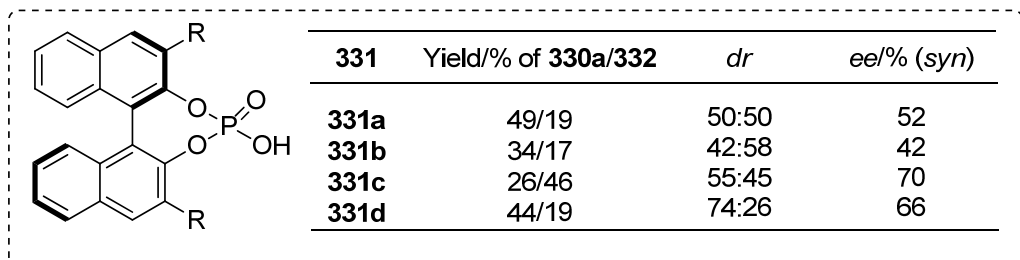

331a: $R=P h ; 331 b: R=3,5-\left(C_{3}\right)_{2} C_{6} H_{3} ; 331 c: R=2,4,6-i-P_{3} C_{3} H_{2} ; 331 d: R=S i P h_{3}$ 


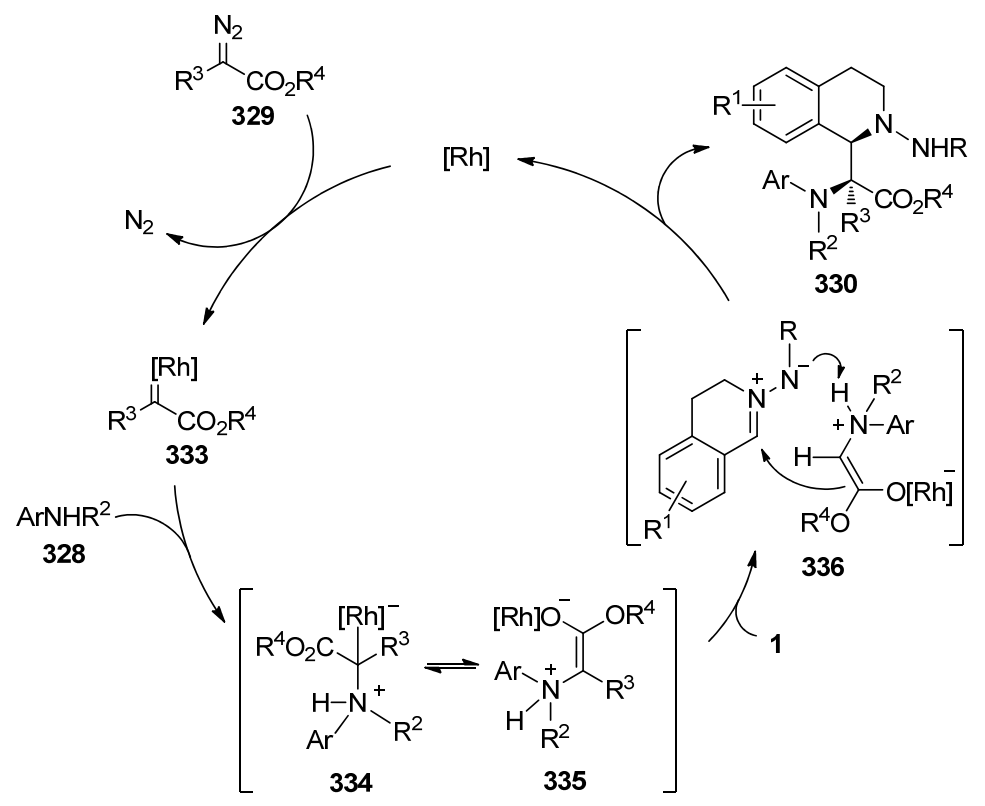

图式 52 铑催化的三组分反应的可能机理

Scheme 52 Proposed mechanism of rhodium-catalysed three-component reaction

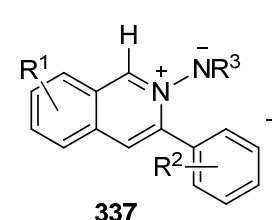

337

$\mathrm{R}^{1}, \mathrm{R}^{2}=$ alkyl, halide, alkoxy $\mathrm{R}^{3}=\mathrm{Boc}, \mathrm{Ts}, \mathrm{Bz}$

Soeta 和 UKaji 等 ${ }^{[71]}$ 报道了异腈 290 和 C,N-环状偶 氮次甲基亚胺 16 的 $[5+1]$ 环加成反应, 在这工作中, 作

者利用了异腈作为 $1 \mathrm{C}$ 来源, 因为它在同一个碳原子上 同时含有亲核和亲电性，在有机合成化学中，硫叶立德 也是常用的 $1 \mathrm{C}$ 合成子，常用于杂环化合物的合成 ${ }^{[83]}$. 作者设想是否可以利用硫叶立德作为 $1 \mathrm{C}$ 合成子, 类似 异腈和 $\mathrm{C}, \mathrm{N}$-环状偶氮次甲基亚胺发生 $[5+1]$ 环加成反 应，结果得到的主要产物是扩环的苯并七元氮杂环化合 物 $345^{[84]}$ (Scheme 54). 作者提出了可能的反应机理, 在 碱作用下, 硫盐 346 产生的硫叶立德与 C,N-环状偶氮次

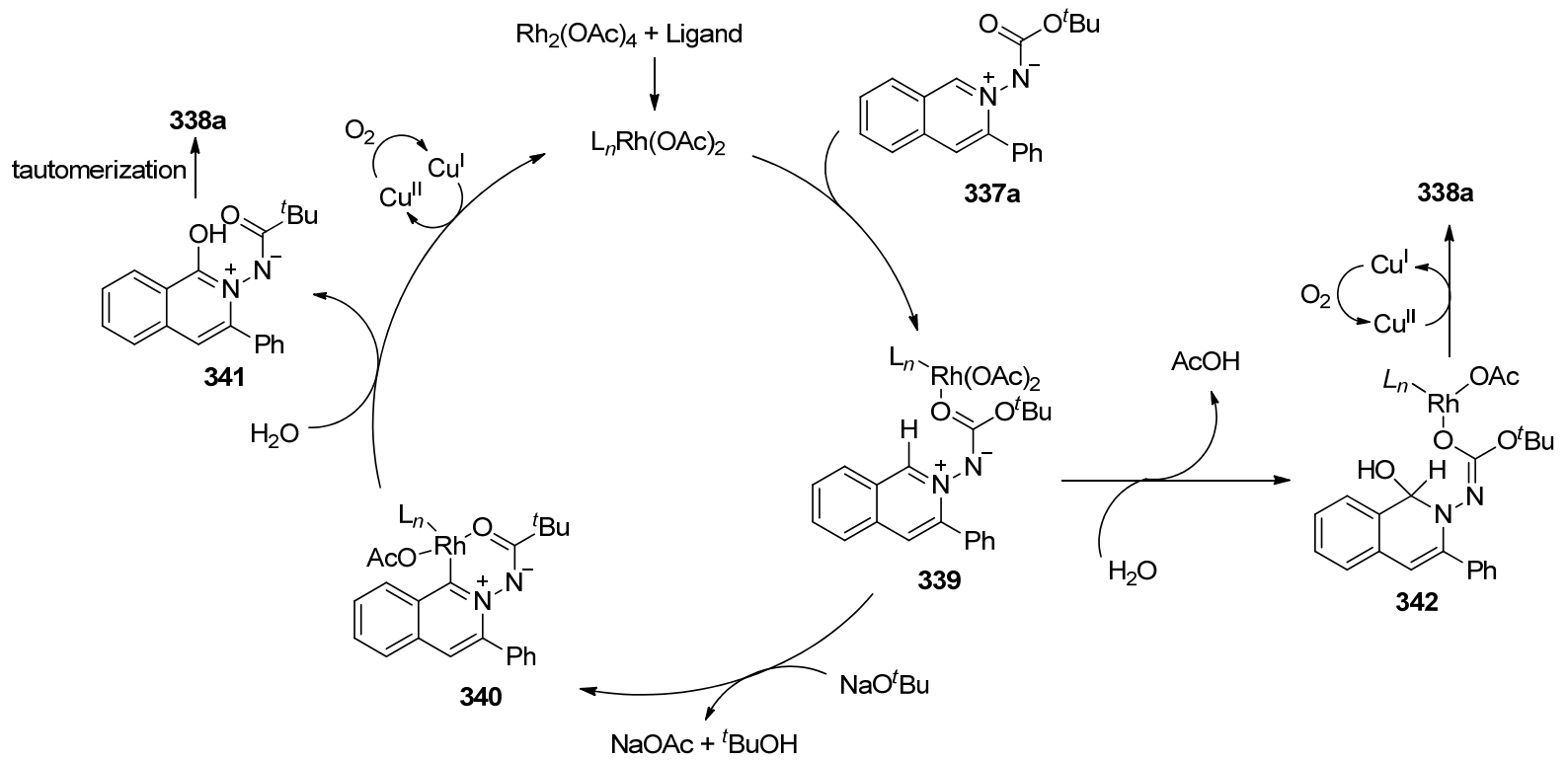

图式 53 铑/铜共催化 C- $\mathrm{H}$ 氧化反应的可能机理

Scheme 53 Proposed mechanism of phodium/copper-cocatalyzed C-H oxidation reaction 


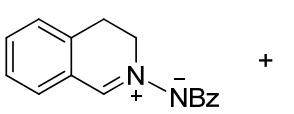

$1 a$

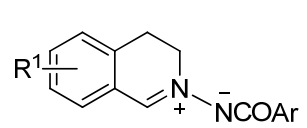

16

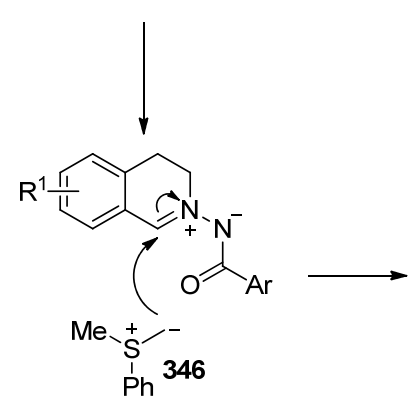

${ }_{\mathrm{NC}}^{\mathrm{OH}}$

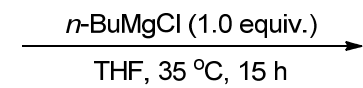

343

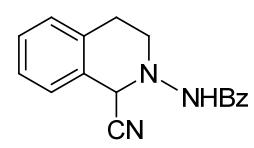

344

$93 \%$ yield
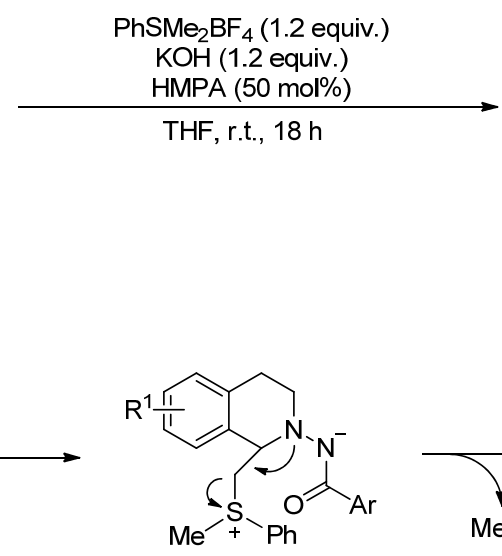

347

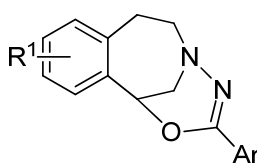

345

up to $90 \%$ yield

图式 $54 \mathrm{C}, \mathrm{N}$-环状偶氮次甲基亚胺与硫叶立德的反应及机理

Scheme 54 Reactions and mechanisms of C,N-cyclic azomethine imines with sulfide

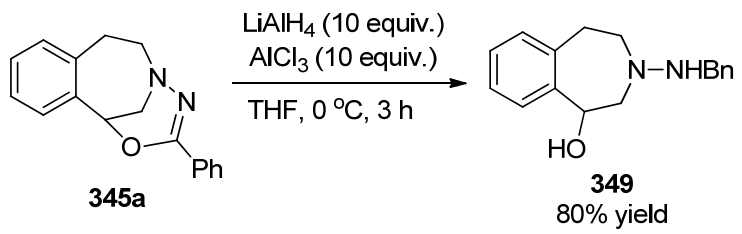

甲基亚胺的 $\mathrm{C}=\mathrm{N}^{+}$片段反应得到 347, 异喹啉的 $\mathrm{N}$ 原子 进攻硫正离子的 $\alpha$ 位形成氮丙啶离子 348 , 最后, 酰胺 的羰基氧亲核进攻 $\mathrm{C}(1)$ 位使得异喹啉骨架发生了扩环, 得到苯并七元氮杂环化合物 345 . 在还原条件下, 产物 345a 的噁二嗪环很容易打开, 产生 1-羟基苯并氮杂七 元环衍生物 349 (Eq. 76). 据报道该分子骨架具有 NR2B 选择性 NMDA(N-甲基-D-天冬氨酸)受体拮抗剂的活性.

\section{7 结论与展望}

论述了 $\mathrm{C}, \mathrm{N}$-环状偶氮次甲基亚胺作为一个高活性 试剂应用于多种类型的加成反应来合成各种具有重要 生物活性的 C(1)-取代的异喹啉骨架, 这些方法学得到 了持续创新和改进, 比如反应底物结构可以进一步拓 宽, 反应条件更加温和, 使用催化剂等. 同时, 随着不 对称合成的不断发展, 这些方法也可应用于手性 C(1)取代的四氢异喹啉类化合物的合成中.

但仍有一些问题需要进一步解决. 在已有的研究成 果中, [3+2]环加成反应的研究相对较多, 其他类型的 反应需要进一步探索; 另外, 对于不对称催化方面, 发 展高效、高选择性、广普使用的催化体系获得手性产物 仍然是研究的热点和重点. 我们相信, 有机化学工作者
会开发出更多的化合物与 $\mathrm{C}, \mathrm{N}$-环状偶氮次甲基亚胺发 生加成反应，来构建更加丰富的 C(1)-取代四氢异喹啉 化合物，期待它们可以进一步转化为更多的有用的天然 产物或药物分子.

\section{References}

[1] (a) Liu, C. J.; Liu, D. Y.; Xiang, L. Acta Pharm. Sin. 2010, 45, 9. (b) Blay, J.-Y. Eur. J. Clin. Med. Oncol. 2010, 2, 1.

(c) Vincenzi, B.; Napolitano, A.; Frezza, A. M.; Schiavon, G.; Santini, D.; Tonini, G. Pharmacogenomics 2010, 11, 865. (d) Carter, N. J.; Keam, S. J. Drugs 2010, 70, 355.

[2] (a) Aune, G. J.; Furuta, T.; Pommier, Y. Anti-Cancer Drugs 2002, 13,545 .

(b) Scott, J. D.; Williams, R. M. Chem. Rev. 2002, 102, 1669.

(c) Mujahidin, D.; Doye, S. Eur. J. Org. Chem. 2005, 2005, 2689.

(d) Bentley, K. W. Nat. Prod. Rep. 2006, 23, 444.

(e) Werner, F.; Blank, N.; Opatz, T. Eur. J. Org. Chem. 2007, 2007, 3911.

(f) Reddy, R. J.; Kawai, N.; Uenishi, J. J. Org. Chem. 2012, 77, 11101.

[3] (a) Sekine Y.; Brossi, A. J. Nat. Prod. 1990, 53, 533.

(b) Luk, L. Y. P.; Bunn, S.; Liscombe, D. K.; Facchini, P. J.; Tanner, M. E. Biochemistry 2007, 46, 10153.

(c) Minami, H.; Dubouzet, E.; Iwasa, K.; Sato, F. J. Biol. Chem. 2007, 282, 6274 .

[4] (a) Chang, F.-R.; Wu, Y.-C. J. Nat. Prod. 2005, 68, 1056.

(b) Kashiwada, Y.; Aoshima, A.; Ikeshiro, Y.; Chen, Y.-P.; Furukawa, H.; Itoigawa, M.; Fujioka, T.; Mihashi, K.; Cosentino, L. M.; Morris-Natschke, S. L.; Lee, K.-H. Bioorg. Med. Chem. 2005, 13, 443.

[5] (a) Padwa, A.; Danca, M. D. Org. Lett. 2002, 4, 715.

(b) Simpkins, N. S.; Gill, C. D. Org. Lett. 2003, 5, 535

(c) Pérard-Viret, J.; Souquet, F.; Manisse, M.-L.; Royer, J. Tetrahedron Lett. 2010, 51, 96.

[6] (a) Yang, Z.; Liu, C.; Xiang, L.; Zheng, Y. Phytother. Res. 2009, 23, 1032.

[7] (a) Davis, F. A.; Mohanty, P. K. J. Org. Chem. 2002, 67, 1290. (b) Benmekhbi, L.; Louafi, F.; Roisnel, T.; Hurvois, J.-P. J. Org. 
Chem. 2016, 81, 6721.

[8] (a) Zou, Y.-Q.; Lu, L.-Q.; Fu, L.; Chang, N.-J.; Rong, J.; Chen, J.-R.; Xiao, W.-J. Angew. Chem., Int. Ed. 2012, 50, 7171.

(b) An, J.; Yang, Q.-Q.; Wang, Q.; Xiao, W.-J. Tetrahedron Lett. 2013, 54,3834

(c) Feng, Z.-J.; Xuan, J.; Xia, X.-D.; Ding, W.; Guo, W.; Chen, J.-R.; Zou, Y.-Q.; Lu, L.-Q.; Xiao, W.-J. Org. Biomol. Chem. 2014, 12, 2037.

(d) Feng, Z.-J.; Zeng, T.-T.; Xuan, J.; Liu, Y.-H.; Lu, L.-Q.; Xiao, W.-J. Sci. China: Chem. 2016, 59, 171.

(e) Cheng, X.; Cao, X.; Xuan, J.; Xiao, W.-J. Org. Lett. 2018, 20, 52 .

(f) Cheng, X.; Cao, X.; Zhou, S.-J.; Cai, B.-G.; He, X.-K.; Xuan, J. Adv. Synth. Catal. 2019, 361, 1230.

(g) Kaur, P.; Kumar, R. Chem. Heterocycl. Compd. 2020, 56, 422.

[9] (a) Wang, F.; Bai, D.-L. Chin. J. Org. Chem. 2006, 26, 9 (in Chinese).

(王峰, 白东鲁, 有机化学, 2006, 26, 9.)

(b) Qiu, G. Y. S.; Kuang, Y. Y.; Wu, J. Adv. Synth. Catal. 2014, 356, 3483 .

(c) Nájera, C.; Sansano, J. M.; Yus, M. Org. Biomol. Chem. 2015, 13,8596 .

(d) Li, Z. Ph.D. Dissertation, China Agricultural University, Beijing, 2015 (in Chinese).

(理珍，博士论文，中国农业大学，北京, 2015.)

(e) Yuan, B.-B.; Li, Y.-N.; Guo, J.-M.; Wang, Q.-L.; Bu, Z.-W. Chem. Res. 2017, 28, 135 (in Chinese).

(袁贝贝，李雅宁，郭娇美，王琪琳，卜站伟，化学研究，2017, 28, 135.)

(f) Zhang, L. M.S. Thesis, Chongqing University, Chongqing, 2018 (in Chinese).

(张龙，硕士论文，重庆大学，重庆, 2018.)

(g) Grošelj, U.; Svete, J.; Al Mamari, H. H.; Požgan, F.; Štefane, B. Chem. Heterocycl. Compd. 2018, 54, 214.

(h) Grošelj, U.; Požgan, F.; Štefane, B.; Svete, J. Synthesis 2018, $50,4525$.

(i) Le, G. Z.; Liu, B. Chin. J. Org. Chem. 2020, 40, 3132 (in Chinese).

(乐贵洲，刘波，有机化学, 2020, 40, 3132.)

[10] (a) Tamura, Y.; Minamikawa, J.-I.; Miki, Y.; Okamoto, Y.; Ikeda, M. Yakugaku Zasshi 1973, 93, 648.

(b) Truce, W. E.; Allison, J. R. J. Org. Chem. 1975, 40, 2260.

[11] Hashimoto, T.; Maeda, Y.; Omote, M.; Nakatsu, H.; Maruoka, K. J. Am. Chem. Soc. 2010, 132, 4076.

[12] Zhou, W.; Chen, P.; Tao, M. N.; Su, X.; Zhao, Q. J.; Zhang, J. L. Chem. Commun. 2016, 52, 7612.

[13] Milosevic, S.; Togni, A. J. Org. Chem. 2013, 78, 9638.

[14] Qurban, S.; Du, Y.; Gong, J.; Lin, S.-X.; Kang, Q. Chem. Commun. 2019, 55, 249 .

[15] Afanaseva, K. K.; Efremova, M. M.; Kuznetsova, S. V.; Ivanov, A. V.; Starova, G. L.; Molchanov, A. P. Tetrahedron 2018, 74, 5665.

[16] Ling, L.; Chen, J. Q.; Song, J. H.; Zhang, Y. H.; Li, X. Q.; Song, L. J.; Shi, F.; Li, Y. X.; Wu, C. R. Org. Biomol. Chem. 2013, 11, 3894.

[17] Alcaide, B.; Almendros, P.; Quirs, M. T. Chem.-Eur. J. 2014, 20, 3384.

[18] Li, Z.; Yu, H.; Liu, H. L.; Zhang, L.; Jiang, H.; Wang, B.; Guo, H. C. Chem.-Eur. J. 2014, 20, 1731

[19] Jia, Q. F.; Chen, L.; Yang, G. M.; Wang, J.; Wei, J.; Du, Z. Y. Tetrahedron Lett. 2015, 56, 7150 .

[20] Jing, C. F.; Na, R. S.; Wang, B.; Liu, H. L.; Zhang, L.; Liu, J.; Wang, M.; Zhong, J. C.; Kwon, O.; Guo, H. C. Adv. Synth. Catal. 2012, 354, 1023.

[21] Wang, D.; Lei, Y.; Wei, Y.; Shi, M. Chem.-Eur. J. 2014, 20, 15325.

[22] Li, W. J.; Jia, Q. F.; Du, Z. Y.; Zhang, K.; Wang, J. Chem.-Eur. J. 2014, 20, 4559

[23] Li, W. J.; Wei, J.; Jia, Q. F.; Du, Z. Y.; Zhang, K.; Wang, J. Chem.Eur. J. 2014, 20, 6592 .

[24] Izquierdo, C.; Esteban, F.; Parra, A.; Alfaro, R.; Alemán, J.; Fraile,
A.; García Ruano, J. L. J. Org. Chem. 2014, 79, 10417.

[25] Hesping, L.; Biswas, A.; Daniliuc, C. G.; Mück-Lichtenfeld, C.; Studer, A. Chem. Sci. 2015, 6, 1252.

[26] (a) Li, B.-S.; Wang, Y. H.; Jin, Z. C.; Chi, Y. R. Chem. Sci. 2015, 6, 6008.

(b) Kirmse, W.; Rondan, N. G.; Houk, K. N. J. Am. Chem. Soc. 1984, 106, 7989

[27] Gao, Z. H.; Chen, X. Y.; Cheng, J. T.; Liao, W. L.; Ye, S. Chem. Commun. 2015, 51, 9328.

[28] Guo, C.; Fleige, M.; Janssen-Müller, D.; Daniliuc, C. G.; Glorius, F. Nat. Chem. 2015, 7, 842.

[29] Zhang, P. F.; Zhou, Y.; Han, X.; Xu, J. Y.; Liu, H. J. Org. Chem. 2018, 83, 3879.

[30] Kobayashi, M.; Kondo, K.; Aoyama, T. Tetrahedron Lett. 2007, 48, 7019.

[31] Liu, X. H.; Wang, Y. J.; Yang, D. X.; Zhang, J. L.; Liu, D. S.; Su, W. Angew. Chem., Int. Ed. 2016, 55, 8100.

[32] Hashimoto, T.; Omote, M.; Maruoka, K. Angew. Chem., Int. Ed. 2011, 50, 3489.

[33] Wang, Y.; Wang, Q.; Zhu, J. P. Chem.-Eur. J. 2016, $22,8084$.

[34] Mousseau, J. J.; Fortier, A.; Charette, A. B. Org. Lett. 2010, 12, 516.

[35] Mousseau, J. J.; Bull, J. A.; Ladd, C. L.; Fortier, A.; Roman, D. S.; Charette, A. B. J. Org. Chem. 2011, 76, 8243.

[36] Zhou, W.; Li, X.-X.; Li, G.-H.; Wu, Y.; Chen, Z. L. Chem. Commun. 2013, 49, 3552.

[37] Mao, B. M.; Xu, Y.; Chen, Y. H.; Dong, J. P.; Zhang, J. Y.; Gu, K. J.; Zheng, B.; Guo, H. C. Org. Lett. 2019, 21, 4424.

[38] Mao, B. M.; Zhang, J. Y.; Xu, Y.; Yan, Z. Y.; Wang, W.; Wu, Y. J.; Sun, C. Q.; Zheng, B.; Guo, H. C. Chem. Commun. 2019, 55, 12841 .

[39] Koptelov, Y. B.; Saik, S. P.; Molchanov. A. P. Russ. J. Org. Chem. 2011, 47, 537.

[40] Koptelov, Y. B.; Molchanov, A. P.; Kostikov, R. R. Russ. J. Org. Chem. 2015, 51, 11343.

[41] Kawai, H.; Yuan, Z.; Tokunaga, E.; Shibata, N. Org. Lett. 2012, 14, 5330.

[42] Wang, D.; Deng, H.-P.; Wei, Y.; Xu, Q.; Shi, M. Eur. J. Org. Chem. 2013, 2, 401 .

[43] Liu, X. H.; Yang, D. X.; Wang, K. Z.; Zhang, J. L.; Wang, R. Green Chem. 2017, 19, 82

[44] Hu, F. Z.; Chen, H.; Zhang, M. M.; Yu, S. W.; Xu, X. Y.; Yuan, W. C.; Zhang, X. M. J. Heterocycl. Chem. 2017, 54, 2922.

[45] (a) Hong, L.; Kai, M.; Wu, C.; Sun, W.; Zhu, G.; Li, G.; Yao, X.; Wang, R. Chem. Commun. 2013, 49, 6713.

(b) Yin, C.; Lin, L.; Zhang, D.; Feng, J.; Liu, X.; Feng, X. J. Org. Chem. 2015, 80, 9691.

(c) Lu, Y. L.; Sun, J.; Jiang, Y. H.; Yan, C. G. RSC Adv. 2016, 6, 50471.

[46] Wu, Y. F.; Tian, B.; Hu, C.; Sekine, K.; Rudolph, M.; Rominger, F.; Hashmi, A. S. K. Org. Biomol. Chem. 2019, 17, 5505.

[47] Na, R. S.; Liu, H. L.; Li, Z.; Wang, B.; Liu, J.; Wang, M.-A.; Wang, M.; Zhong, J. C.; Guo, H. C. Tetrahedron 2012, 68, 2349.

[48] Zhang, L.; Jing, C. F.; Liu, H. L.; Wang, B.; Li, Z.; Jiang, H.; Yu, H.; Guo, H. C. Synthesis 2013, 45, 0053.

[49] Li, F. L.; Chen, J. F.; Hou, Y. D.; Li, Y. J.; Wu, X.-Y.; Tong, X. F. Org. Lett. 2015, 17, 5376.

[50] He, L. W. Z.; Liu, L.; Han, R. F.; Zhang, W. W.; Xie, X. G.; She, X. G. Org. Biomol. Chem. 2016, 14, 6757.

[51] Zhao, J. J.; Li, P.; Wu, C. R.; Chen, H. L.; Ai, W. Y.; Sun, R. H.; Ren, H. L.; Larockb, R. C.; Shi, F. Org. Biomol. Chem. 2012, 10, 1922.

[52] Li, Y.-K.; Cui, M.-X.; Sha, F.; Li, Q.; Wu, X.-Y. Org. Biomol. Chem. 2019, 17, 8963.

[53] Zhang, L.; Liu, H. L.; Qiao, G. Y.; Hou, Z. F.; Liu, Y.; Xiao, Y. M.; Guo, H. C. J. Am. Chem. Soc. 2015, 137, 4316.

[54] Li, Z.; Yu, H.; Liu, Y.; Zhou, L. J.; Sun, Z. H.; Guo, H. C. Adv. Synth. Catal. 2016, 358, 1880 . 
[55] (a) Xia, Y. Z.; Liang, Y.; Chen, Y. Y.; Wang, M.; Jiao, L.; Huang, F.; Liu, S.; Li, Y. H.; Yu, Z. X. J. Am. Chem. Soc. 2007, 129, 3470. (b) Mercier, E.; Fonovic, B.; Henry, C.; Kwon, O.; Dudding, T. Tetrahedron Lett. 2007, 48, 3617.

(c) Liang, Y.; Liu, S.; Xia, Y. Z.; Li, Y. H.; Yu, Z. X. Chem.-Eur. J. 2008, 14, 4361 .

(d) Liang, Y.; Liu, S.; Yu, Z. X. Synlett 2009, 905.

(e) Huang, G.-T.; Lankau, T.; Yu, C.-H. J. Org. Chem. 2014, 79, 1700 .

[56] Zhu, C.-Z.; Feng, J.-J.; Zhang, J. L. Chem. Commun. 2017, 53, 4688.

[57] Yu, L.; Zhong, Y.; Yu, J.; Gan, L.; Cai, Z. J.; Wang, R.; Jiang, X. X. Chem. Commun. 2018, 54, 2353.

[58] Zhou, Y.-Y.; Li, J.; Ling, L.; Liao, S.-H.; Sun, X.-L.; Li, Y.-X.; Wang, L.-J.; Tang, Y. Angew. Chem., Int. Ed. 2013, 52, 1452.

[59] Xu, X. F.; Zavalij, P. Y.; Doyle, M. P. Angew. Chem., Int. Ed. 2013, $52,12664$.

[60] Marichev, K. O.; Adly, F. G.; Carranco, A. M.; Garcia, E. C.; Arman, H.; Doyle, M. P. ACS Catal. 2018, 8, 10392.

[61] Wang, K. K.; Li, Y. L.; Wang, Z. Y.; Hu, M. W.; Qiua, T. T.; Zhu, B. K. Org. Biomol. Chem. 2019, 17, 244.

[62] Li, Z.; Yu, H.; Feng, Y. L.; Hou, Z. F.; Zhang, L.; Yang, W. J.; Wu, Y.; Xiao, Y. M.; Guo, H. C. RSC Adv. 2015, 5, 34481.

[63] Wang, Y. F.; Zhu, L. P.; Wang, M. R.; Xiong, J. L.; Chen, N. N.; Feng, X.; Xu, Z. Q.; Jiang, X. X. Org. Lett. 2018, 20, 6506.

[64] (a) Wang, Q.; Li, T.-R.; Liu, L.-Q.; Li, M.-M.; Zhang, K.; Xiao, W.-J. J. Am. Chem. Soc. 2016, 138, 8360.

(b) Li, T.-R.; Wang, Y.-N.; Xiao, W.-J.; Liu, L.-Q. Tetrahedron Lett. 2018, 59, 1521.

[65] Hu, X. Q.; Chen, J. R.; Gao, S.; Feng, B.; Lu, L. Q.; Xiao, W.-J. Chem. Commun. 2013, 49, 7905.

[66] (a) Yang, Q.-Q.; Xiao, C.; Lu, L.-Q.; An, J.; Tan, F.; Li, B.-J.; Xiao, W.-J. Angew. Chem., Int. Ed. 2012, 51, 9137.

(b) Yang, Q.-Q.; Wang, Q.; An, J.; Chen, J.-R.; Lu, L.-Q.; Xiao, W.-J. Chem.-Eur. J. 2013, 19, 8401.

(c) Liu, Y.-Y.; Yu, X.-Y.; Chen, J.-R.; Qiao, M.-M.; Qi, X.; Shi, D.-Q.; Xiao, W.-J. Angew. Chem., Int. Ed. 2017, 56, 9527.

(d) Yang, Q.-Q.; Xiao, W.-J. Eur. J. Org. Chem. 2017, 2017, 233.

(e) Zheng, Y.; Tu, L.; Li, N.; Huang, R.; Feng, T.; Sun, H.; Li, Z.; Liu, J. Adv. Synth. Catal. 2019, 361, 44. (f) Hua, T.-B.; Yang, Q.-Q.; Zou, Y.-Q. Molecules 2019, 24, 3191. (g) Hua, T.-B.; Chao, F.; Wang, L.; Yan, C.-Y.; Xiao, C.; Yang, Q.-Q.; Xiao, W.-J. Adv. Synth. Catal. 2020, 362, 2615.

[67] Chen, L.; Yang, G. M.; Wang, J.; Jia, Q. F.; Wei, J.; Du, Z. Y. RSC Adv. 2015, 5, 76696.

[68] Zhi, Y.; Zhao, K.; Shu, T.; Enders, D. Synthesis 2016, 48, 238.

[69] Xu, J. F.; Yuan, S. R.; Peng, J. Y.; Miao, M. Z.; Chen, Z. K.; Ren, H. J. Org. Biomol. Chem. 2017, 15, 7513.

[70] Zheng, P. F.; Zeng, R.; Jiang, K.; Li, H. W.; Ye, Y.; Mu, C.; Shuai, L.; Ouyang, Q.; Chen, Y. C. Org. Lett. 2019, 21, 10052.

[71] Soeta, T.; Tamura, K.; Ukaji, Y. Org. Lett. 2012, 14, 1226.

[72] Soeta, T.; Tamura, K.; Fujinami, S.; Ukaji, Y. Org. Biomol. Chem. 2013, 11, 2168.

[73] Lariveé, A.; Mousseau, J. J.; Charette, A. B. J. Am. Chem. Soc. 2008, 130, 52 .

[74] Zhao, Z.-Q.; Zhao, X.-L.; Shi, M.; Zhao, M.-X. J. Org. Chem. 2019, 84, 14487.

[75] Fang, L.; Chen, L. S.; Yu, J. J.; Wang, L. M. Eur. J. Org. Chem. 2015, 2015, 1910.

[76] Hashimoto, T.; Omote, M.; Maruoka, K. Angew. Chem., Int. Ed. 2011, 50, 8952.

[77] Hua, Z. R.; Fang, L.; Wu, S. Y.; Wang, L. M. Eur. J. Org. Chem. 2016, 2016, 4953.

[78] Li, D.; Yang, D. X.; Wang, L. Q.; Liu, X. H.; Wang, K. Z.; Wang, J.; Wang, P. X.; Liu, Y. Y.; Zhu, H. Y.; Wang, R. Chem.-Eur. J. 2017, 23, 6974.

[79] Zhang, D.; Liu, J. W.; Kang, Z. H.; Qiu, H.; Hu, W. H. Org. Biomol. Chem. 2019, 17, 9844.

[80] Hua, T.-B.; Xiao, C.; Yang, Q.-Q.; Chen, J.-R. Chin. Chem. Lett. $2020,31,311$.

[81] Zhou, Z.-L.; Liu, Y.-L.; Song, J.-L.; Deng, C.-L. Synthesis 2016, 48, 2057.

[82] Sakai, T.; Soeta, T.; Inomata, K.; Ukaji, Y. Bull. Chem. Soc. Jpn. 2012, 85, 231.

[83] (a) Lu, L.-Q.; Li, T.-R.; Wang, Q.; Xiao, W.-J. Chem. Soc. Rev. 2017, 46, 4135. (b) Chen, J.-R.; Hu, X.-Q.; Lu, L.-Q.; Xiao, W.-J. Chem. Rev. 2015, 115,5301 .

[84] Soeta, T.; Ohgai, T.; Sakai, T.; Fujinami, S.; Ukaji, Y. Org. Lett. 2014, $16,4854$. 